\title{
Guidelines for the management of gastroenteropancreatic neuroendocrine (including carcinoid) tumours (NETs)
}

\author{
John K Ramage, ${ }^{1}$ A Ahmed, ${ }^{2}$ J Ardill, ${ }^{3} \mathrm{~N} \mathrm{Bax},{ }^{4} \mathrm{D} \mathrm{J}$ Breen, ${ }^{5} \mathrm{M} \mathrm{E}$ Caplin, ${ }^{6} \mathrm{P}$ Corrie, ${ }^{7}$ \\ J Davar, ${ }^{8}$ A H Davies, ${ }^{9}$ V Lewington, ${ }^{10}$ T Meyer, ${ }^{11} \mathrm{~J}$ Newell-Price, ${ }^{12} \mathrm{G}$ Poston, $^{13}$ \\ N Reed, ${ }^{14}$ A Rockall, ${ }^{15}$ W Steward, ${ }^{16} \mathrm{R}$ V Thakker, ${ }^{17} \mathrm{C}$ Toubanakis, ${ }^{18} \mathrm{~J}$ Valle, ${ }^{19}$ \\ C Verbeke, ${ }^{20}$ A B Grossman ${ }^{17}$
}

- Additional appendices are published online only. To view these files, please visit the journal online (http://gut.bmj. com)

For numbered affiliations see end of article.

\section{Correspondence to}

Dr John K Ramage, Basingstoke and North Hampshire Hospital, Aldermaston Road, Basingstoke RG24 9NA, UK:

john.ramage@bnhft.nhs.uk

Revised 12 August 2011 Accepted 19 September 2011 Published Online First

3 November 2011

\begin{abstract}
These guidelines update previous guidance published in 2005. They have been revised by a group who are members of the UK and Ireland Neuroendocrine Tumour Society with endorsement from the clinical committees of the British Society of Gastroenterology, the Society for Endocrinology, the Association of Surgeons of Great Britain and Ireland (and its Surgical Specialty Associations), the British Society of Gastrointestinal and Abdominal Radiology and others. The authorship represents leaders of the various groups in the UK and Ireland Neuroendocrine Tumour Society, but a large amount of work has been carried out by other specialists, many of whom attended a guidelines conference in May 2009. We have attempted to represent this work in the acknowledgements section. Over the past few years, there have been advances in the management of neuroendocrine tumours, which have included clearer characterisation, more specific and therapeutically relevant diagnosis, and improved treatments. However, there remain few randomised trials in the field and the disease is uncommon, hence all evidence must be considered weak in comparison with other more common cancers.
\end{abstract}

\section{RECOMMENDATIONS}

General recommendations

- Multidisciplinary teams (MDTs) at referral centres should give guidance on the definitive management of patients with all varieties of neuroendocrine tumours (NETs). Level of evidence 5, Grade of recommendation D.

- MDT representation should normally include specialist physicians in NETs (gastroenterologists, oncologists and/or endocrinologists), surgeons, radiologists, nuclear medicine specialists, histopathologists and clinical nurse specialists. Level of evidence 5 , Grade of recommendation D.

\section{Genetics}

- Clinical examination to exclude complex cancer syndromes (eg, multiple endocrine neoplasia 1 (MEN1)) should be performed in all cases of NETs, and a family history taken. Level of evidence 4, Grade of recommendation C.

online under the BMJ Journals unlocked scheme, see http:// gut.bmi.com/site/about/ unlocked.xhtml

- In all cases where there is a family history of NETs, or a second endocrine tumour, a familial syndrome should be suspected. Level of evidence 4, Grade of recommendation C.

- In all patients, secondary tumours and other gut cancers should be considered. Level of evidence 4 , Grade of recommendation C.

\section{Diagnosis (biochemical measurements)}

If a patient presents with symptoms suspicious of a gastroenteropancreatic NET:

- Baseline tests should include plasma chromogranin $\mathrm{A}$ and urinary 5-hydroxyindoleacetic acid. Level of evidence 3, Grade of recommendation C.

- Specific biochemical tests should be requested depending on which syndrome is suspected. Level of evidence 3, Grade of recommendation C.

\section{Imaging}

- For detecting the primary tumour a multimodality approach is best. CT, MRI and somatostatin receptor scintigraphy (SSRS) are recommended. Gallium-68 $\left({ }^{68} \mathrm{Ga}\right)$ positron emission tomography (PET)/CT is recommended for the detection of an unknown primary. Level of evidence 3, Grade of recommendation A/B.

- Additional imaging modalities may include endoscopic ultrasound (EUS), endoscopy, digital subtraction angiography (DSA) and venous sampling. Level of evidence 4, Grade of recommendation $\mathrm{B} / \mathrm{C}$.

- For assessing secondaries, ${ }^{68} \mathrm{Ga}$ PET/CT is the most sensitive modality. Where this is not available, SSRS in combination with CT is the most sensitive modality. Level of evidence 3 , Grade of recommendation B.

- Histopathology is required to confirm the diagnosis. Level of evidence 3, Grade of recommendation $B$.

- When a primary has been resected, crosssectional imaging (CT and MRI) using RECIST criteria and SSRS may be indicated for followup $^{1}$ if the patient is involved in a clinical trial. Level of evidence 5, Grade of recommendation D.

\section{Pathology}

- Pathology is currently the diagnostic gold standard. Level of evidence 5, Grade of recommendation $\mathrm{D}$.

- Pathology reporting and reviews should be made by the MDT pathologist. Level of evidence 5 , Grade of recommendation $\mathrm{D}$. 
- Pathological characterisation and classification of NETs should be based on the WHO 2010 classification, the Union for International Cancer Control (UICC) TNM (7th edition), and the European Neuroendocrine Tumour Society (ENETS) site-specific T-staging system. Level of evidence 5, Grade of recommendation $\mathrm{D}$.

\section{Therapy}

- The aim of treatment should be curative where possible.

- The main aim is to keep the patient disease and symptomfree for as long as possible and to maintain a good quality of life (QoL).

- The extent of the tumour, its metastases, histological grade and secretory profile should be determined as far as possible before planning treatment. Level of evidence 4, Grade of recommendation $\mathrm{C}$.

- The choice of treatment depends on the symptoms, stage of disease, degree of uptake of radionuclide and the histological features of the tumour. Level of evidence 4, Grade of recommendation $\mathrm{C}$.

- Surgery should be offered when NETs are resectable and there is curative intent (or when debulking offers palliation) to patients who are fit and have limited disease-primary \pm regional lymph nodes. Level of evidence 4, Grade of recommendation C.

- Surgery should be considered in those with liver metastases and potentially resectable disease. Level of evidence 4, Grade of recommendation $\mathrm{D}$.

- For patients who are not fit for surgery, the aim of treatment is to improve symptoms and maintain an optimal QoL, and where possible to improve survival. Level of evidence 5, Grade of recommendation $\mathrm{D}$.

- Treatment choices for non-resectable disease include somatostatin analogues, biotherapy, targeted radionuclide therapy, locoregional treatments including ablation and (chemo) embolisation and chemotherapy. Level of evidence 4, Grade of recommendation $\mathrm{C}$.

- External beam radiotherapy may relieve bone pain from metastases. Level of evidence 4, Grade of recommendation C.

- Chemotherapy may be used for inoperable or metastatic pancreatic NETs. Level of evidence 1, Grade of recommendation A

- Chemotherapy may be used for poorly differentiated NETs and in selected non-pancreatic NETs of high grade or aggressive clinical course. Level of evidence 2, Grade of recommendation B.

- Sunitinib or everolimus may be used as a line of therapy for patients with advanced (inoperable or metastatic), progressive (radiological evidence of disease progression within 12 months), well-differentiated pancreatic NETs. Level of evidence 1, Grade of recommendation $\mathrm{A}$.

- If possible, patients with NETs should be entered into formal trials of new drug treatments. Level of evidence 4, Grade of recommendation $\mathrm{C}$.

\section{Ablation}

- In the setting of metastatic NET, ablation most commonly has a role in small volume tumours, paucilesional disease or in combination with resection. Level of evidence 3, Grade of recommendation $\mathrm{C}$.

- Ablation, in common with resection, has been shown to be useful in symptom relief. Level of evidence 3, Grade of recommendation $\mathrm{C}$.

- Image-guided ablation can contribute to the cytoreductive approach to metastatic disease. Level of evidence 3, Grade of recommendation $\mathrm{C}$.

\section{Carcinoid heart disease (CHD)}

- All patients with midgut NETs, with or without hepatic metastasis, and all patients with the carcinoid syndrome, should be screened for CHD: this may include N-terminal pro-brain natriuretic peptide (NT-proBNP) and echocardiography. Level of evidence 1b, Grade of recommendation B.

- Patients with elevated NT-proBNP (>260 pg/ml (>30 pmol/ 1) based on single institution data) should be screened with echocardiography. Level of evidence $1 \mathrm{~b}$, Grade of recommendation B.

- Referral of patients with confirmed CHD to a cardiology department with expertise in dealing with CHD should be considered. Level of evidence 5, Grade of recommendation D.

- Cardiac surgery should be considered in appropriate cases and should be performed by skilled operators in selected centres with experience of dealing with patients with NET. Level of evidence $2 c$, Grade of recommendation C.

\section{ORIGIN AND PURPOSE OF THESE GUIDELINES}

These guidelines update previous guidance published in $2005{ }^{2}$ They have been revised by a group who are members of the UK and Ireland Neuroendocrine Tumour Society (UKINETS), with endorsement from the clinical committees of the British Society of Gastroenterology, the Society for Endocrinology, the Association of Surgeons of Great Britain and Ireland (and its Surgical Specialty Associations), the British Society of Gastrointestinal and Abdominal Radiology, and others. The authorship represents leaders of the various groups within UKINETS, but a large amount of work has been carried out by other specialists, many of whom attended a guidelines conference in May 2009. We have attempted to represent this work in the acknowledgements section. Over the past few years, there have been advances in the management of NETs, which have included clearer characterisation, more specific and therapeutically relevant diagnosis, and improved treatments. However, there remain few randomised trials in the field and the disease is uncommon, hence all evidence must be considered weak in comparison with other more common cancers.

It is the unanimous view of the guideline authors that MDTs at referral centres should give guidance on the definitive management of patients with all varieties of NETs, with a particular emphasis on gastroenteric and pancreatic NETs, but also including pulmonary NETs. MDT representation should normally include physicians (gastroenterologists, oncologists and/or endocrinologists), surgeons, radiologists, nuclear medicine specialists, histopathologists and clinical nurse specialists.

The working party that produced these updated guidelines included specialists from these various disciplines who contribute to the management of all NETs, including gastrointestinal NETs. The purpose of these guidelines is to identify and inform the key decisions to be made in the management of gastroenteropancreatic NETs.

The guidelines are not intended to be a rigid protocol, but form a basis upon which to aim for improved standards in the quality of treatment given to affected patients.

The terminology used in this guideline has been chosen to reflect the more modern use of the term 'NET' rather than the older but often more familiar term 'carcinoid tumour'. This decision reflects both the aetiology of NETs and that these tumours are found in diverse locations, not just in the gastrointestinal tract. The term 'carcinoid tumour' is still commonly used in clinical practice, but is deemed obsolete by many experts. However, we retain the terms 'carcinoid syndrome' 
and 'CHD' and will do so until newer terminology is introduced.

\section{FORMULATION OF THE GUIDELINES Literature search}

Members of the guidelines working party were assigned sections of the 2005 guidance to update. A systematic review of the relevant literature was performed, with synthesis of the available evidence; this was followed by peer group appraisal and then expert review.

\section{Categories of evidence}

The Oxford Centre for Evidence-based Medicine's Levels of Evidence (May 2001) were used to evaluate the evidence cited in these guidelines. ${ }^{3}$

\section{AETIOLOGY, EPIDEMIOLOGY, CLINICAL FEATURES, PROGNOSIS AND GENETICS Aetiology}

The aetiology of NETs is poorly understood. Most NETs are sporadic but there is a small familial risk (see under Genetics). NETs constitute a heterogeneous group of neoplasms that share certain characteristic biological features, and can therefore be considered a common entity. The origin of the cells in the gut is debated, but they may arise from pluripotential progenitor cells that develop neuroendocrine characteristics. It seems unlikely that these cells migrate in from the neural crest, as previously thought. Such tumours originate from pancreatic islet cells, gastroenteric tissue (from diffuse neuroendocrine cells distributed throughout the gut), neuroendocrine cells within the respiratory epithelium, and parafollicullar cells distributed within the thyroid (these tumours being referred to as medullary carcinomas of the thyroid). Pituitary, parathyroid and adrenomedullary neoplasms share certain characteristics with these tumours, but are not considered here. These guidelines apply to all NETs arising from the gut, including the pancreas and liver (gastroenteropancreatic), as well as those arising from the lung that have metastasised to the liver or abdominal lymph nodes. Small intestinal and pancreatic NETs have different signatures, as do benign and malignant tumours. The general term of NET is preferred and encouraged for describing gastrointestinal and pancreatic NETs (often denoted pNET), although the term carcinoid is still in common usage and usually denotes a well-differentiated serotonin (5-hydroxytryptamine)-secreting midgut tumour.

Historically, gut-derived NETs were classified according to their embryological origin, into tumours of the foregut (bronchi, stomach, pancreas, gallbladder, duodenum), midgut (jejunum, ileum, appendix, right colon) and hindgut (left colon, rectum). ${ }^{4}$ The WHO has issued guidance on the classification of NETs according to histopathological characteristics (see under Pathology). The molecular biology of NETs is still poorly understood but there are emerging data to suggest that molecular profiling and identification of common genetic elements may enhance tumour classification and identify potential targets that may be involved in tumour progression. ${ }^{5-7}$

\section{Epidemiology}

The incidence of NETs is reported to be rising. Early data from the UK, Sweden and Switzerland ${ }^{8-11}$ suggested that the incidence of gastrointestinal NETs was between 2 and 3 per 100000 persons per year with an overall slight preponderance in women. The largest and most recent analyses of the epidemiology of
NETs have examined data from the USA (the Surveillance, Epidemiology and End Results (SEER) Programme) and Norway (the Norwegian Registry of Cancer (NRC)). ${ }^{12-14}$ The USA data cover nearly five decades and demonstrate a steady increase in the incidence, or reporting, of stomach and rectal tumours and a decrease in that of appendiceal NETs. ${ }^{12} 14$ There are reported ethnic differences in NET incidence, with African-Americans having the highest overall value at 6.5 per 100000 per year. ${ }^{12}$ The most common site for a primary NET in Caucasians in the USA is the lung, accounting for about $30 \%$ of all new cases, whereas in Asian/Pacific, American Indian and African-Americans the rectum is the most common site, with about $27 \%$ of new cases having the primary here. ${ }^{12}$ In Norway the most common primary site is the small intestine $(25 \%) .{ }^{13}$ The overall incidence of NETs in Caucasians is 4.44 per 100000 persons per year in the USA and 3.24 per 100000 persons per year in Norway. This rate of occurrence is higher than previously thought, but is in keeping with data from autopsy studies in Sweden from 30 years ago. 15

Other analyses suggest an even higher incidence of NETs, reporting a fourfold increase between 1973 and 2004, from 2.1 to 9.3 new cases per 100000 persons per year. ${ }^{16}$ This report concluded that NETs are the most common small bowel tumour $(37.4 \%)$, followed by adenocarcinoma (36.9\%), lymphomas $(17.3 \%)$ and stromal tumours (8.4\%). However, another analysis of the SEER dataset from the USA suggests that the rate of increase in the incidence of NETs has been from 1.09 to 5.25 per 100000 persons per year over the same time period. ${ }^{14}$ The incidence of tumours in the appendix, caecum and pancreas almost doubled between 1975 and 2005, but collectively these tumours make up only a small percentage of the total number of cases, and for each the incidence is about $0.1-0.2$ per 100000 persons per year. The incidence of rectal, small intestinal and pulmonary primaries increased by $4-5$-fold over the same period with incidences of between 0.9 and 1.3 per 100000 persons per year. $^{12} 1417$

Whatever the precise incidence of NETs, it appears that the number of patients presenting with these tumours has been steadily increasing. ${ }^{18}$ Indeed, since many NETs are slow-growing or of uncertain malignant potential, with even malignant NETs associated with prolonged survival, the prevalence of NETs is relatively high. ${ }^{14}$ It is reported that, despite the rising number of cases, there is still a delay of up to 7 years between the appearance of first symptoms and a diagnosis of NET. ${ }^{18}$

It is not possible to predict who might develop a NET. There is an increased risk in patients with atrophic gastritis and persons of Afro-Caribbean origin. ${ }^{19}$ In the USA, there is evidence that a long-term history of diabetes mellitus, especially when combined with a family history of cancer, also increases the risk of developing a gastric NET. ${ }^{20}$ This work also reported that a history of smoking or alcohol use has no apparent effect on the risk of developing a NET. Overall, men have a greater risk than women of developing small bowel cancer, and small intestinal NETs are $30 \%$ more common in men than in women. ${ }^{13}$

The sites and overall frequencies of primary NETs, as reported in the USA and Norway, are shown in table $1 .^{13} \mathrm{~A}$ number of other national databases are in the process of reporting and publication, although most suffer from selective reporting and accrual from specialist centres. In general, however, the rates and tumour types in table 1 are in agreement with these series.

The frequencies of primary NETs reported as occurring in the liver or biliary tract were $<1 \%$. Unknown primary sites or sites other than those listed in table 1 accounted for $11-14 \%$ of cases. $^{13}$ 
Table 1 Sites and overall frequencies of primary NETs in the USA (from the SEER Programme) and Norway (from the NRC) ) $^{12-14}$

\begin{tabular}{llll}
\hline & \multicolumn{2}{l}{ Percentage of cases } & \\
\cline { 2 - 3 } PEER (n=17 321) & NRC $(\mathbf{n}=\mathbf{2 0 1 3})$ \\
\cline { 2 - 3 } Primary NET & Black patients & White patients & N \\
\hline Lung & 18.3 & 31.9 & 21.0 \\
Stomach & 5.7 & 5.7 & 5.7 \\
Small intestine & 21.0 & 17.7 & 25.5 \\
Pancreas & 3.7 & 4.1 & 6.9 \\
Meckel & 0.1 & 0.4 & 0.5 \\
Appendix & 2.0 & 3.2 & 4.8 \\
Colon & 7.9 & 7.4 & 8.0 \\
Rectum & 27.0 & 12.3 & 7.2 \\
Breast & 0.4 & 0.4 & 1.6 \\
Prostate & 0.3 & 0.4 & 1.5 \\
Ovary & 1.2 & 1.6 & 2.4 \\
\hline
\end{tabular}

NET, neuroendocrine tumour; NRC, Norwegian Registry of Cancer; SEER, Surveillance, Epidemiology and End Results.

For patients with a small bowel primary NET, the likelihood of nodal metastases being present at the time of diagnosis is about $60 \%$, irrespective of the precise site of origin within the small bowel; with a colonic primary, the likelihood is about $40-70 \%$, with a greater risk within this range if the primary is in the ascending colon, and a lower risk if the primary is in the rectum. ${ }^{12}$ Nodal metastases are present in $5 \%$ of patients with an appendiceal primary and $15 \%$ of those with a pulmonary primary. ${ }^{12}$ The chance of liver metastases being present at the time of diagnosis is about half the risk of nodal spread having occurred. $^{12}$

The chance of metastases being present at the time of diagnosis and the likelihood of MEN1 is shown in table 2.

\section{Clinical features}

Gastroenteropancreatic NETs may be classified into non-functioning tumours, which have no hormone-related clinical features, and functioning tumours, which cause symptoms due to peptide and hormone release. In all NETs, presenting features may include non-specific symptoms such as pain (which may be intermittent and present for many years), nausea and vomiting, and, in some cases, anaemia due to intestinal blood loss (table 3). ${ }^{18} 25-27$ Pain may be due to local tumour invasion, bowel obstruction or mesenteric ischaemia. Most gastroenteropancreatic NETs are non-functioning and present with mass effects of the primary tumour or metastases (usually liver). A high index of suspicion is needed to identify patients, and diagnosis is often delayed for several years, often made as an incidental finding at surgery or during radiological

Table 2 Location, likelihood of metastasis and association with MEN1 in NETs ${ }^{21} 22$

\begin{tabular}{llll}
\hline Tumour & \% Metastases & \% MEN1 & $\begin{array}{l}\text { Incidence per } \\
\text { million per year }\end{array}$ \\
\hline Insulinoma & 10 & 5 & $1-2$ \\
Gastrinoma* & 60 & $25-40$ & $1-2$ \\
Glucagonoma & $50-80$ & 10 & 0.1 \\
VIPoma & $40-70$ & 5 & 0.1 \\
Somatostatinoma* & $50-70$ & 45 & $<0.1$ \\
Non-syndromic & 60 & 20 & $1-2$ \\
\hline
\end{tabular}

${ }^{*}$ About half of cases arise in the duodenum.

MEN1, multiple endocrine neoplasia 1; NET, neuroendocrine tumour; VIPoma, vasoactive intestinal peptide-secreting tumour.
Table 3 Clinical features of pancreatic NETs

\begin{tabular}{ll}
\hline Tumour & Symptoms \\
\hline Insulinoma & $\begin{array}{l}\text { Confusion, sweating, dizziness, weakness, } \\
\text { unconsciousness, relief with eating }\end{array}$ \\
Gastrinoma & $\begin{array}{l}\text { Zollinger-Ellison syndrome of severe peptic } \\
\text { ulceration and diarrhoea, or diarrhoea alone }\end{array}$ \\
Glucagonoma & $\begin{array}{l}\text { Necrolytic migratory erythema, weight loss, } \\
\text { diabetes mellitus, stomatitis, diarrhoea }\end{array}$ \\
VIPoma & $\begin{array}{l}\text { Verner-Morrison syndrome of profuse watery } \\
\text { diarrhoea with marked hypokalaemia } \\
\text { Cholelithiasis, weight loss, diarrhoea and } \\
\text { Somatostatinoma }\end{array}$ \\
Non-syndromic pancreatic NET & $\begin{array}{l}\text { Symptoms from pancreatic mass and/or liver } \\
\text { metastases }\end{array}$ \\
\hline
\end{tabular}

NET, neuroendocrine tumour; VIPoma, vasoactive intestinal peptide-secreting tumour.

assessment. $^{28-32}$ Gastroenteropancreatic NETs are also associated with other primary malignancies.

\section{Non-functioning gastroenteropancreatic NETs}

Gastric and rectal NETs are often diagnosed coincidentally at endoscopy, or may be the source of anaemia. Type I and II gastric NETs are related to hypergastrinaemia, and are usually small (measuring several millimetres) and multiple. Type I tumours are associated with achlorhydria, while type II are associated with Zollinger-Ellison syndrome and MEN1; neither are likely to metastasise when small. In contrast, type III gastric NETs are often larger (measuring several centimetres) and solitary, are not associated with elevated gastrin, and usually have malignant potential. Appendiceal NETs may be identified during surgery for appendicitis, or during colonic surgery, and are less commonly associated with a secretory syndrome. Approximately $60 \%$ of all pancreatic NETs are non-functioning. The primary tumour may be large at presentation, when approximately $50 \%$ have metastasised. UK data show that bronchial NETs may present with cough and recurrent pneumonia (22\%), incidentally on chest radiography $(18 \%)$, with haemoptysis $(13 \%)$, or with shortness of breath (9\%). ${ }^{33}$ Rarely, these tumours may be associated with ectopic adrenocorticotropic hormone (ACTH) secretion and Cushing's syndrome.

\section{Functioning tumours}

Functioning pancreatic NETs cause symptoms dependent on the peptide hormone released (table 3 ).

\section{Carcinoid syndrome}

Carcinoid syndrome occurs in $\sim 20 \%$ of cases of well-differentiated endocrine tumours of the jejunum or ileum (midgut NET) and consists of (usually) dry flushing (without sweating; $70 \%$ of cases $^{34}$ ) with or without palpitations, diarrhoea (50\% of cases) and intermittent abdominal pain ( $40 \%$ of cases) ${ }^{35}$; in some patients, there is also lacrimation and rhinorrhoea. Carcinoid syndrome occurs less often with NETs of other origins and is very rare in association with rectal NETs. It is usually due to metastasis to the liver, with the release of vasoactive compounds, including biogenic amines (eg, serotonin and tachykinins), into the systemic circulation. However, it may also occur in the absence of liver metastases if there is direct retroperitoneal involvement, with venous drainage bypassing the liver. Pain due to hepatic enlargement may also be a presenting feature, as may upper right abdominal pain (similar to that of pulmonary infarction) secondary to either haemorrhage into, or necrosis of, a hepatic secondary tumour. Wheezing and pellagra are less common presenting features. CHD is present in $\sim 20 \%$ of patients at presentation and usually 
indicates that the syndrome has been present for several years (see also under Carcinoid heart disease). ${ }^{36}$

\section{Carcinoid crisis}

Carcinoid crisis is characterised by profound flushing, bronchospasm, tachycardia and widely and rapidly fluctuating blood pressure. It is thought to be due to the release of mediators, which lead to the production of high levels of serotonin and other vasoactive peptides. It is usually precipitated by anaesthetic induction for any operation, intraoperative handling of the tumour, or other invasive therapeutic procedures such as embolisation and radiofrequency ablation.

\section{Prognosis}

NETs are slow-growing tumours and survival depends on a number of factors. The highest 5 -year survival rates in both the SEER and NRC epidemiological studies were for patients with rectal primary tumours (74-88\%), while the lowest were found among patients with pancreatic primaries (27-43\%; table 4). ${ }^{12} 13$ However, for patients with a benign insulinoma, the 5-year survival rate may be over $95 \%{ }^{38}$ It had been thought that appendiceal NETs were relatively benign in their behaviour, yet the SEER data have reported 5-year survival rates of $95 \%$ for patients with localised disease and $35 \%$ for patients with distant spread at the time of diagnosis. ${ }^{12}$ The most recent SEER and NRC data show that, overall, patients with appendiceal primaries have 5 -year survival rates between $70 \%$ and $80 \%{ }^{13}$

The SEER data show that the 5-year survival of all patients with NETs, regardless of the primary site and degree of spread, did not change between 1973 and 2002 and remained at $60-65 \%$. Over this period there may have been a slight improvement in outcome for patients with a small bowel primary, with an overall 5 -year survival of $\sim 65 \%$ in $2002 .{ }^{18}$ The 5 -year survival among just over 4000 patients from England and Wales presenting between 1986 and 1999 was 57\% for those with a well-differentiated tumour, and $5 \%$ for those with a 'small-cell' tumour. ${ }^{37}$

Length of survival is directly related to both the extent of the disease at the time of diagnosis and the degree of differentiation of the tumour. According to the most recent SEER data, the 5-year survival of patients with well or moderately well-differentiated tumours was:

- $82 \%$ for local spread.

- $68 \%$ for regional spread.

- $35 \%$ for distant spread.

For poorly differentiated tumours these values were lower:

- $38 \%$ for local spread.
- $21 \%$ for regional spread.

- $4 \%$ for distant spread. ${ }^{14}$

The histopathological type of the tumour, its Ki-67 or MIB-I proliferation index, size and location, as well as the age of the patient, also affect survival. ${ }^{13} 14{ }^{39-45}$ It is no longer appropriate to quote survival figures based on overall survival of all patients with a tumour at a particular site. Such information, when discussed with patients, should be based on a consideration of the impact of the above factors.

Using the newer pathological classification aids in the prognostication of survival. Thus, the 5 -year survival rates for grades 1,2 and 3 tumours are $96 \%, 73 \%$ and $28 \%$, respectively. Similarly, using the recommended TNM staging system, 5-year survival rates for stages I, II, III and IV are 100\%, 90\%, 79\% and $55 \%$, respectively, demonstrating the utility of such newer classifications. $^{46}$

\section{Genetics}

NETs may occur as part of complex familial endocrine cancer syndromes such as MEN1, MEN2, ${ }^{47}$ neurofibromatosis type 1 (NF1), ${ }^{48} 49$ Von Hippel Lindau (VHL) and Carney complex, although the majority occur as non-familial (ie, sporadic) isolated tumours. The incidence of MEN1 in gastroenteropancreatic NETs varies from virtually nil in gut NETs, to $5 \%$ in insulinomas, to $25-30 \%$ in gastrinomas. ${ }^{28}$ However, it is important to search thoroughly for MEN1, MEN2 and NF1 syndromes in all patients with NETs by obtaining a detailed family history and undertaking a clinical examination with appropriate biochemical and radiological investigations. The diagnosis can now be confirmed by genetic testing. In addition, mutations involving the succinate dehydrogenase subunit $\mathrm{D}$, which are usually associated with paragangliomas and phaeochromocytomas, have been reported in patients with midgut NETs. ${ }^{50}$

A diagnosis of MEN1, MEN2, NF1 or a paraganglioma syndrome not only has important implications for the patient but also for the patient's relatives, who should be considered for screening for the associated tumours and genetic testing. Gastrointestinal NETs may, on rare occasions, occur as an isolated familial cancer, without evidence of a MEN syndrome. ${ }^{51}$ This is consistent with results from epidemiological studies, which show a small increased familial risk, with standardised incidence rates of 4.35 ( $n=4 ; 95 \%$ CI 1.86 to 7.89$)$ for small intestinal and 4.65 ( $n=4 ; 95 \%$ CI 1.21 to 10.32 ) for colon NETs in offspring of parents affected by NETs. This familial clustering was seen to be more pronounced with midgut and hindgut tumours, and very few patients had obvious MEN1, indicating

Table 4 Sites and overall 5-year survival rates in patients with gastroenteropancreatic NETs in the USA (from the SEER Programme), Norway (from the NRC) and England and Wales ${ }^{12-14} 37$

\begin{tabular}{|c|c|c|c|c|c|}
\hline \multirow[b]{3}{*}{ Site } & \multicolumn{5}{|c|}{ Percentage surviving } \\
\hline & \multicolumn{2}{|c|}{ SEER data $(n=17312)$} & \multirow[b]{2}{*}{ NRC data $(n=2013)$} & \multicolumn{2}{|l|}{ England and Wales } \\
\hline & Black patients & White patients & & $\begin{array}{l}\text { Well-differentiated } \\
\text { tumours }\end{array}$ & $\begin{array}{l}\text { Small cell } \\
\text { tumours* }\end{array}$ \\
\hline Lung & 36 & 48 & 54 & - & - \\
\hline Stomach & 56 & 64 & 45 & 52 & 18 \\
\hline Small intestine & 64 & 70 & 59 & 59 & 27 \\
\hline Pancreas & 27 & 35 & 43 & 39 & 17 \\
\hline Appendix & 70 & 79 & 74 & - & - \\
\hline Colon & 61 & 53 & 41 & 65 & 27 \\
\hline Rectum & 85 & 88 & 74 & - & - \\
\hline
\end{tabular}

*Data are for 1-year survival.

NET, neuroendocrine tumour; NRC, Norwegian Registry of Cancer; SEER, Surveillance, Epidemiology and End Results. 
that much of this association is independent of MEN1. ${ }^{10}$ Patients with tuberous sclerosis complex may also be at increased risk of NETs. ${ }^{52}$

A family history of cancer is also a significant risk factor for all types of NETs. Risk is elevated more often in women than in men. In a USA-based case-control study, the adjusted ORs (95\% CI) of positive family history of cancer for small bowel, gastric, lung, pancreatic and rectal NETs were 1.4 (0.9 to 2.2), 0.8 (0.3 to 2.6), 2.7 (1.2 to 6.1$), 1.5$ (0.8 to 2.9 ) and 1.8 (0.5 to 5.8$)$ among men and 2.3 (1.2 to 4.3), 5.2 (1.4 to 19.6), 2.1 (1.1 to 4.3), 3.7 (1.4 to 9.9) and 1.3 (0.4 to 3.0) among women, respectively. ${ }^{20}$ Moreover, it appears that up to $\sim 20 \%$ of patients with gastric NETs may also develop another synchronous cancer, typically affecting the gastrointestinal tract. ${ }^{12}$ There are insufficient data to know whether this is a feature in patients with other NETs. Risks for second cancers in men were increased during the first year of follow-up. Slightly lower risks were noted in women.

\section{DIAGNOSIS}

Diagnosis of NETs is based on clinical manifestations, peptide and amine secretion, ${ }^{53}$ and specialised radiological and nuclear imaging. Diagnosis is secured by detailed histology, which should be obtained whenever possible.

\section{Biochemistry}

The measurement of the secretory products of NETs is helpful in three respects:

- To assist with initial diagnosis.

- To assess the efficacy of treatment.

- To assess changing prognosis.

The life of patients with NET may be under more immediate threat from the syndrome than from the underlying malignancy. As the syndromes are driven by circulating secretory products, it is usually beneficial to reduce these.

Chromogranin A (CgA) is the only general marker for NETs as it is usually found in high concentrations regardless of whether the tumour is accompanied by hormone-related clinical features. ${ }^{29} 5455$ However, chromogranin B $(\mathrm{CgB})$ may be elevated when $\mathrm{CgA}$ is in the reference range. ${ }^{56-58}$ Two chromogranin $\mathrm{B}$ assays are commercially available, from Euro Diagnostic UK and Byorbyt Ltd. Pancreastatin, one of the post-translational products of CgA, is a useful additional marker, ${ }^{59} 60$ as it is only raised in metastatic NETs and results are not confounded by conditions that raise CgA (eg, treatment with proton pump inhibitors, or atrophic gastritis).

Pancreatic polypeptide (PP), a product of the normal pancreas, is secreted in high concentrations from a significant proportion of NETs throughout the gastroenteropancreatic tract (50-80\% of pancreatic NETs and $>30 \%$ of all gut NETs). Therefore PP is a useful additional or alternative general marker in some circumstances, particularly when $\mathrm{CgA}$ or $\mathrm{CgB}$ are within the reference range. ${ }^{26} 61$

The measurement of specific markers is useful for the diagnosis and monitoring of specific tumours. ${ }^{53}$

The majority of tumours of the jejunum, ileum, proximal colon and appendix ( $>70 \%)$ and a significant number of NETs of the stomach and respiratory system (10-35\%) secrete serotonin. Reliable assay of serotonin in blood has been problematic, but is performed in a few centres. ${ }^{62}$ The breakdown product of serotonin, 5-hydroxyindoleacetic acid (5-HIAA), has been used as an alternative and may be readily measured in a $24 \mathrm{~h}$ urine collection. However, there are many dietary restrictions and drug interference problems associated with the measurement of serotonin and 5-HIAA, and the laboratory should be contacted to ensure that inappropriate foods and drugs are excluded for 3 days before and during the urine collection (online appendix 1).

As many tumours in the ileum and colon present with bowel obstruction, and will have been resected surgically before diagnosis of tumour type, laboratory specimens are often collected postoperatively. Urinary 5-HIAA may then be within the reference range. $\mathrm{CgA}$ and neurokinin $\mathrm{A}$ measurement, ${ }^{63}$ together with measurement of 5-HIAA, will indicate residual disease in more than $90 \%$ of patients. ${ }^{64}{ }^{65}$ As surgical cure is rare, all of these patients should be followed-up indefinitely using laboratory testing (and imaging), with the exception of those with some small tumours of the appendix (see under Surgery).

A range of peptide markers specific to the tumour site may also be measured. These are detailed in table 5 .

Laboratory diagnosis of some tumour types is not straightforward.

In the stomach, type I NETs are associated with atrophic gastritis, while in type II NETs the gastrin results from a gastrinsecreting tumour. Circulating gastrin is raised in both types I and II, and causes enterochromaffin-like (ECL) cell hyperplasia and, ultimately, may cause ECL NETs. In type III tumours, gastrin is not raised. CgA is raised in all three types. ${ }^{66} 67$

The laboratory diagnosis of gastrinoma may be difficult. Both gastrin and $\mathrm{CgA}$ are raised in gastrinoma. However, both gastrin and $\mathrm{CgA}$ are also raised in many common conditions, particularly when gastric acid is reduced or absent-for example, in patients with atrophic gastritis or in those receiving proton pump inhibitor (PPI) therapy. Upper gastrointestinal endoscopy and gastric biopsy is always required to differentiate gastrinoma from atrophic gastritis; secretin stimulation and intragastric $\mathrm{pH}$ may also be needed in some cases.

When circulating gastrin and CgA are raised, a fasting specimen is required; autoimmune atrophic gastritis must be excluded, and Helicobactor pylori should be eradicated. Recurrent peptic ulcer disease, especially with gastrointestinal bleeding in the absence of $H$ pylori, gives a strong suspicion of gastrinoma. PPIs and $\mathrm{H}_{2}$ antagonists raise both circulating $\mathrm{CgA}$ and gastrin (online appendix 2). PPIs should be withdrawn with great caution and ideally stopped 10 days to 2 weeks before any planned estimation of circulating fasting gastrin. In patients with suspected gastrinoma, oral $\mathrm{H}_{2}$ antagonists may be used instead for this period, but it is advisable for these to also be interrupted $48 \mathrm{~h}$ before the test. ${ }^{68}$ Patients with a gastrinoma should be advised that it is dangerous to stop PPIs without supervision. Where a question regarding the diagnosis remains, a secretin test may be performed, with or without gastric acid studies.

Patients with gastrinoma may present with circulating gastrin $<10 \%$ above the reference range. ${ }^{69}$ The majority of gastrinomas are located in the duodenum rather than in the pancreas.

All patients with gastrinoma should be considered as candidates for MEN1 syndrome. Fasting calcium, parathyroid hormone and prolactin measurements should be made.

Insulinoma may be difficult to diagnose, as circulating insulin concentrations are often within the reference range in these patients. The insulin level, however, will be inappropriate to the blood glucose. Measurement of $\mathrm{C}$ peptide or pro-insulin is helpful. The majority of insulinomas are benign, and CgA will not be raised unless the tumour is metastatic. A $48-72 \mathrm{~h}$ fast under hospital supervision with serial blood glucose analysis is the gold standard diagnostic tool and will usually trigger hypoglycaemia within $24 \mathrm{~h}$. In $\sim 5 \%$ of patients, however, the hypoglycaemia may only be revealed postprandially. ${ }^{70}$ 
Table 5 Peptide markers specific to the tumour site

\begin{tabular}{|c|c|c|c|}
\hline Site & Type & Laboratory tests required & Results expected \\
\hline \multirow[t]{2}{*}{ Gastric } & I and II & $\mathrm{CgA}$, gastrin & Raised \\
\hline & III & $\mathrm{CgA}$, gastrin & Raised $\mathrm{CgA}$, gastrin not raised \\
\hline \multirow[t]{2}{*}{ Duodenal } & & $\begin{array}{l}\text { CgA, gastrin, PP, urinary 5-HIAA, } \\
\text { SOM }\end{array}$ & Raised $\mathrm{CgA}$ in $90 \%$ \\
\hline & & & Consider MEN1 \\
\hline $\begin{array}{l}\text { Jejunal, ileal and } \\
\text { proximal colon }\end{array}$ & & $\mathrm{CgA}$, urinary 5-HIAA, NKA & $\begin{array}{l}\text { Raised CgA }(>80 \%) \text {, U-5-HIAA (70\%) } \\
\text { and/or NKA }(>80 \%) \text {; see text }\end{array}$ \\
\hline Proximal colon & & $\mathrm{CgA}$, urinary 5 -HIAA, NKA, (PP) & $\begin{array}{l}\text { Raised CgA }(>80 \%) \text {, U-5-HIAA }(70 \%) \\
\text { and/or NKA }(>80 \%) \text {; see text }\end{array}$ \\
\hline \multirow[t]{2}{*}{ Appendiceal } & & $\mathrm{CgA}$, urinary 5-HIAA, NKA, (PP) & None raised unless metastatic \\
\hline & & & Metastatic: markers as ileal \\
\hline Goblet cell & & $\mathrm{CgA}$, urinary 5 -HIAA, NKA, (PP) & None raised \\
\hline \multirow[t]{2}{*}{ Rectal } & & $\mathrm{CgA}, \mathrm{CgB}, \mathrm{PP}$, glucagon, HCG- $\beta$ & Raised CgA (rarely); see text \\
\hline & & & $\begin{array}{l}\text { Raised } \mathrm{CgB}, \mathrm{PP} \text {, glucagon and/or } \\
\text { HCG- } \beta \text { in some }\end{array}$ \\
\hline \multirow[t]{9}{*}{ Pancreatic } & & $\operatorname{CgA}$ & $\begin{array}{l}\text { Raised } \operatorname{CgA} \text { in metastatic tumours } \\
\text { only }\end{array}$ \\
\hline & Insulinoma & $\mathrm{CgA}$, insulin, blood glucose, & $\begin{array}{l}\text { Insulin inappropriate to glucose; } \\
\text { see text }\end{array}$ \\
\hline & & C peptide or pro-insulin & Raised C peptide and pro-insulin \\
\hline & Gastrinoma & Gastrin & Raised gastrin; see text \\
\hline & Glucagonoma & Glucagon, enteroglucagon & Raised glucagon \\
\hline & VIPoma & VIP & Raised VIP \\
\hline & Somatostatinoma & SOM & Raised SOM \\
\hline & PPoma & $\mathrm{PP}$ & Raised PP \\
\hline & MEN1 & $\begin{array}{l}\mathrm{CgA} \text {, gastrin, (calcium, PTH), } \\
\text { insulin, glucagon, PP }\end{array}$ & \\
\hline
\end{tabular}

Non-functioning tumours of the pancreas often secrete PP, and this may be a helpful marker in patients with these tumours. $^{61}$

The majority of rectal tumours do not secrete CgA. Many secrete PP and some may secrete enteroglucagon, human chorionic gonadotropin- $\beta$ or acid phosphatase. When a marker is identified, this is helpful. However, the absence of a marker does not equate to the absence of a tumour.

A range of peptide markers can be measured in two laboratories in the UK, and specimens may be sent to these laboratories through local hospitals. Some other NHS laboratories measure CgA.

Some peptides show a significant rise postprandially, particularly insulin, gastrin and PP. These peptides may remain elevated for more than $6 \mathrm{~h}^{71}$; therefore it is ideal that all specimens should be collected after an overnight fast. For some of the markers (eg, CgA), a fasting specimen is not required. If specimens at clinics are not always collected after a fast, the fasting or random status of the specimen should be recorded on the accompanying form to enable appropriate interpretation by the laboratory. With the exception of insulin, peptide markers for NETs are all raised in the circulation of patients with renal failure. $^{72} 73$ Interpretation of results from these patients is difficult.

A number of circulating markers have been reported to be of prognostic value: $\mathrm{CgA}$ for the majority of tumours, ${ }^{74}$ pancreastatin for hepatic tumour bulk, ${ }^{59}$ and neurokinin A for serotonin-secreting tumours of the small bowel. ${ }^{64}$

In a significant number of sporadic NETs, cell type may change and tumours will produce different peptides in addition to the original ones. This indicates worsening prognosis; in particular, ACTH is associated with poor prognosis. ${ }^{75-77}$
Circulating prognostic indicators are of value in progressive disease and in assessing treatment response since they may be repeated frequently.

\section{IMAGING}

Imaging is indicated at different stages in the patient's care, including:

1. Screening of at-risk populations

2. Primary lesion detection

3. Assessing extent of disease

4. Follow-up and assessing response to treatment.

\section{Screening of at-risk populations}

Patients with a family history of MEN1 syndromes should be considered for screening according to the established MEN syndrome guidelines. ${ }^{78}$ In principle, screening of asymptomatic family members should, where possible, be undertaken without exposure to radiation, and thus ideally with MRI.

\section{Primary tumour detection}

Precise localisation and measurement of the primary tumour is helpful for surgical planning. It is unclear whether locating and resecting the primary tumour changes prognosis. However, primary tumour resection may reduce the likelihood of local complications, such as bleeding and obstruction.

\section{Gastrointestinal and pulmonary NETs}

Endoscopy is the investigation of choice for suspected gastric, duodenal and colorectal NETs. EUS, where available, is a useful adjunct for the assessment of depth of invasion and for biopsy when a mass is detected. ${ }^{79-81}$ CT and/or bronchoscopy are 
recommended for the investigation of suspected bronchial NETs. ${ }^{82}$ SSRS and $\mathrm{CT}^{83}$ provide additional staging information.

CT is the most widely used initial imaging investigation for patients with a suspected gastrointestinal NET involving the small bowel. The sensitivity for detection of the primary tumour is limited (table 6), but mesenteric disease, lymphadenopathy and liver disease are well demonstrated. ${ }^{93} 94$ The technique of CT enteroclysis combines the cross-sectional display of solid organs with the luminal and mural display of the small bowel and is more sensitive than routine CT in demonstrating an occult primary tumour in patients strongly suspected of having a gastrointestinal NET of the small bowel. Multiplanar reformatting facilitates viewing of the small bowel loops. The reported sensitivity and specificity for detection of small bowel lesions by CT enteroclysis is $85 \%$ and $97 \%$, respectively, and midgut NETs are well demonstrated. ${ }^{84} 95$ Magnetic resonance (MR) enteroclysis is currently under investigation as a radiation-free alternative for small bowel assessment. $^{85} 96$ Transabdominal ultrasound is no longer generally used for the initial detection of gastrointestinal NETs.

\section{Capsule endoscopy}

Small-scale studies have reported the successful detection of occult small bowel NETs using capsule endoscopy where other techniques have failed. ${ }^{96} 97$ It is advisable to use a dissolvable 'patency' capsule to safeguard against the capsule being retained within strictures. A disadvantage of capsule endoscopy is that precise localisation of the tumour within the small bowel is not usually possible.

\section{Pancreatic NETs}

Functioning pancreatic NETs (ie, those associated with a hormonal syndrome) may be picked up at an earlier stage than non-functioning tumours. The potential for surgical cure necessitates accurate localisation, ideally using a combination of CT, MRI and EUS, often together with SSRS and, in some centres, DSA with intra-arterial calcium stimulation. Meticulous technique is required to optimise detection rate (online appendix 3).

CT

With the development of multidetector CT (MDCT) and the use of thin reformats, there has been a reported increase in

Table 6 Sensitivities of the various imaging modalities for locating specific NETs ${ }^{80}{ }^{84-92}$

\begin{tabular}{ll}
\hline Pancreatic NETs & Tumour and Frequency \\
\hline Dual-phase multi-detector CT & $57-94 \%$ \\
MRI & $74-94 \%$ \\
EUS & $82-93 \%$ \\
SSRS insulinomas & $50-60 \%$ \\
SSRS gastrin/VIP/somatostatin & $75 \%$ \\
${ }^{68}$ Ga DOTATOC PET & $87-96 \%$ \\
Primary gastrointestinal NETs & \\
CT enteroclysis & $85 \%$ \\
MR enteroclysis & $86 \%$ \\
SSRS for detection of lesions in & $86-95 \%$ \\
non-pancreatic GI NETs & \\
Neuroendocrine liver metastases & \\
CT & $44-82 \%$ \\
MRI & $82-95 \%$ \\
\hline
\end{tabular}

EUS, endoscopic ultrasound; Gl, gastrointestinal; MR, magnetic resonance; NET, neuroendocrine tumour; PET, positron emission tomography; SSRS, somatostatin receptor scintigraphy; VIP, vasoactive intestinal peptide.

All of the above sensitivities for detecting tumour are further enhanced by intraoperative ultrasound. sensitivity for the detection of insulinomas to $94 \% .{ }^{86}$ When the results of MDCT are combined with experienced EUS, a sensitivity of $100 \%$ can be achieved. ${ }^{86}$ Small functioning tumours are usually isodense to pancreas before contrast and enhance strongly after contrast, although the vascular blush is often transient. The best visualisation is usually with arterial phase imaging but portal venous phase imaging is complementary. Large tumours are more likely to be non-functioning than small tumours. Signs of malignancy include large size, necrosis, calcification and invasion/infiltration of surrounding structures.

\section{MRI}

Marked improvements in MR technology have occurred in the past decade. The diagnostic performance of MRI has improved and has been shown, in several studies, to exceed or equal that of CT. $^{879899}$ MRI has a sensitivity of $94 \%$ for pancreatic lesions, but this is lower for extrapancreatic lesions. ${ }^{88} 98$

Pancreatic NETs are typically of high signal intensity on T2weighted and T2 fat-saturated images and of low signal intensity on T1-weighted and T1 fat-saturated images. Enhancement of a lesion following intravenous contrast administration may render it isointense to the surrounding pancreatic parenchyma.

\section{EUS}

EUS is invasive, operator-dependent and is not available at all centres. It greatly improves the sensitivity for the detection of small tumours and multiple pancreatic NETs in MEN1 or VHL syndromes compared with cross-sectional imaging. ${ }^{100}{ }^{101}$ The primary aims of EUS are to obtain a tissue sample, and to decide whether the patient should have an enucleation or a Whipple's procedure.

Although the diagnostic performance of EUS is operatordependent, reports indicate that overall the technique is highly sensitive in experienced hands, with sensitivities as high as 79-100\%. ${ }^{101} 102$ There is a close correlation between aspiration cytology and the final histology after resection, and it has a low complication rate. ${ }^{103-106}$

\section{Intraoperative ultrasound (IOUS)}

This technique has similar advantages to EUS. IOUS may improve the intraoperative sensitivity for identifying small lesions in the pancreatic head and show multiple lesions in up to $92-97 \%$ in patients with the MEN1 syndrome; it may be a useful adjunct to palpation of the gland. ${ }^{107} 108$ IOUS has the advantage over EUS of being able to assess the liver. However, it is not as sensitive as surgical palpation in detecting extrapancreatic lesions.

\section{Intra-arterial calcium with DSA}

This technique may be particularly important for localising occult gastrinomas. ${ }^{109}$ Intra-arterial calcium stimulation combined with hepatic venous sampling has been reported to achieve a success rate of up to $90 \%$ in the localisation of insulinomas. Results should be interpreted in combination with those from other imaging modalities. ${ }^{110} 111$

\section{Scintigraphy (in all gastroenteropancreatic NETs)}

Scintigraphy, including PET/CT, may be used to locate the primary tumour in cases where endoscopic or CT findings are inconclusive. These techniques are considered in the next section.

\section{Assessing extent of disease}

Many patients with NET present with metastatic disease without a known primary site. Investigations for localising the primary site have been described above. In cases where CT has 
not identified the primary lesion, and in cases where the primary lesion has been detected but whole-body imaging for the detection of metastatic disease is indicated, whole-body scintigraphy is indicated, using SSRS with single-photon emission CT (SPECT) or PET/CT (using gallium-labelled somatostatin analogues). ${ }^{112}$ Imaging with SSRS or meta-iodobenzylguanidine (mIBG) will also identify patients with inoperable or metastatic disease who might be candidates for high-activity targeted radiotherapy. Krenning et al ${ }^{113}$ reported that SSRS before surgery revised the staging and changed management in 33\% of patients with NET. In patients with poorly differentiated NET, $\left[{ }^{18} \mathrm{~F}\right]$ fluorodeoxyglucose ( $\left.{ }^{18} \mathrm{~F}-\mathrm{FDG}\right)$ PET/CT may be helpful for staging.

\section{${ }^{111}$ Indium ( $\left.{ }^{111} \mathrm{I}\right)$-octreotide}

The observation that NETs overexpress somatostatin receptors (SSTRs) has led to the development of radiolabelled somatostatin analogues for diagnostic imaging. Of the five recognised receptor subtypes, SSTRs 2 and 5 have been targeted for imaging purposes. SSRS is widely available and well established for the localisation of primary NETs. ${ }^{113-115}$ The reported sensitivity of SSRS is $61-96 \% .{ }^{1}{ }^{116-124}$ Sensitivity and specificity are enhanced by topographic image acquisition (SPECT) and by the recent development of SPECT/CT image fusion. In pancreatic NETs, diagnostic performance varies by tumour type. Sensitivities approaching $75 \%$ have been reported for gastrinomas, VIPomas, glucagonomas and non-functioning tumours, compared with $50-60 \%$ for primary insulinomas. ${ }^{89}$

Limitations of SSRS include: (1) reduced sensitivity in smaller (sub-centimetre) lesions and in lesions exhibiting low receptor density; (2) 2-day imaging protocol; and (3) potential interference by co-adminstration of therapeutic somatostatin analogues (online appendix 4). The demonstration of somatostatin receptor status by ${ }^{111} \mathrm{In}$-octreotide or ${ }^{68} \mathrm{Ga}$-labelled peptide PET/ CT imaging positively predicts response to somatostatin analogue therapy.

\section{Meta-iodobenzylguanidine}

NETs of pancreatic origin are rarely mIBG avid. In gastrointestinal NETs of the small bowel, ${ }^{123}$ I-mIBG scintigraphy is less sensitive than ${ }^{111}$ In scintigraphy. ${ }^{125} 126$ The main indication for mIBG imaging lies in selecting patients for high activity

${ }^{131}$ I-mIBG-targeted radionuclide therapy. Between $40 \%$ and $85 \%$ of NETs accumulate mIBG depending on primary tumour origin.

\section{$\mathrm{PET} / \mathrm{CT}$}

\section{${ }^{68} \mathrm{Ga}$ somatostatin analogues}

Several ${ }^{68} \mathrm{Ga}$-labelled somatostatin analogues have been developed for diagnostic imaging. DOTA octreotide (DOTATOC) and DOTA octreotate (DOTATATE) bind to SSTR2 and SSTR5, whereas DOTA-NaI-octreotide (DOTANOC) binds to SSTR2, SSTR3 and SSTR5. Rapid tumour accumulation and background clearance facilitate imaging within 100 min of administration. ${ }^{90}$ In a study of 84 patients, the sensitivity (96\%) and specificity $(92 \%)$ of ${ }^{68} \mathrm{Ga}-D O T A T O C$ proved superior to that of CT or SSRS for detection of unknown primary, initial tumour staging or follow-up after therapy. There was an increase in the detection of unrecognised bone metastases, and additional sites of metastatic disease were identified. ${ }^{90}$ However, CT is required to ensure detection of liver and lung metastases. ${ }^{90} 127 \mathrm{~A}$ retrospective study of ${ }^{68} \mathrm{Ga}$-DOTATOC PET in duodenopancreatic NETs reported a sensitivity of $87 \%$ and a specificity of $83 \% .{ }^{91}{ }^{68} \mathrm{Ga}$-DOTANOC PET/CT has recently been reported to have led to either staging or treatment change in 50 of 90 patients $(56 \%)$ assessed prospectively. ${ }^{128}$ The major practical disadvantage of ${ }^{68} \mathrm{Ga}$-peptide PET/CT in the UK remains its limited availability.

\section{${ }^{18} \mathrm{~F}-\mathrm{FDG}$ PET/CT}

Although well-differentiated NETs are not typically ${ }^{18} \mathrm{~F}$-FDG avid, ${ }^{18}$ F-FDG PET/CT is useful in staging primary bronchial and poorly differentiated aggressive NETs. ${ }^{129}$

\section{Emerging tools \\ ${ }^{18} \mathrm{~F}$-DOPA PET/CT $\left({ }^{18} \mathrm{~F}\right.$-DOPA)}

The sensitivity of ${ }^{18} \mathrm{~F}$-DOPA in metastatic NETs approaches $100 \%$, demonstrating more lesions than SSRS, CT, or SSRS and CT combined. Carbidopa pretreatment is used to reduce artefacts related to physiological activity in the peripancreatic tissues. $^{130}$

\section{${ }^{11} \mathrm{C}$-5- Hydroxytryptophan (HTP) PET/CT $\left({ }^{11} \mathrm{C}-5 \mathrm{HTP}\right)$}

High detection rates are reported using ${ }^{11} \mathrm{C}$-labelled 5HTP for both gastrointestinal and pancreatic NETs. ${ }^{131}$ Pretreatment with carbidopa is recommended. ${ }^{132}$

At present, neither technique is routinely available in the UK.

\section{Follow-up and assessing response to treatment}

The role of follow-up imaging and optimal imaging frequency depend on clinical circumstances and tumour grade. ${ }^{133-135}$ The modality of choice should be that which best demonstrated the tumour at diagnosis. Thus, SSRS imaging is recommended for tumours known to be SSTR-positive, supplemented by CT and MRI where necessary. Follow-up for SSTR-negative tumours relies on MDCT or MRI.

The follow-up interval depends on the rate of growth of the tumour. Initially, follow-up imaging may be taken at 3-6-month intervals. If the disease is relatively slow growing, the interval can be increased to 9-12 months. In slow-growing tumours, particularly in younger patients, MRI may be used for follow-up in order to to reduce radiation exposure to the patient. In the context of clinical trials, standardised criteria may be used to assess response, although these remain imperfect for the evaluation of NETs. Functional MRI techniques, including diffusion-weighted MRI and dynamic contrast-enhanced MRI, are currently being evaluated.

\section{ASSESSMENT OF OOL}

Metastatic disease is a common presentation in patients with NETs; therefore, often the aim of treatment is to improve QoL rather than achieve a cure. It is therefore recommended that $\mathrm{QoL}$ should be assessed regularly throughout management.

Patients with NETs, in spite of long-term and metastatic disease, often perceive their health-related $\mathrm{OoL}$ as good, ${ }^{136}$ but the treatment options available to these patients are expensive and are not without side effects. The data derived from QoL measurement may be helpful to both patients and clinicians in decisions about treatment options. ${ }^{137}$ It can be used to help inform economic analyses and resource allocation and to influence healthcare policy. ${ }^{138}$ QoL data may also be useful in highlighting those areas where we need to develop interventions for the amelioration or prevention of treatment-related problems. ${ }^{139}$ A specific QoL score questionnaire for patients with NETs is in phase IV validation. ${ }^{140}$ At present, the best tool to assess healthrelated QoL in patients with NETs is the European Organization for the Research and Treatment of Cancer's Quality of Life Questionnaire (EORTC OLQ) C-30. ${ }^{141}$ 


\section{PATHOLOGY}

\section{Pathological reporting of NETs}

Pathologists dealing with NETs should have a special interest in endocrine or gastrointestinal pathology, or participate in a network with the opportunity for pathology review. Tumours should be classified according to the WHO 2010 classification. ${ }^{142}$ This classification is fundamentally different from the WHO 2000 classification scheme, ${ }^{143}$ as it no longer combines stagerelated information with the two-tiered system of well and poorly differentiated NETs. The WHO 2010 classification is based on the concept that all NETs have malignant potential, and has therefore abandoned the division into benign and malignant NETs and tumours of uncertain malignant potential. Instead, it organises the classification of NETs according to grade and stage. The classification scheme uses the terms NET (or neuroendocrine neoplasm) and neuroendocrine carcinoma as outlined in table 1 of online appendix 5.

Grading is performed on the basis of morphological criteria and the proliferative activity of the tumour (online appendix 5). Tumour staging is performed according to a system of sitespecific criteria. While the WHO 2010 classification recommends using the Union for International Cancer Control (UICC) TNM ( 7 th edition) staging system, ${ }^{144}$ it acknowledges the existence of the ENETS staging system, ${ }^{145} 146$ and the fact that grading and staging definitions may need adjustment in the future as the schemes evolve.

The ENETS TNM staging system for gastrointestinal and pancreatic endocrine tumours has been described previously. ${ }^{145} 146$ The T-staging criteria differ from those proposed by UICC TNM (7th edition) ${ }^{144}$ for gastric and pancreatic NETs, and in particular, for NETs of the appendix.

The recommendations are therefore:

1. To grade the tumour according to the WHO 2010 grading system ${ }^{142}$

2. To stage the tumour according to the UICC TNM (7th edition) ${ }^{144}$ site-specific system

3. To also stage the tumour according to the ENETS site-specific T-staging system when different from the UICC TNM (7th edition) - that is, for NETs of the stomach, pancreas and appendix ${ }^{145} 146$

4. To state which TNM classification is used

5. To document the underlying features that contribute to the T-stage classification (eg, tumour size, extent of invasion, etc) to allow translation between different current and future classification systems. ${ }^{147}$

In addition, pathologists should refer to the WHO 2000 classification $^{143}$ for those NETs that, according to this system, fall into the category of benign tumours. This is applicable to NETs that are small and locally confined without distant spread, and relates in particular to a proportion of pancreatic insulinomas, gastric NETs in the context of chronic atrophic gastritis, and incidental appendiceal NETs. The benign behaviour of these NETs is widely accepted and established in clinical practice, and it is therefore deemed clinically useful to report on this additional information at a time of transition between both classification systems.

The prognostic validity of the TNM system as proposed by ENETS has been established, ${ }^{46}{ }^{148-152}$ but similar validation studies are still awaited for the recently introduced WHO 2010 and UICC TNM (7th edition) classification and staging schemes.

Specimen handling, and gross and microscopic assessment should be carried out according to a standard protocol that is based on the Royal College of Pathologists dataset for NETs of the gastrointestinal tract and pancreas ${ }^{153}$ and that follows the ENETS consensus guidelines. ${ }^{154}$ Further detailed recommendations are given in online appendix 5 .

\section{TREATMENT}

\section{Objectives}

The aim of treatment should be curative where possible but it is palliative in the majority of cases. Patients often maintain a good QoL for a long period despite having metastases. Although rate of growth and malignancy are variable, the aim should always be to maintain a good QoL for as long as possible. For all patients, the aim is to keep the patient free from disease and symptoms for as long as possible.

\section{Surgery}

\section{General approach}

Surgery is the only curative treatment for NETs. As with all gastrointestinal tumours, the conduct of surgery with intent to cure depends on the method of presentation and the stage of disease. Specific issues with NETs include determining the extent of local and distant tumours, identification of synchronous non-NETs, recognition of fluid and electrolyte depletion from diarrhoea, and, in advanced cases, detection of less obvious cases of carcinoid syndrome as well as detection of cardiac abnormalities. The treatment plan should be modified accordingly, whether to meet immediate or long-term objectives, within a multidisciplinary framework. With NETs, if the primary lesion is $<2 \mathrm{~cm}$ in diameter (depending on the site of origin), the incidence of metastasis is low. ${ }^{30} 155$ However, nodal or liver metastases are found at presentation in $40-70 \%$ of patients. ${ }^{30} 155-157$

\section{Perioperative preparation of patients with functional NETs}

When major surgery or hepatic artery embolisation are planned in patients with carcinoid syndrome, prophylactic administration of somatostatin analogues should be considered to prevent a potential carcinoid crisis, even in patients who are receiving long-acting formulations of these agents. Short-acting octreotide is preferably used by constant intravenous infusion at a dose of $50 \mu \mathrm{g}$ per hour, initiated $12 \mathrm{~h}$ before, and given for $24-48 \mathrm{~h}$ after, surgical intervention. ${ }^{158-163}$ It is also important to avoid drugs that release histamine or activate the sympathetic nervous system. ${ }^{164}$ Despite octreotide therapy, patients may still develop life-threatening cardiorespiratory complications that can tax even the most experienced anaesthetist, who may have to use $\alpha$ - and $\beta$-adrenoreceptor blocking drugs to avoid severe complications. ${ }^{165}$

In addition, short-acting octreotide should always be available, even when a non-syndromic patient with a small bowel NET undergoes an interventional procedure. In cases of unexpected carcinoid crisis, bolus intravenous doses of $100-500 \mu \mathrm{g}$ octreotide should be given, followed by continuous infusion (see doses above). Antihistamines and corticosteroids may also be beneficial. $^{35}$

Similar prophylactic measures may be required for pancreatic and periampullary NETs, for example glucose infusion for insulinoma, PPI (oral or infusion) and intravenous octreotide for gastrinoma.

\section{Lung}

The treatment of choice is a major lung resection or wedge resection plus node dissection. ${ }^{166}$ Direct bronchial ultrasound may assist in determining the resection margin. ${ }^{167}$ Five-year 
survival after such surgery is between $67 \%$ and $96 \%$, depending on the histology of the tumour ${ }^{168-171}$ and the extent of lymph node involvement. ${ }^{172-178}$

\section{Emergency abdominal presentations}

Patients presenting with suspected appendicitis, intestinal obstruction or other gastrointestinal emergencies are likely to require resections sufficient to correct the immediate problem. Once definitive histopathology is obtained, a further, more radical resection may have to be considered. The most common circumstance is when a NET arising in the appendix $2 \mathrm{~cm}$ or more in diameter has been removed. Under these circumstances, a right hemicolectomy is usually indicated, despite the common absence of obvious malignant features characterising the NET. ${ }^{179-181}$ Goblet cell appendix tumours always require right hemicolectomy because they behave in a much more aggressive way. ${ }^{182-184}$

Well-differentiated tumours that are $<2 \mathrm{~cm}$ may require further resection if they:

- Breach the serosal surface

- Invade the mesoappendix by more than $3 \mathrm{~mm}$

- Are located at the base of the appendix. ${ }^{185}$

There is no definite evidence for the requirement of further surgery if histology shows vascular, neural or lymphatic invasion, but close follow-up is advisable, and further surgery could be discussed with the patient.

Most patients should be followed-up for 10 years. ${ }^{186}$ Complete resection by appendicectomy of lesions smaller than $1 \mathrm{~cm}$ in diameter with no other adverse features is likely to be curative. ${ }^{180}$ Extended follow-up in this case does not appear to be necessary.

If a perforation has occurred at the site of the tumour, some authorities would recommend right hemicolectomy, although there is no direct evidence relating to this.

\section{Practice point}

Although not underpinned by any evidence from prospective studies, the guideline development group holds the view that, particularly in women, there is an increased risk of pelvic peritoneal metastases (especially bilateral ovarian) with goblet cell NETs of the appendix. Such patients should therefore be counselled about this risk and the provision of 'prophylactic' bilateral oophorectomy should be discussed. ${ }^{185} 187188$

Level of evidence 5, Grade of recommendation C.

A limited emergency small bowel resection for an obstructing NET can be followed at a later date by elective surgery to remove further small bowel or to undertake mesenteric lymphadenectomy. This is particularly appropriate if a second tumour has been identified. A substantial minority of patients with midgut NETs have multiple tumours, ${ }^{189} 190$ so a search should be made after removal of an obstructing lesion before any further surgery. Furthermore, it is not uncommon to encounter significant desmoplastic reaction in the mesentery (occasionally with varices), which renders resection extremely difficult and dangerous in inexperienced hands. In such cases it is not unreasonable to refer intervention on to a surgeon with greater experience of midgut NETs.

Level of evidence 3-5, Grade of recommendation C.

\section{Stomach}

In patients with gastric NETs, the surgical approach depends on the type of tumour, of which there are three types.

Type 1 gastric NETs are associated with hypergastrinaemia and chronic atrophic gastritis. They originate from ECL cells, and can synthesise and store histamine. The frequency of direct invasion into muscularis and metastasis is extremely low, and in most cases only annual endoscopic surveillance is appropriate. ${ }^{191-195}$ Limited surgery with endoscopic polypectomy and/or antrectomy may be preferable, especially when B12 deficiency anaemia is compounded by iron-deficiency anaemia due to bleeding from the gastric NETs, ${ }^{191}$ 196-198 although achlorhydria also contributes to iron deficiency due to iron malabsorption.

Type 2 gastric NETs occur in patients with hypergastrinaemia due to Zollinger-Ellison syndrome in combination with MEN1 syndrome. ${ }^{199}$ Small type 1 and 2 tumours with no extension into muscle on EUS or CT can be resected endoscopically, and a combined laparoscopic and endoscopic technique has been used.

Type 3 gastric NETs are sporadic and have a more malignant course. ${ }^{192} 200$ They are not associated with hypergastrinaemia. These tumours have often metastasised at the time of diagnosis. Most lesions will need resection and clearance of regional lymph nodes and are effectively treated as for gastric adenocarcinoma. ${ }^{191} 201-203$

Level of evidence 3-5, Grade of recommendation C.

\section{Small intestinal NETs}

By far the majority of small intestinal NETs are malignant in nature. Whether liver metastases are present or not, resection of the primary tumour and extensive resection of associated mesenteric lymph nodes is appropriate to cure or to delay progression that would otherwise endanger the small bowel. Occasionally, nodal metastases cause sclerosis with vascular compromise of the associated small bowel, which can lead to pain, malabsorption and even death. Patients who are discovered to have small intestinal NETs only after laparotomy and histological examination may be candidates for further surgery, notably for extensive mesenteric lymphadenectomy. Resection of mesenteric metastases may alleviate symptoms dramatically and, in large series, is associated with prolonged survival. It is recommended that such surgery is undertaken in centres where surgeons have experience of operating on patients with midgut NET disease.

Level of evidence 2, Grade of recommendation B.

As yet there is no clear guidance on the role of resection of asymptomatic primary NETs in the presence of unresectable liver metastases; ideally this question should be answered by a randomised controlled trial. Data from a UKINETS audit ${ }^{204}$ and other authors ${ }^{205}$ suggest that there may be a survival benefit for such practice.

Level of evidence 4, Grade of recommendation C.

\section{Colorectum}

Standard resection with locoregional lymphadenectomy is appropriate. $^{206}$ Clearance of metastatic lymph nodes is a worthwhile objective that may contribute to long-term survival, and nodal clearance does not add significantly to the risk of mortality, which should in any case be $<2 \%$ when conducted by specialist colorectal teams. Small lesions that are $<1 \mathrm{~cm}$ in diameter and that have a well-differentiated histology (particularly those in the rectum, which tend to have a less aggressive course) may be considered adequately treated by complete endoscopic removal or transanal mucosal resection; however, the patient will require follow-up endoscopy to ensure this has been accomplished. Lesions that are more than $2 \mathrm{~cm}$ in diameter should be managed as per adenocarcinoma; there is debate concerning lesions of $1-2 \mathrm{~cm}$, but some of these will invade locally and metastasise.

Level of evidence 3, Grade of recommendation C. 


\section{Pancreas}

Pancreatic and periampullary NETs form a special group that requires particular consideration. ${ }^{207-212}$ As with all other neoplasms at these sites, surgery should only be undertaken in specialist hepatopancreatobiliary units. It is recognised that pancreatic resectional surgery is increasingly being performed via laparoscopic access. ${ }^{213-216}$ For the moment, the decision as to whether this surgery is performed by the traditional open or laparoscopic route should be left to the discretion of each designated specialist pancreatic surgery centre.

According to the WHO classification, tumour size correlates with malignant potential. Localised tumours larger than $2 \mathrm{~cm}$ in diameter warrant aggressive resection. Surgical management remains to be proven effective for non-functioning pancreatic NETs in MEN1 syndrome. Often the diagnosis is established biochemically before surgery and, although preoperative localisation can be difficult, the biochemical diagnosis provides some indication of the likelihood of malignancy (eg, low with insulinoma), and localisation can be aided by hepatic venous sampling after calcium stimulation. Thus, for insulinoma, if the lesion is clearly localised before surgery, and is near or at the surface of the pancreas and easily defined at surgery, enucleation may be sufficient, provided histopathology demonstrates complete excision and benign features. ${ }^{217}$ However, this may not be possible, and Kausch-Whipple pancreatoduodenectomy, left pancreatectomy or even total pancreatectomy may be justified in selected cases. ${ }^{218}$ These operations are also applied to selected cases with localised disease arising from other functioning, as well as non-functioning, NETs of the pancreas. ${ }^{219}$

In patients with Zollinger-Ellison syndrome who do not have MEN1 syndrome, surgical exploration should be offered for a possible cure of the disease. There is controversy concerning patients with this syndrome who have MEN1, however, since older data suggest poorer survival in patients treated surgically. ${ }^{220}$ Nevertheless, the majority of these patients die from malignant spread of their gastrinomas, suggesting that resection is preferable for tumours $2 \mathrm{~cm}$ or larger to prevent metastatic spread. ${ }^{221}$

Level of evidence 3, Grade of recommendation B.

With advances in diagnostic imaging, small non-functioning $(<2 \mathrm{~cm})$ pancreatic NETs are increasingly being diagnosed in asymptomatic, otherwise well patients. ${ }^{222} 223$ While, intuitively, such patients should benefit from surgical resection of such tumours, the management of these patients remains controversial. In the absence of consensus, these patients should be managed by an expert MDT experienced in the management of pancreatic NETs.

Level of evidence 4, Grade of recommendation C.

While there is evidence to support hepatectomy for resectable NET liver metastases, ${ }^{224}$ the role of resection of asymptomatic primary pancreatic NETs in the presence of unresectable liver metastases remains controversial. ${ }^{225}$ In the absence of adequate evidence, such decisions should be made by an expert MDT experienced in the management of pancreatic NETs.

Level of evidence 4, Grade of recommendation C.

\section{Appendix}

The appendix is a common primary site, with tumours often found incidentally at appendicectomy. Some $75 \%$ of these NETs are located near the tip. Classical NETs $<1 \mathrm{~cm}$ in size can usually be managed by appendicectomy, while for tumours $>2 \mathrm{~cm}$ in size or for goblet cell tumours of any size, right hemicolectomy is the treatment of choice. ${ }^{184}{ }^{226-228}$ For tumours $1-2 \mathrm{~cm}$ in size, any of the following mandates right hemicolectomy: serosal breach by tumour, cellular atypia, invasion of mesoappendix by more than $3 \mathrm{~mm}$, or involvement of the base of the appendix. 229230 Some centres recommend right hemicolectomy for perforation of the appendix in the presence of a NET and for lymphovascular and perineural invasion, but no definite evidence exists. Long-term (10-year) follow-up is required for any high-risk features.

Level of evidence 3-4, Grade of recommendation C.

\section{Liver}

In the presence of liver metastases 'curative' liver resection is possible in about $10 \%$ of cases, ${ }^{224}$ if the lesion(s) is confined to one lobe. With bilobar metastases and one very dominant lesion causing symptoms, a debulking operation may be carried out for palliation, particularly if there is resistance to medical therapy. The 5-year survival after resection of the primary and/or liver secondary is up to $87 \%$, and postoperative mortality is $6 \% .{ }^{161-163}{ }^{231-236}$ Several series have shown low morbidity and excellent medium-term survival after liver resection, with better outcomes than for patients whose tumours are not resected (although this may partly reflect stage of disease). ${ }^{231} 237238 \mathrm{~A}$ very small number of patients with no obvious primary tumour may have primary hepatic neuroendocrine malignancy, and surgery can be curative ${ }^{239}$; for such patients, surgery is the treatment of choice, with a recurrence rate of $18 \%$ and 5 -year survival of $74 \%$ reported in one series. ${ }^{240}$ Many patients will need somatostatin analogues, which predispose patients to gallstones, hence the gallbladder is usually removed at the time of liver surgery.

Level of evidence 3, Grade of recommendation B.

\section{Orthotopic liver transplantation (OLT)}

Patients with end-stage NET and uncontrollable symptoms that are unresponsive to any other therapy have been considered for liver transplantation. ${ }^{241-248}$ The highest disease-free survival reported to date at 1 year is $77 \%{ }^{247}$

An analysis of UK transplants for NETs ${ }^{249}$ reported actuarial disease-free survival of $62 \%$ at 1 year and $23 \%$ at 5 years, with similar data in a series from France. ${ }^{250}$ The UK and French series both included patients from many years ago, when survival rates would be expected to be lower, and many patients in these series predated modern imaging techniques. More recent data from the French group 251252 show 5-year survival at 47\%, which is close to the acceptable limit for transplantation in the UK.

OLT is currently outside the routine remit of UK Transplant Agency guidelines in view of the disease-free survival of $<50 \%$ at 5 years. However, survival has progressively increased ${ }^{245-247}$ such that in the future, in selected patients and using new drug treatments, OLT may be a management option. At present, only exceptional cases that cannot be treated by other means should be considered, and this should preferably be part of a national trial so that data are standardised and examined regularly. OLT should be avoided in patients who have undergone multiple organ transplants, and those who have pancreatic primary sites and high Ki-67-expressing tumours.

At present, organ shortage combined with the low survival data suggest that liver transplantation should only be considered in exceptional circumstances. Further research is needed to try to assess pretransplant prognostic factors.

\section{Symptomatic treatment}

Symptoms associated with NET hormonal hypersecretion may impair patients' QoL and in some instances can be lifethreatening (eg, severe diarrhoea and hypokalaemia in VIPomas). Administration of specific medications to treat symptoms 
should therefore start as soon as clinical and biochemical signs indicate the presence of hypersecretory NETs, even before the precise localisation of primary and metastatic lesions is confirmed. Treatments include somatostatin analogues, and the use of PPIs for gastrinomas and diazoxide for insulinomas. Additional medications such as loperamide, cholestyramine and corticosteroids may be used as required.

\section{Somatostatin analogues}

The only proven hormonal management of NETs is by the administration of somatostatin analogues. SSTRs are present in the vast majority (75-95\%) of NETs, but are identified in only $50-60 \%$ of insulinomas, and are less evident in poorly differentiated NETs and somatostatinomas. Since natural somatostatin has a very short half-life (2-3 min), analogues with longer half-lives have been developed for clinical use. Somatostatin analogues bind principally to SSTR subtypes 2 (with high affinity) and 5 (with lower affinity), ${ }^{253}$ thus inhibiting the release of various peptide hormones in the gut, pancreas and pituitary; they also antagonise growth factor effects on tumour cells, and, at very high dosage, may induce apoptosis. The effects of somatostatin analogues are demonstrable as biochemical response rates (inhibition of hormone production) in $30-70 \%$ of patients and as symptomatic control in the majority of patients.

There are two commercially available somatostatin analogues: octreotide and lanreotide. The immediate-release form of octreotide (half-life of $1.5-2 \mathrm{~h}$ ) has to be administered subcutaneously two to three times per day or by continuous intravenous infusion. Longer-acting (slow-release and depot) formulations of somatostatin analogues include octreotide long-acting release (LAR), lanreotide Autogel and lanreotide LA. ${ }^{254}$ The long-acting agents have produced significant improvement in the QoL of patients with NET and have comparable or better efficacy than shortacting octreotide. ${ }^{255-258}$ Long-acting formulations of somatostatin analogues should therefore now be considered the standard of care for symptomatic treatment of NETs. Short-acting formulations may still have a role in patient stabilisation (used over short periods) and in the management of carcinoid crisis.

The licensed dosage of octreotide LAR is 10,20 or $30 \mathrm{mg}$ every 4 weeks, and for lanreotide Autogel the recommended dose is 60 , 90 or 120 mg every 4 weeks. Patients should generally be started on lower doses with treatment up-titrated to achieve stabilisation. In cases of breakthrough symptoms, rescue doses of subcutaneous octreotide can be used two or three times per day up to a maximum daily dose of around $1 \mathrm{mg}$. Alternatively, if the breakthrough symptoms occur mainly during the week before the next long-acting injection, a reduction of administration intervals from 4 to 3 weeks may be considered. ${ }^{259}$

\section{Role in prevention of carcinoid crisis}

See under 'Perioperative preparation of patients with functional NETs' for an overview of the use of somatostatin analogues in the prevention of carcinoid crisis.

\section{Nuclear medicine imaging and treatment with radiolabelled somatostatin analogues during treatment with somatostatin analogues}

In theory, co-administration of somatostatin analogues may reduce the sensitivity of SSRS imaging. Where possible, most UK centres recommend withdrawal of short-acting somatostatin analogues for $24-48 \mathrm{~h}$ before ${ }^{111}$ In-octreotide or ${ }^{68} \mathrm{Ga}$-peptide injection until imaging is completed.

In patients receiving long-acting analogues, SSRS or ${ }^{68} \mathrm{Ga}$ PET/ CT, studies should ideally be scheduled towards the end of the dosing interval and just before the next planned injection.
ENETs guidelines suggest withdrawing long-acting somatostatin analogues for 6 weeks before planned radiopeptide treatment, and substituting short-acting somatostatin analogues for symptom control until $24 \mathrm{~h}$ before treatment. ${ }^{260}$ In the absence of evidence from randomised controlled trials, most UK centres avoid the potential morbidity of this approach by adhering to the simpler regimen described above for diagnostic imaging.

Somatostatin analogue treatment does not interfere with mIBG or ${ }^{18}$ F-FDG PET/CT imaging.

\section{Adverse effects}

The most common adverse effects of somatostatin analogues are usually mild and resolve with time. ${ }^{8} 261262$ They include local reactions (pain and erythema) at the injection site, abdominal cramps, nausea, flatulence, diarrhoea and steatorrhoea. There is also a risk of cholelithiasis (10-50\%), ${ }^{263} 264$ which may be asymptomatic; in such cases, cholecystectomy is not necessary. However, prophylactic cholecystectomy during abdominal surgery is recommended in patients who are already receiving, or are due to start, long-term treatment with somatostatin analogues. ${ }^{265}$ Rare adverse effects include bradycardia, abnormal metabolism of glucose, malabsorption of vitamins A, B12 and D, and alopecia. ${ }^{266}$

\section{Efficacy and indications in various syndromes}

Functioning small bowel NETs (carcinoid syndrome). Somatostatin analogues are effective in the management of the symptoms of carcinoid syndrome. Most studies report improvements in diarrhoea and flushing in $60-70 \%$ and $70-80 \%$ of patients, respectively, and a significant reduction $(>50 \%)$ in biochemical markers (especially 5-HIAA) in 40-60\% of patients. ${ }^{123} 256267$

\section{VIPoma (watery diarrhoea, hypokalaemia, achlorhydria (WDHA) syndrome, Werner-Morrison syndrome)}

Rehydration and electrolyte replacement are always indicated and may improve the clinical condition considerably. In patients with this rare life-threatening syndrome, the administration of somatostatin analogues results in significant improvement of symptoms in $80-90 \%$ of patients and in reduction of vasoactive intestinal peptide levels in $60-80 \% .{ }^{268}{ }^{269}$ However, biochemical improvement does not always correlate with symptomatic improvement, and thus the drug dose should be titrated mainly against symptoms.

\section{Glucagonomas}

Somatostatin analogues have been reported to result in improvements in patients with the glucagonoma syndrome (migratory necrolytic erythema rash, diabetes, weight loss, etc). The characteristic rash of necrolytic migratory erythema can be life-threatening. After the initiation of somatostatin analogue treatment, $80-90 \%$ of patients with glucagonomas show a significant improvement in migratory necrolytic erythema rash. Treatment is less effective in terms of controlling diabetes and weight loss, which are common symptoms in these patients. Treatment with somatostatin analogues may result in a reduction in circulating glucagon levels in about $60 \%$ of patients, although in many cases these levels are very high, so normalisation is unlikely. ${ }^{258} 270$

\section{Gastrinomas}

PPIs are currently the treatment of choice for the control of gastric acid hypersecretion-associated symptoms (see under Proton pump inhibitors). Somatostatin analogues are not considered as first choice agents by the majority of clinicians and should only be used in refractory cases. 


\section{Insulinomas}

Somatostatin analogues are often not effective in the control of hypoglycaemia in patients without SSTR 2-positive tumours (50-60\% of insulinomas), and their use may lead to variable effects on blood glucose levels, possibly because of inhibition of glucagon secretion. ${ }^{271} 272$ Diazoxide has been shown to be effective in controlling hypoglycaemic symptoms in many patients with insulinoma (see under Other medications). ${ }^{273}$

\section{Other clinical syndromes}

Somatostatin analogues have been reported to improve parathyroid hormone related peptide (PTHrP)-related hypercalcaemia in rare PTHrP-secreting pancreatic NETs. ${ }^{274}$ They may also be beneficial in NETs patients with paraneoplastic Cushing's syndrome or acromegaly, associated with ectopic secretion of ACTH or growth hormone-releasing hormone (GHRH), respectively. ${ }^{275} 276$

\section{Non-functioning NETS}

The role of somatostatin analogues in patients with nonfunctioning NETs is unclear and the routine use of these agents in such NETs can only be recommended once further evidence is available.

\section{Antiproliferative potential of somatostatin analogues}

It has been postulated that somatostatin analogues may have an antiproliferative effect. Several studies suggest that, in pancreatic NETs, partial/complete tumour response is achieved in fewer than $10 \%$ of patients, although stabilisation of radiologically documented tumour progression has been demonstrated in $24-57 \%$ of patients. ${ }^{277-284}$

Similar results have been demonstrated for small bowel NETs. $256257267277-283$ In addition, recent data from one doubleblind, placebo-controlled study (PROMID; Placebo-controlled, double-blind, prospective, Randomised study on the effect of Octreotide LAR in the control of tumour growth in patients with metastatic neuroendocrine MIDgut tumours) demonstrated prolonged progression-free survival (PFS) in patients with metastatic NETs of midgut origin receiving octreotide LAR with a median time to progression of 14.3 months compared with 6 months in the placebo group. In this study, the best results were demonstrated in patients with low hepatic tumour load and a resected primary lesion. ${ }^{285}$

Finally, there is an ongoing study assessing the antiproliferative effects of lanreotide Autogel in patients with nonfunctioning intestinal and pancreatic NETs.

While the evidence is thus not wholly conclusive, and further studies in a wider range of tumours and using different doses will be valuable, at present there is a rationale for the use of somatostatin analogues in attempting to moderate the tumoural progression of NETs.

\section{New somatostatin analogues}

New somatostatin analogues are in development, with the agent SOM-230 (pasireotide) in phase II at the time of writing. These studies may extend the use of somatostatin analogues for symptomatic therapy, and may offer treatment for patients resistant to conventional octreotide and lanreotide.

\section{Proton pump inhibitors}

PPIs are currently the treatment of choice for the control of gastric acid hypersecretion-associated symptoms and prevention of peptic complications in gastrinoma patients. Higher doses of PPIs may be required in patients with complicated disease.

\section{Other medications}

Diazoxide is used as short-term treatment in patients with insulinoma scheduled for surgery, or as a long-term therapy in patients with unresectable disease. Diazoxide is a hypertensive medication with hyperglycaemic effects, and is usually effective in controlling hypoglycaemia symptoms in patients with insulinoma. The recommended daily dose is $200-600 \mathrm{mg}$ orally. Adverse effects, including oedema, weight gain, hirsutism and renal dysfunction, are common but are not usually troublesome. $^{273}$ There are two small case series of patients with malignant insulinoma refractory to conventional agents that report significant improvement in glycaemic control with the novel mammalian target of rapamycin (mTOR) inhibitor, everolimus, ${ }^{286287}$ and also a case report of a similar patient showing control of hypoglycaemia with oral rapamycin. ${ }^{287}$

In patients with small bowel NETs, loperamide and ondansetron can be used for the management of secretory diarrhoea, cholestyramine for bile salt malabsorption-related diarrhoea, and oral pancreatic supplements for steatorrhoea following treatment with somatostatin analogues. Oral antibiotics may be used for control of small bowel bacterial overgrowth in patients with extensive mesenteric fibrosis. Patients may also benefit from oral vitamin $B$ compounds to prevent clinical features of vitamin $B$ deficiency.

In some patients with insulinoma, verapamil and phenytoin can be used as alternatives to diazoxide. Corticosteroids can be used in patients with insulinoma with refractory hypoglycaemia and in those with VIPoma with life-threatening diarrhoea that does not respond to maximum doses of somatostatin analogues. $^{288}$

In patients with glucagonoma, zinc salts can be used to prevent further skin lesions.

Appropriate prophylaxis should be considered in all patients with NETs with increased risk of thromboembolic episodes (eg, those with glucagonoma).

Bisphosphonates may be used for symptom control in patients with bone metastases, although they are not specifically indicated for NETs. ${ }^{289}$

\section{Interferon $\alpha$}

Interferons are immune modulators necessary to combat viral infections. Interferon $\alpha$ acts via specific cell-surface receptors to activate downstream cytoplasmic kinases. In addition, it induces arrest in the G1 and G0 phases of the cell cycle, inhibits production of growth factors, induces class 1 antigens, and has antiangiogenic properties. ${ }^{290}$ It is used for the treatment of both functional and other NETs, either on its own or added to longacting somatostatin analogues if the patient is not responding to maximum dosage of somatostatin analogues. Interferon $\alpha 3-5$ mega units three times per week subcutaneously is the usual dose used. However, there is conflicting evidence as to its efficacy, with only one major group supporting its widespread use. However, there is some evidence that it may have a greater effect in tumours with low mitotic rate. ${ }^{266}$ Biochemical response has been demonstrated in $40-60 \%$ of patients, while symptomatic improvement and significant tumour shrinkage have been reported in $40-70 \%$ and a median of $10-15 \%$ of patients, respectively. ${ }^{291-293}$

Somatostatin analogues have been added to interferon $\alpha$ with the aim of enhancing its antitumour effect, ${ }^{294}$ but studies thus far have failed to demonstrate this. An increase in 5-year survival from $37 \%$ with interferon $\alpha$ alone to $57 \%$ in combination with octreotide was seen in one study (HR 0.62 (95\% CI 0.3 to 1.1); $\mathrm{p}=0.132$ ), although the results were not statistically significant 
because of small patient numbers $(n=68) .{ }^{295}$ Two other small randomised studies have shown this combination to increase toxicity without any additional survival benefit (although both studies were underpowered to do so). ${ }^{296} 297$ Although sometimes useful for control of refractory hormonal symptoms, the combination of interferon $\alpha$ and somatostatin analogues for the prolongation of survival should still be considered investigational.

Emerging evidence suggests that pegylated interferon is better tolerated and also demonstrates some activity ${ }^{298} 299$; however, current data do not support its use outside of clinical trials.

\section{Chemotherapy}

There are only four published randomised trials of chemotherapy for NETs, and none have compared chemotherapy with best supportive care. ${ }^{300} 301$ There are numerous small, uncontrolled, retrospective studies in heterogeneous or poorly characterised patient populations. Many older studies report response rates in terms of clinical, radiological and biochemical response rather than according to WHO or RECIST criteria. ${ }^{302} 303$

For pancreatic NETs the seminal randomised trials performed by Moertel et al ${ }^{304} 305$ established streptozotocin (STZ)-based regimens as the standard of care. The first trial demonstrated a superior, but non-significant, survival benefit for patients treated with the combination of STZ and 5-fluorouracil (5-FU) compared with STZ alone, ${ }^{304}$ while the second showed better survival for the combination of STZ and doxorubicin (DOX; 26 months) over single-agent chlorozotocin (18 months) or the 5 -FU/STZ combination (17 months). ${ }^{305}$ In these trials, the best response rates were $63 \%$ and $69 \%$, respectively, but these rates were based on clinical and biochemical responses as well as radiological response.

A more realistic response rate is provided by three recent single-arm studies, which applied WHO or RECIST criteria in patient cohorts of at least 45 patients. Using STZ/DOX, ${ }^{306}$ STZ/5-FU/DOX ${ }^{307}$ or STZ/5-FU/cisplatin (FCiSt), ${ }^{308}$ response rates were remarkably consistent at $36 \%, 39 \%$ and $38 \%$, and were associated with median overall survival of 24,37 and 32 months, respectively. The results of the recently completed randomised phase II NET01 trial comparing STZ/capecitabine with or without cisplatin (FCiSt; http://Clinicaltrials.gov identifier NCT00602082) are awaited.

Temozolomide (TMZ), like STZ, is an alkylating agent but is orally bioavailable, and has been reported to have a $70 \%$ response rate in a recent small $(\mathrm{n}=30)$ single-arm study when used in combination with capecitabine. ${ }^{309}$ Previous results using TMZ as a single agent or in combination with thalidomide or bevacizumab have been less impressive, ${ }^{310} 311$ and randomised comparisons with STZ regimens are required. Of interest, response to TMZ may be related to expression of the DNA repair enzyme methylguanine DNA methyltransferase (MGMT), and two small retrospective studies have shown increased responses to TMZ by MGMT-deficient tumours. ${ }^{311} 312$ The value of MGMT expression as a potential predictive marker of response of NETs to alkylating agents needs to be investigated further before changing clinical practice.

For non-pancreatic NETs, there are two randomised trials. The first compared 5-FU/STZ versus DOX in 172 patients and, using clinical, biochemical and radiological criteria, reported respective response rates of $22 \%$ and $21 \%$, with no significant difference in survival. ${ }^{301}$ The second trial compared 5 -FU/DOX versus 5 -FU/ STZ in 176 patients and reported a response rate (WHO criteria) of $16 \%$ in both arms, but a superior survival of 24 months for 5-FU/STZ compared with 16 months for 5-FU/DOX $(p=0.027) .{ }^{300}$ Small, single-arm, single-agent studies exploring newer cytotoxic agents including the taxanes, ${ }^{313}$ gemcitabine, ${ }^{314}$ pemetrexed $^{315}$ and topotecan ${ }^{316}$ have not been encouraging, with response rates of $<10 \%$.

Tumour grade (WHO criteria based on Ki-67 and mitotic index) and differentiation status also influence response to chemotherapy. A recent analysis of 82 patients treated with FCiSt demonstrated responses ranging from 14\% for low-grade tumours to $33 \%$ for intermediate-grade tumours, and $60 \%$ for high-grade tumours $(p=0.025)$. Both Ki-67 $(p=0.019)$ and mitotic index $(p=0.008)$ correlated independently with response. ${ }^{308}$ For Ki-67, a minimum cut-off of $10 \%$ was associated with a response rate of over $38 \%$, but further studies are required to define the optimum value to direct therapy. For poorly differentiated carcinomas, response rates of $42-67 \%$, lasting a median of 8-9 months, are reported in historical studies using cisplatin and etoposide. ${ }^{317-319}$ Increasing the intensity of treatment by adding paclitaxel to carboplatin and etoposide, although feasible, had no obvious advantage over doublet therapy. ${ }^{320}$

Given the paucity of adequately powered definitive phase III studies incorporating modern response assessments and upto-date histological subtyping aimed at reducing patient heterogeneity, patients and clinicians should be encouraged to participate in well-designed, prospective clinical trials of chemotherapy or novel targeted therapies. See under Emerging therapies below for a discussion of newer agents.

At the time of writing, the use of chemotherapy should be based on the following principles:

- Where appropriate, patients should be invited to participate in clinical trials (eg, chemotherapy or novel targeted therapy trials-see under Emerging therapies below).

- For poorly differentiated NETs, a platinum-based regimen should be considered.

Level of evidence 2, Grade of recommendation B.

- A STZ-based combination should be considered for moderately and well-differentiated tumours, particularly when the following apply:

- The tumour is pancreatic in origin.

- The tumour is of intermediate or high grade, based on mitotic index or Ki-67.

- There is rapid clinical or radiological progression.

Level of evidence 1, Grade of recommendation A.

Although there are limited data in terms of efficacy, systemic chemotherapy could also be considered in patients with recurrent and/or metastatic goblet cell appendiceal NETs. The optimal regimen needs to be defined; however, colorectal cancer regimens have been used in view of the aggressive nature of this tumour.

\section{Ablation therapies}

\section{Radiofrequency ablation: image-guided ablation}

Radiofrequency ablation has been used with some effect in stabilising or reducing tumour size, but randomised trials are lacking. ${ }^{32}$ It may be indicated in patients with inoperable bilobar metastases. ${ }^{322}$ Ablation therapies are rapidly evolving. Treatment by ablation can be performed percutaneously or laparoscopically. Most devices are now able to deliver $3-5 \mathrm{~cm}$ spherical ablation zones, and large expandable probes and multipolar devices can yield larger treatments. The percutaneous approach is the most commonly used, as it is least invasive, cheapest and has the additional benefit of CT or MRI guidance. The laparoscopic approach has the benefit of intraoperative ultrasound scanning, which is ideal for the detection of tiny tumours, but it does require considerable skill. ${ }^{323}$ 
Ablation can be used to reduce hormone secretion and/or to reduce tumour burden. Most patients with neuroendocrine metastases have a large number of small metastases that are hormonally active. Parallels should not be drawn with the ablation experience seen in metastatic colorectal disease. The Cleveland Clinic group assessed ablation outcomes following laparoscopic radiofrequency ablation, noting a 34\% local recurrence rate for colorectal metastases, but only $6 \%$ recurrence for neuroendocrine metastases. ${ }^{324}$

The Essen group has usefully stratified metastatic NETs into three groups: (1) solitary or paucilesional disease; (2) isolated metastatic bulk with smaller deposits (often contralobar); and (3) disseminated metastatic spread. ${ }^{325}$ Ablation is usually most appropriate in groups 1 or 2 alongside resection or as an adjunct to somatostatin analogue radionuclide therapy. As with surgical resection or embolisation in the setting of a functioning NET (usually metastatic midgut NETs), the procedure should be carried out in conjunction with a prophylactic continuous octreotide infusion (see under Surgery above).

The main limitation for radiofrequency ablation is the size and number of tumours. Neuroendocrine metastases are small, numerous and very slow growing. Therefore, it is possible to treat patients with indolent disease, with as many as 20 small $(<3 \mathrm{~cm})$ tumours, at multiple treatment sessions over a period of years. Complete ablation is, however, still limited to small volume $(<4 \mathrm{~cm})$ tumours

Destroying the largest lesion may not necessarily switch off hormone production. To achieve a reduction in hormone secretion, it is usually necessary to ablate at least $90 \%$ of the visible tumour. $^{326-331}$ Tumour location is not as important as for liver resection. Recent case series suggest that after laparoscopic radiofrequency ablation for NET liver metastases, local recurrence is around $6 \%$ and symptomatic relief is achieved in $70-95 \%$ of patients, with a 5 -year survival of $57 \%$ and a median survival of 3.9 years after the first radiofrequency ablation. ${ }^{324} 332$ Patients who have biliary-enteric anastomoses after pancreatic surgery are at significant risk of secondary infection in the ablated area of the liver and require 3 months of rotating oral antibiotics after the procedure. All cases considered for cytoreductive ablation should be discussed at a specialist hepatobiliary MDT meeting.

\section{Targeted radionuclide therapy}

\section{Systemic targeted radionuclide therapy}

This is a useful approach for patients with inoperable or symptomatic NETs and has become a standard of care for these patients in the UK and Europe. Significant responses have been observed in patients who would otherwise not be treatable.

Indications for treatment include symptom palliation after maximal medical therapy and tumour progression. Patient selection criteria include demonstration of superior radiopharmaceutical uptake at all known tumour sites on diagnostic imaging by comparison with normal tissues, reasonable bone marrow reserve, and adequate renal function. Contraindications include pregnancy and breast feeding. Patients should be continent and self-caring in order to minimise risk to nursing staff. Several different therapeutic radiopharmaceuticals are available. No randomised controlled trials have been performed.

\section{${ }^{131}$ I-mIBG}

Up to $80 \%$ of functioning malignant NETs concentrate $\mathrm{mIBG}^{333}$ although the intensity of tumour uptake by comparison with normal tissues is often too low to justify high-activity radionuclide therapy. Treatment protocols vary between different centres. ${ }^{131} \mathrm{I}-\mathrm{mIBG}$ therapy is administered in a dedicated, shielded isolation facility for radiation protection reasons. Thyroidal uptake of free radioiodide is prevented by potassium iodide/iodate blockade.

The usual prescribed ${ }^{131} \mathrm{I}-\mathrm{mIBG}$ activities in the UK range between 7.4 and $11.2 \mathrm{GBq}$ administered at 3-6-month intervals. mIBG therapy is the only licensed radionuclide therapy for NETs. Treatment is well tolerated, and toxicity limited to temporary myelosuppression 4-6 weeks after therapy. Myelotoxicity is more severe in patients who have bone marrow infiltration by tumour at the time of treatment or who have undergone previous chemotherapy or radionuclide therapy. Myelosuppression is cumulative and may be dose-limiting after repeated treatment cycles.

Response rates of $40-60 \%$ have been reported after repeated cycles of ${ }^{131}$ I-mIBG therapy. ${ }^{334-336}$ Treatment offers symptom palliation, improved $\mathrm{QoL}$ and reduced requirements for somatostatin analogue therapy. Partial objective responses (by the WHO criteria) of $10-15 \%$ have been reported, ${ }^{335}$ but complete radiological response is rare. Survival benefit appears to be related to symptom response and initial administered activity, with a reported actuarial survival improvement of $22 \%$ at 5 years. ${ }^{335}$ Hormone response is not associated with survival gain.

\section{Radiolabelled peptide therapy}

Experience using different radiolabelled peptides has been published but no randomised controlled comparison between individual radiopharmaceuticals has been undertaken. The radiolabels of choice are Yttrium-90 $\left({ }^{90} \mathrm{Y}\right)$ and Lutetium-177 $\left({ }^{177} \mathrm{Lu}\right)$. Available peptides include DOTATOC, DOTATATE, DOTA-lanreotide and DOTANOC, which exhibit different affinities for individual SSTR populations. Optimal peptide selection in an individual patient is determined by diagnostic tracer imaging. The main toxicities of radiopeptide treatment are temporary myelosuppression and radiation nephritis. Nausea and vomiting during and immediately after treatment are partly attributed to co-administration of amino acids for renal protection (see below) and are mitigated by prophylactic antiemetics. Pain due to temporary radiation oedema may occur in patients with bulky tumours and is managed by corticosteroids and analgesics.

\section{${ }^{90} \mathrm{Y}$-DOTATOC and ${ }_{90}$ YDOTATATE}

Activities in the range 3-6 GBq administered at 6-8-week intervals, to a cumulative activity of $12-18 \mathrm{GBq}$, are recommended. Most patients report subjective benefit within two treatment cycles, often in association with a reduction in biochemical tumour markers.

A phase II single-arm study ${ }^{337}$ of 90 patients with refractory NETs treated with three cycles of ${ }^{90}$ Y-edotreotide reported a response rate of $74.4 \%$ (objective response + stable disease), and prolonged overall survival compared with historical controls (26.9 vs 12 months). ${ }^{338}$ Objective response ( $>50 \%$ partial and complete response) in the range $9-33 \%$ by the WHO/RECIST criteria has been reported with ${ }^{90}$ Y-DOTATOC, 339340 with a median time to progression of 29 months and overall survival of 36.7 months from treatment. A study of ${ }^{90}$ Y-DOTATATE in patients with progressive disease reported partial responses in $23 \%$ of patients, with the remaining $77 \%$ having stable disease. $^{341}$

Toxicity is actively related and includes reversible myelosuppression, which is maximal at 4-6 weeks after treatment, and nephrotoxicity. ${ }^{340}$ Co-administration of amino acids, 
particularly D-lysine, reduces tubular peptide binding and is essential to minimise renal toxicity. Patients with pre-existing microangiopathy due to hypertension or diabetes are at increased risk of cumulative nephrotoxicity, which may lead to a decrease in creatine clearance of $7.9 \%$ per annum. ${ }^{340}$

\section{${ }^{177}$ Lu-DOTATATE}

Responses to cumulative activities of 22-29.6 GBq administered in 3.7-7.4 GBq fractions at 6-10-week intervals have been reported: rates of $28 \%$ partial response and $54 \%$ minor response/ stable disease were recorded in a population of patients with refractory, progressive disease at the time of treatment. ${ }^{342}$ Predictive factors for favourable objective response included high selective tumour uptake on pretreatment imaging and limited hepatic metastatic tumour burden. ${ }^{339}$ Haematological toxicity is similar to that reported for ${ }^{90}$ Y-DOTATOC, ${ }^{341}$ although the risk of nephrotoxicity in a small, unrandomised study was reportedly lower, with a decrease in creatinine clearance of $3.8 \%$ per annum. Symptom palliation and QoL improvement as assessed by EORTC OLQ-30 have been demonstrated, although not in a randomised trial. ${ }^{342}$

\section{Future developments}

The therapeutic potential of peptides radiolabelled with $\alpha$ particle emitters ${ }^{343}$ and combination treatment with radiosensitisers ${ }^{344}$ is being investigated in preclinical studies. On the basis of emitted $\beta$ particle range, long-range ${ }^{90} \mathrm{Y}$ may be more suitable for treating bulky metastases, whereas ${ }^{177} \mathrm{Lu}$ would be preferable for small volume disease. Combined ${ }^{90} \mathrm{Y}$ and ${ }^{177} \mathrm{Lu}$ radiolabelled therapy is under consideration. Access to some form of radionuclide therapy should be made available to centres treating patients with NET.

\section{Transhepatic artery embolisation/chemoembolisation}

Particle embolisation (polyvinyl alcohol and gel foam powder) of the hepatic artery in patients with liver metastatic NETs has been shown to reduce tumour size and hormone output. It is primarily used for palliation of symptoms. ${ }^{345-348}$ Chemoembolisation is the regional delivery of chemotherapy (DOX, STZ or cisplatin) in combination with hepatic artery embolisation. The benefits of chemoembolisation have been documented by several investigators, ${ }^{349-351}$ but there are no completed comparative studies between the two modalities.

There have been several studies since the last guidelines ${ }^{2}$ looking at outcomes from embolisation and chemoembolisation. ${ }^{204} 352-358$ The predominant benefit of the procedure is palliation of symptoms, with $70-90 \%$ of patients achieving benefit. There may be an additional benefit of radiographic regression of metastasis with a possible improvement in survival, although this has not been demonstrated in a systematic study. Five-year post-embolisation survival rates of $28-44 \%$ for NET liver metastases and $18-35 \%$ for islet cell metastases have been documented. PFS of 8-22 months and 16 months for NETs and islet cell liver metastasis, respectively, has also been reported. Serious adverse events (sepsis, hepatorenal syndrome and necrotising cholecystitis) have been reported in $7.5-23.8 \%$ of patients. Post-embolisation syndrome (fever, abdominal pain and nausea) is common and usually lasts for 24-72 h.

The 30-day mortality from published data is $1.9-9.3 \%$. However, recently the technique of selective hepatic embolisation has developed, whereby the left or right hepatic arterial branches arising from the main hepatic artery are embolised separately. This is thought to reduce the risk of morbidity and mortality. Patient selection is the key to reduce major complications. Patients with $>75 \%$ liver involvement with or without liver insufficiency, portal vein thrombosis and significant carcinoid heart disease are at increased risk of mortality from the procedure. Other considerations include the presence of systemic infections, significant renal impairment and biliary reconstructive surgery/obstruction. We recommend a multistage technique, aggressive hydration and octreotide infusion $(50 \mu \mathrm{g} /$ $\mathrm{h}$ ), starting $12 \mathrm{~h}$ before the procedure and continued until $48 \mathrm{~h}$ after. Intravenous hydrocortisone, prophylactic antibiotics and allopurinol for tumour lysis syndrome may also be considered.

On the basis of published data, there seems no significant advantage of chemoembolisation over embolisation. However, given the better response of islet cell cancers to chemotherapy, these tumours may have a better response to chemoembolisation.

\section{Selective internal radiation microsphere therapy}

Embolisation of the hepatic artery with ${ }^{90} \mathrm{Y}$ microspheres for unresectable neuroendocrine liver metastases was first described in 1968. ${ }^{359} 360$ Three recent studies have investigated the benefits of ${ }^{90} \mathrm{Y}$ radioembolisation. ${ }^{360-362}$ Early data indicate that it is safe, with no observed deaths within 30 days of treatment in 148 patients. Post-embolisation syndrome was common, and there was a small risk of radiation gastritis and ulceration. Embolisation of the gastroduodenal artery before the procedure may be considered to avoid this. The symptomatic response rate was $55 \%$ at 3 months and $50 \%$ at 6 months; $2.7 \%$ of procedures resulted in complete response, with $60 \%$ showing a partial response. Median survival was 70 months. ${ }^{361}$ Further long-term studies are needed to clarify the role of ${ }^{90} \mathrm{Y}$ microsphere embolisation in the management of patients with unresectable NET liver metastases.

\section{External-beam radiotherapy}

NETs have often been regarded as being radioresistant. However, external-beam radiotherapy may provide excellent relief of the pain from bone secondaries, and there has been a suggestion that some secondary deposits in the liver and elsewhere shrink in response to radiotherapy. It is also useful for the occasional patients with brain metastases. ${ }^{363}$

\section{Emerging therapies}

Current systemic anticancer agents (conventional cytotoxics) have limited efficacy in metastatic NETs. Although results are somewhat better for poorly differentiated carcinomas and pancreatic primaries than for other sites, response rates are low and the impact on survival is small. The greatest unmet need in the management of NETs is for new agents and approaches to therapy to improve outcomes. An increasing understanding of the biology of these tumours, together with the ability to synthesise drugs that can interfere with relevant targets, provides an opportunity for the discovery of new therapies.

A major recent development has been the emergence of two new treatment options (sunitinib and everolimus) for patients with advanced (inoperable locally advanced or metastatic), progressive (defined as evidence of radiological disease progression within the previous 12 months by RECIST), well-differentiated pancreatic NETs. ${ }^{364} 365$

The first of these, sunitinib malate (Sutent; Pfizer), is an oral inhibitor of the tyrosine kinases downstream from key drivers of tumour angiogenesis, including vascular endothelial growth factor (VEGF) types 2 and 3, platelet-derived growth factor and stem-cell factor (c-kit). Pancreatic NETs are highly vascular tumours that have increased VEGF expression; xenograft models treated with VEGF antibodies show significant growth 
inhibition and reduction of liver metastases. High VEGF expression in tumour biopsy samples correlates with metastatic potential and poorer survival.

On the basis of encouraging results from a phase II study, ${ }^{366}$ a phase III double-blind study of sunitinib $37.5 \mathrm{mg}$ per day (continuous daily dosing) or placebo was conducted in patients with well-differentiated, progressive pancreatic NETs. The study was closed prematurely (after enrolment of 171 of the planned 340 patients) by the Independent Safety Monitoring Committee following an observed increase in the number of adverse events and deaths in patients receiving placebo. The primary end point (PFS) was statistically superior for patients receiving sunitinib compared with placebo (median 11.4 months vs 5.5 months; $\mathrm{p}=0.0001)$, with a HR of $0.42(95 \%$ CI 0.26 to $0.66 ; \mathrm{p}<0.001)$. The objective response rate was $9.3 \%$ for sunitinib, with an additional $63 \%$ of patients having stable disease (radiologically, by RECIST); in comparison, $60 \%$ of patients receiving placebo had stable disease and none had a response $(p=0.007)$. Toxicities were as expected from the use of sunitinib in other tumour types: the most common major (grade 3-4) toxicities included neutropenia (12\% of patients) and hypertension $(10 \%$ of patients). Other notable toxicities (usually grade 1-2) included diarrhoea, nausea, fatigue, vomiting, hand/foot skin reaction and, rarely, thyroid dysfunction. ${ }^{364}$

The mTOR is particularly interesting as a potential therapeutic target because genetic abnormalities in the mTOR pathway may be critical to the development of some NETs. A phase II study of the mTOR inhibitor RAD001 (everolimus (Afinitor); Novartis Pharmaceuticals) in 160 heavily pretreated patients with pancreatic NETs revealed an overall response rate of $9.6 \%$, with a further $67.8 \%$ of patients experiencing stable disease. $^{367}$ The subsequent phase III study has confirmed this activity in patients with well or moderately differentiated, progressive pancreatic NETs. Four hundred and ten patients were randomised to everolimus $10 \mathrm{mg}$ once daily (continuous dosing) or placebo. Once again, the study demonstrated a significantly better PFS (the primary end point) of 11.0 months for everolimus and 4.6 months for placebo (HR 0.35 (95\% CI 0.27 to 0.45$) ; \mathrm{p}<0.001)$. Treatment was well tolerated, with most toxicities of grade 1-2 severity (stomatitis, rash, diarrhoea, fatigue and infections). More severe toxicities (grade 3-4) included anaemia ( $6 \%$ of patients) and hyperglycaemia (5\% of patients). Stable disease (by RECIST) was evident in $73 \%$ of patients receiving everolimus, compared with $51 \%$ in the placebo group. ${ }^{365}$

The emergence of sunitinib and everolimus as new treatment options for patients with advanced pancreatic NETs raises a number of additional questions, including the sequencing with other treatment options, activity in higher grade (ie, poorly differentiated) disease, combination with other therapy modalities, activity in non-pancreatic NETs, and use in the different stages of the disease (eg, in the adjuvant setting). Recommendations cannot be made for any of these with the data currently available and these questions remain a focus for ongoing and future research

Similarly, the effects of targeting other cell signalling pathways (eg, insulin-like growth factor and its receptors, and the epidermal growth factor receptor among others) are subject to ongoing studies. There are many advantages to exploring the potential value of new agents in patients with NETs. Patients are generally fit, despite having extensive disease, and usually have good organ function preservation. Compared with other disseminated malignancies, patients with NETs have a relatively long median survival, which gives new agents a chance to demonstrate their effect. It is clearly essential to include NET patients in programmes of phase I and II trials of new agents, as only in this way will new therapeutic approaches emerge to produce improved outcomes in the future. The networks that now exist for the management of these patients provide large patient numbers and high-quality centres that can undertake early phase trials.

\section{CARCINOID HEART DISEASE}

The development of $\mathrm{CHD}$ leads to dramatic worsening of prognosis in patients with NETs. The 3-year survival of patients with carcinoid syndrome and CHD was found to be $31 \%$ compared with $68 \%$ in patients with carcinoid syndrome without CHD. ${ }^{368}$

The reported prevalence of $\mathrm{CHD}$ in patients with carcinoid syndrome has decreased in recent decades, from $50 \%$ to $70 \% 368369$ to about $20 \%$, ${ }^{36}$ probably as a result of the introduction of somatostatin analogues and other therapies designed to reduce the tumour load and the production of tumour secretory products.

Up to $20 \%$ of patients with carcinoid syndrome present with CHD at diagnosis. ${ }^{369}$ The most common pathology in CHD is involvement of right-sided valves (tricuspid valve affected more often than pulmonary). Left-sided lesions occur in up to $15 \%$ of patients with the carcinoid syndrome, but in $47 \%$ of patients with CHD. ${ }^{36} 368370$ Almost invariably in patients with involvement of left-sided valves, patency of the foramen ovale is involved. ${ }^{36}$ Left-sided CHD is very rarely due to a bronchopulmonary $\mathrm{NET}^{371}$ or very severe, poorly controlled carcinoid syndrome.

\section{Clinical examination}

Auscultatory and clinical examination is not an accurate predictor of the presence of tricuspid regurgitation. ${ }^{372}$ Murmurs may be difficult to detect because velocities in the right heart are low. Peripheral oedema, ascites and pulsatile hepatomegaly develop as the disease progresses.

\section{Biomarkers}

Urinary 5-HIAA levels have a high sensitivity (100\%) but low specificity for $\mathrm{CHD}$ and are not suitable as diagnostic biomarkers for this condition. Natriuretic peptides are neurohormones released by the atria and ventricles in response to an increase in wall stress due to both volume and pressure overload. ${ }^{373} \mathrm{NT}$ proBNP seems to be a very useful biomarker of CHD (cut-off level of $260 \mathrm{pg} / \mathrm{ml}(30.68 \mathrm{pmol} / \mathrm{l}))$ and could be used to rule out CHD morbidity in patients with carcinoid syndrome. ${ }^{374} 375$

\section{Electrocardiography}

The ECG changes in patients with CHD are non-specific, ${ }^{376} 377$ but the ECG is very important for detecting arrhythmias.

\section{Echocardiography}

Echocardiography is the mainstay tool for diagnosis of $\mathrm{CHD} .^{36}$ The features of CHD are well described ${ }^{368} 378$ and are pathognomonic in the absence of exposure to the appetite suppressants fenfluramine and phentermine, ergot-derived dopamine agonists, and ergot alkaloid agents such as methysergide and ergotamine. ${ }^{377} 379380$ Patients develop thickening and reduction of the mobility and retraction of the leaflets/cusps of cardiac valves. The subvalvular apparatus also becomes involved. Functionally, a combination of valvular regurgitation and stenosis occurs, and the right heart chambers become enlarged. The development of left-sided lesions may be expected in up to half of patients with CHD. ${ }^{36}$ 


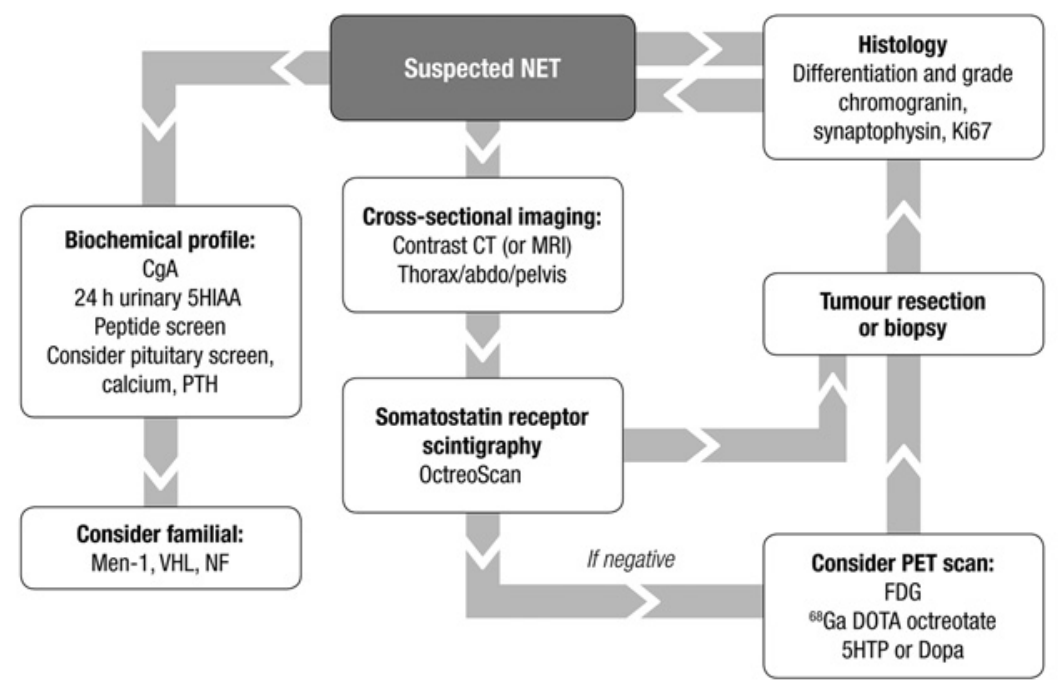

Additional investigations for specific NETs
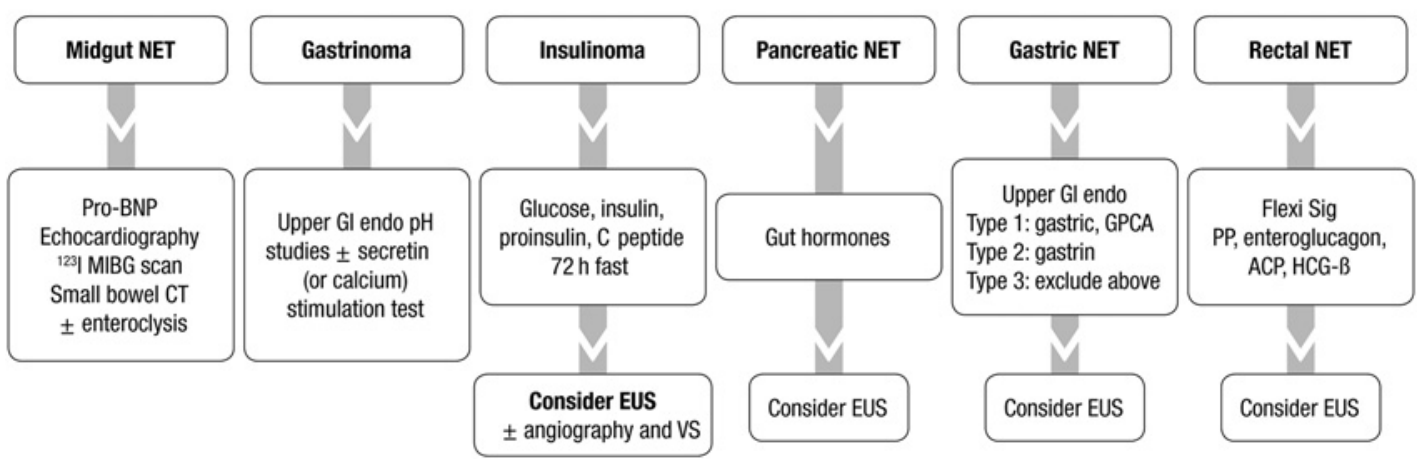

Figure 1 Algorithm for the investigation of neuroendocrine tumours (NETs). ACP, Acid Phosphatase; BNP, brain natriuretic peptide; CgA, chromogranin A; EUS, endoscopic ultrasound; FDG, fluorodeoxyglucose; Gl, gastrointestinal; GPCA, gastric parietal cell autoantibody; HCG, human chorionic gonadotrophin; 5HIAA, 5-hydroxyindoleacetic acid; 5HTP, 5-hydroxytryptophan; Men-1, multiple endocrine neoplasia 1; MIBG, meta iodobenzylguanidine; NF, neurofibromatosis; PET, positron emission tomography; PP, pancreatic polypeptide; PTH, parathyroid hormone; VHL, Von Hippel Lindau.

Figure 2 Algorithm for the treatment of neuroendocrine tumours (NETs). MIBG, meta_iodobenzylguanidine; OLT, orthotopic liver transplantation; SIRT, selective internal radiation therapy.

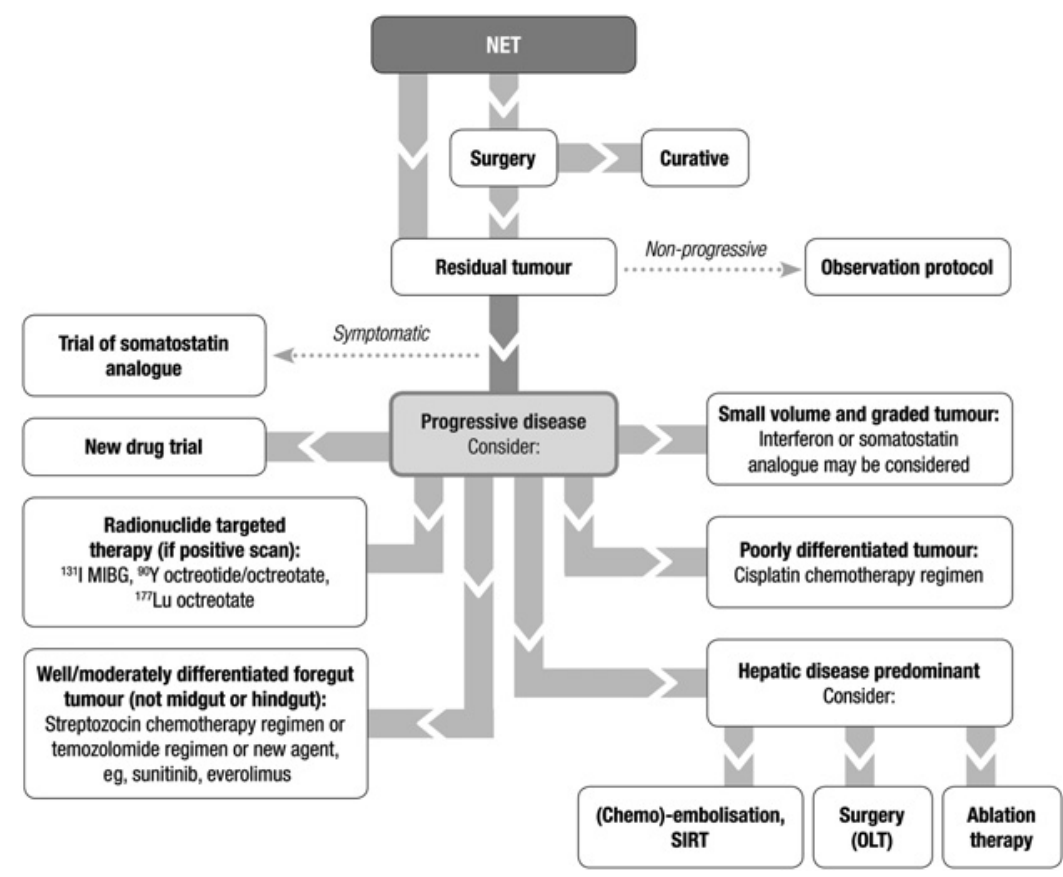


Contrast echocardiography should be performed in order to detect intracardiac shunts and patency of the foramen ovale. Multiple views of each valve should be obtained for optimal evaluation of right-sided heart valves. ${ }^{381}$ When necessary, transoesophageal echocardiography (two-dimensional and three-dimensional) should be used. ${ }^{382}$

Three carcinoid score models have been developed for assessment of the severity of $\mathrm{CHD}^{383-385}$; two of these include right ventricular as well as valvular parameters.

\section{Cardiac MRI and CT}

Cardiac MRI can be useful when evaluating the pulmonary valve, in providing accurate data of right ventricular function, ${ }^{386} 387$ and for the detection of cardiac metastases.

\section{Management}

Intuitively, optimising somatostatin analogue therapy should reduce circulating vasoactive substances and carcinoid syndrome and therefore may stabilise CHD. However, to date there is no evidence to support this effect. ${ }^{384}$ Cytotoxic chemotherapy has been associated with an elevated risk of progressive heart disease. $^{384}$

Medical management of pure right heart failure is limited and consists of relieving symptoms of right heart failure with diuretic therapy.

\section{Cardiac surgery}

Cardiac surgery offers definitive therapy for symptoms. Marked symptomatic improvement of at least one New York Heart Association class occurs after valve replacement. ${ }^{383}$ A median survival of 6 years compares favourably with medically treated patients, but perioperative mortality is significant. ${ }^{388-390}$

\section{ORGANISATION OF CARE}

There are many treatment modalities available and most are very expensive with a poor evidence base. Because of the rarity of NETs, not all clinicians and local hospitals will have the full expertise to deal with these patients. It is therefore important that all NET cases are discussed and managed by an MDT or a regional cancer network group that includes at least one recognised member with an interest in NETs. The Department of Health and National Institute for Health and Clinical Excellence (NICE) have developed a comprehensive package of national guidance (the Improving Outcomes Guidance) for different cancers, including rare tumours. The vital role of the MDT has been emphasised in all NICE guidance. In a Department of Health Cancer Plan publication, it was stated that MDTs led to improved communication between various specialists and therefore patients were likely to receive better continuity and coordination of care. ${ }^{391}$ Although there is no specific guidance for NETs, they are classified as rare cancers; guidance for rare cancers should therefore apply.

For patients with a suspected familial syndrome (eg, MEN1), referral to a genetic centre should be accompanied by appropriate counselling for the patient and their relatives. Even those without a familial syndrome will benefit from psychosocial support and counselling. ${ }^{392}$

The patient should have information available with which to make rational choices about various treatments. Patients should not only be informed about healthcare and treatment options, but also be given the opportunity to be involved in decisions about their own care at all stages of the cancer journey. 391393394 The role of the clinical nurse specialist/practitioner or nurse consultant in the MDT is very important in directing the patient through the treatment and decision-making process. It has been shown that nurses are better than doctors in providing information about disease and treatment, and at breaking bad news to patients. Information can also be obtained through centres that regularly treat these patients and from the organisations below.

UKINETS is an organisation composed of specialist doctors and nurses from the UK and Ireland that was set up to discuss the management of NETs. UKINETS can be contacted via their website: http://www.ukinets.org. The patient support group Net Patient Foundation (incorporating 'Living with Carcinoid') is open to membership for patients and can be contacted at http://www.netpatientfoundation.com.

It has been reported that cancer patients prefer doctor- or nurse-led support groups to patient-led groups ${ }^{395}$; therefore the link between UKINETS and the NET Patient Foundation should continue to be strengthened.

\section{ALGORITHMS FOR OVERALL CARE}

Algorithms for the investigation and treatment of NETs are given in figures 1 and 2 .

\section{Author affiliations}

'Basingstoke and North Hampshire Hospital, Basingstoke, UK

${ }^{2}$ Department of Gastroenterology, County Durham and Darlington Foundation Trust, Darlington, UK

${ }^{3}$ Peptide Laboratory, Royal Victoria Hospital, Belfast, UK

${ }^{4}$ Department of Clinical Pharmacology, University of Sheffield, Sheffield, UK

${ }^{5}$ Department of Radiology, Southampton General Hospital, Southampton, UK

${ }^{6}$ Department of Gastroenterology, University College London, London, UK

${ }^{7}$ Department of Oncology, Addenbrookes Hospital, Cambridge University Hospitals NHS Foundation Trust, Cambridge, UK

${ }^{8}$ Department of Cardiology, Royal Free Hospital, London, UK

${ }^{9}$ Department of Gastroenterology, University Hospitals of Morecambe Bay Foundation Trust, Barrow-in-Furness, UK

${ }^{10}$ Nuclear Medicine, Kings College London, London, UK

${ }^{11}$ Department of Oncology, University College London, London, UK

${ }^{12}$ Department of Endocrinology, University of Sheffield, Sheffield, UK

${ }^{13}$ Department of Surgery, University of Liverpool, Liverpool, UK

${ }^{14}$ Department of Oncology, Beatson Centre, Glasgow, UK

${ }^{15}$ Department of Radiology, Queen Mary's University, London, UK

${ }^{16}$ Department of Oncology, University of Leicester, Leicester, UK

${ }^{17}$ Academic Department of Endocrinology, Diabetes and Metabolism, Oxford

University, Oxford, UK

${ }^{18}$ Department of Gastroenterology, Royal Free Hospital, London, UK

${ }^{19}$ Department of Medical Oncology, The Christie Hospital NHS Foundation Trust,

Manchester, UK

${ }^{20}$ Department of Histopathology, St James's University Hospital, Leeds, UK

Acknowledgments In addition to the authors, the following attended a UKINETS guidelines meeting in May 2009 at Basingstoke, Hampshire, UK and contributed to discussion on which these guidelines were revised: Dr Alan Antoney; Dr John Ayuk; Ms Melissa Banks; Ms Andrea Burgess; Dr Muriel Buxton-Thomas; Ms Louise Causer; Dr Joseph Davar; Ms Philippa Davies; Ms Gill Doodson; Mrs Sue Gower; Mrs Barbara King; Professor Derek Manas; Mr Satvinder Mudan; Dr Alberto Quaglia; Dr Aled Rees; Dr Tahir Shah; Dr Christopher Wong. Editorial support was provided by Winnie McFadzean and by Emma Handley and Andrea Carrodus of Porterhouse Medical Ltd.

Funding Novartis Pharmaceuticals UK Ltd and Ipsen UK provided unrestricted educational grants for the original working party meeting. Novartis Pharmaceuticals UK Ltd also provided financial assistance to allow Porterhouse Medical Ltd, a medical writing agency, to aid the drafting of this manuscript.

Competing interests JR has received honoraria and educational grants from Ipsen and Novartis; AA has received educational support and research grants from Ipsen and Novartis; JA has received research funding, educational grants and travel grants from Ipsen and Novartis; NB has received educational grants and research funding from Ipsen and Novartis; DB has no conflicts of interest; MC has received honoraria from Novartis, Ipsen, Pfizer and Lexicon for advisory boards or invited lectures, and research/educational grants from Novartis and Ipsen; PC has received honoraria for advisory boards and lectures from Novartis and educational travel support grants from Ipsen; AD has received research funding and travel expenses for meetings from Novartis; VL has received honoraria for advisory boards and educational 
grants from Novartis and Ipsen; TM has sat on an advisory board for Keocyte and received partial funding from Pfizer for attendance at ENETs in 2010; JD has received educational grants from Novartis and Ipsen; JN-P has received honoraria and undertaken consultancy work from Novartis and Ipsen, research funding from Novartis, and educational grants for attending meetings from Novartis and Ipsen; GP has received honoraria for advisory boards and lectures from Novartis and Ipsen, educational travel support grants from Novartis and Ipsen, and support for clinical personnel (NET CNS) from Novartis; NR has received honoraria for advisory boards from Novartis and Ipsen and a travel grant from Pfizer; AR has received honoraria for an advisory board and educational lectures from Novartis as well as travel support to those events; WS has received educational grants and honoraria from Ipsen and Novartis; RT has received honoraria and lecture fees from Ipsen, support for clinical personnel from the MRC and Wellcome Trust Clinical Training Fellowships, and educational grants from MRC, Wellcome Trust, EU FP6 and EU FP7; CT has received honoraria and educational support from Novartis and educational support from Ipsen; JV has received honoraria from Pfizer and Novartis, funding for clinical personnel from Novartis, an educational grant from Novartis and research funding from Pfizer, Novartis and Ipsen; CV has received educational grants for conference attendance from Ipsen; AG has received honoraria and educational grant support from Novartis and Ipsen.

Contributors All authors attended a meeting to discuss the required changes to the guidelines. All were subsequently involved in rewriting and reviewing the manuscript in line with discussion from the meeting.

Provenance and peer review Not commissioned; externally peer reviewed.

\section{REFERENCES}

1. Jensen RT, Gibril F, Termanini B. Definition of the role of somatostatin receptor scintigraphy in gastrointestinal neuroendocrine tumor localization. Yale $\mathrm{J}$ Biol Med 1997;70:481-500.

2. Ramage JK, Davies AH, Ardill J, et al; UKNETwork for Neuroendocrine Tumours. Guidelines for the management of gastroenteropancreatic neuroendocrine (including carcinoid) tumours. Gut 2005;54(Suppl 4):iv1-16.

3. Centre for Evidence Based Medicine. Levels of Evidence. http://www.cebm. net/index.aspx?0=1025 (accessed Jun 2011).

4. Williams ED, Sandler M. The classification of carcinoid tumours. Lancet 1963;1:238-9

5. Duerr EM, Mizukami Y, $\mathrm{Ng} \mathrm{A}$, et al. Defining molecular classifications and targets in gastroenteropancreatic neuroendocrine tumors through DNA microarray analysis. Endocr Relat Cancer 2008;15:243-56.

6. Kidd M, Modlin IM, Mane SM, et al. Utility of molecular genetic signatures in the delineation of gastric neoplasia. Cancer 2006:106:1480-8.

7. Nagano $Y$, Kim do H, Zhang $L$, et al. Allelic alterations in pancreatic endocrine tumors identified by genome-wide single nucleotide polymorphism analysis. Endocr Relat Cancer 2007;14:483-92

8. Buchanan KD, Collins JS, Varghese A, et al. Sandostatin and the Belfast experience. Digestion 1990;45(Suppl 1):11-14; discussion 15-16.

9. Hemminki K, Li X. Incidence trends and risk factors of carcinoid tumors: a nationwide epidemiologic study from Sweden. Cancer 2001;92:2204-10.

10. Hemminki K, Li X. Familial carcinoid tumors and subsequent cancers: a nationwide epidemiologic study from Sweden. Int J Cancer 2001;94:444-8.

11. Levi F, Te VC, Randimbison L, et al. Epidemiology of carcinoid neoplasms in Vaud, Switzerland, 1974-97. Br J Cancer 2000;83:952-5.

12. Modlin IM, Lye KD, Kidd M. A 5-decade analysis of 13,715 carcinoid tumors. Cancer 2003:97:934-59.

13. Hauso 0, Gustafsson Bl, Kidd M, et al. Neuroendocrine tumor epidemiology: contrasting Norway and North America. Cancer 2008;113:2655-64.

14. Yao JC, Hassan M, Phan A, et al. One hundred years after "carcinoid": epidemiology of and prognostic factors for neuroendocrine tumors in 35,825 cases in the United States. J Clin Oncol 2008;26:3063-72.

15. Berge T, Linell F. Carcinoid tumours. Frequency in a defined population during a 12year period. Acta Pathol Microbiol Scand A 1976;84:322-30.

16. Bilimoria KY, Bentrem DJ, Wayne JD, et al. Small bowel cancer in the United States: changes in epidemiology, treatment, and survival over the last 20 years. Ann Surg 2009;249:63-71.

17. Modlin IM, Champaneria MC, Chan AK, et al. A three-decade analysis of 3,911 small intestinal neuroendocrine tumors: the rapid pace of no progress. Am $J$ Gastroenterol 2007;102:1464-73.

18. Modlin IM, Oberg K, Chung DC, et al. Gastroenteropancreatic neuroendocrine tumours. Lancet Oncol 2008;9:61-72.

19. Haselkorn T, Whittemore AS, Lilienfeld DE. Incidence of small bowel cancer in the United States and worldwide: geographic, temporal, and racial differences. Cancer Causes Control 2005;16:781-7.

20. Hassan MM, Phan A, Li D, et al. Risk factors associated with neuroendocrine tumors: A U.S.-based case-control study. Int J Cancer 2008:123. $867-73$

21. Taheri S, Ghatei MA, Bloom SR. Gastrointestinal hormones and tumour syndromes. In: Jameson JL, DeGroot LJ, eds. Endocrinology. Philadelphia: Saunders Elsevier, 2010:2742-73
22. Thakker R. Multiple endocrine neoplasia type 1. In: Jameson JL, DeGroot LJ, eds. Endocrinology. Philadelphia: Saunders Elsevier, 2010:2719-41.

23. Osefo N, Ito T, Jensen RT. Gastric acid hypersecretory states: recent insights and advances. Curr Gastroenterol Rep 2009:11:433-41.

24. Nesi G, Marcucci T, Rubio CA, et al. Somatostatinoma: clinico-pathological features of three cases and literature reviewed. J Gastroenterol Hepatol 2008;23:521-6.

25. Davis Z, Moertel CG, Mcllrath DC. The malignant carcinoid syndrome. Surg Gynecol Obstet 1973;137:637-44.

26. Norheim I, Oberg K, Theodorsson-Norheim E, et al. Malignant carcinoid tumors. An analysis of 103 patients with regard to tumor localization, hormone production, and survival. Ann Surg 1987;206:115-25.

27. Eriksson B, Klöppel G, Krenning E, et al. Consensus guidelines for the management of patients with digestive neuroendocrine tumors-well-differentiated jejunal-ileal tumor/carcinoma. Neuroendocrinology 2008;87:8-19.

28. Debas HT, Mulvihill SJ. Neuroendocrine gut neoplasms. Important lessons from uncommon tumors. Arch Surg 1994;129:965-71; discussion 71-2.

29. Tomassetti P, Migliori M, Simoni P, et al. Diagnostic value of plasma chromogranin A in neuroendocrine tumours. Eur $J$ Gastroenterol Hepatol 2001:13:55-8.

30. Fink G, Krelbaum T, Yellin A, et al. Pulmonary carcinoid: presentation, diagnosis, and outcome in 142 cases in Israel and review of 640 cases from the literature. Chest 2001;119:1647-51.

31. Gerstle JT, Kauffman GL Jr, Koltun WA. The incidence, management, and outcome of patients with gastrointestinal carcinoids and second primary malignancies. J Am Coll Surg 1995;180:427-32.

32. Kaltsas G, Rockall A, Papadogias D, et al. Recent advances in radiological and radionuclide imaging and therapy of neuroendocrine tumours. Eur J Endocrinol 2004;151:15-27.

33. Srirajaskanthan R, Toumpanakis C, Karpathakis A, et al. Surgical management and palliative treatment in bronchial neuroendocrine tumours: a clinical study of 45 patients. Lung Cancer 2009;65:68-73.

34. Vinik Al, Woltering EA, Warner RR, et al. NANETS consensus guidelines for the diagnosis of neuroendocrine tumor. Pancreas 2010;39:713-34.

35. Caplin ME, Buscombe JR, Hilson AJ, et al. Carcinoid tumour. Lancet 1998:352:799-805.

36. Bhattacharyya S, Toumpanakis C, Caplin ME, et al. Analysis of 150 patients with carcinoid syndrome seen in a single year at one institution in the first decade of the twenty-first century. Am J Cardiol 2008;101:378-81.

37. Lepage C, Rachet B, Coleman MP. Survival from malignant digestive endocrine tumors in England and Wales: a population-based study. Gastroenterology 2007; 132:899-904.

38. Oberg K, Eriksson B. Endocrine tumours of the pancreas. Best Pract Res Clin Gastroenterol 2005:19:753-81.

39. Madeira I, Terris B, Voss M, et al. Prognostic factors in patients with endocrine tumours of the duodenopancreatic area. Gut 1998;43:422-7.

40. Amarapurkar AD, Davies A, Ramage JK, et al. Proliferation of antigen MIB-1 in metastatic carcinoid tumours removed at liver transplantation: relevance to prognosis. Eur J Gastroenterol Hepatol 2003;15:139-43.

41. Johanson V, Tisell LE, Olbe $\mathrm{L}$, et al. Comparison of survival between malignant neuroendocrine tumours of midgut and pancreatic origin. $\mathrm{Br} \mathrm{J}$ Cancer 1999:80:1259-61.

42. Rosenau J, Bahr MJ, von Wasielewski R, et al. Ki67, E-cadherin, and p53 as prognostic indicators of long-term outcome after liver transplantation for metastatic neuroendocrine tumors. Transplantation 2002:73:386-94.

43. Granberg D, Wilander E, Oberg K, et al. Prognostic markers in patients with typical bronchial carcinoid tumors. J Clin Endocrinol Metab 2000;85:3425-30.

44. Gentil M, Tournier CL. Differences in fine control of forces generated by the tongue, lips and fingers in humans. Arch Oral Biol 1998;43:517-23.

45. Beasley MB, Thunnissen FB, Brambilla E, et al. Pulmonary atypical carcinoid: predictors of survival in 106 cases. Hum Pathol 2000:31:1255-65.

46. Pape UF, Jann H, Müller-Nordhorn J, et al. Prognostic relevance of a novel TNM classification system for upper gastroenteropancreatic neuroendocrine tumors. Cancer 2008;113:256-65.

47. Duh QY, Hybarger CP, Geist $\mathrm{R}$, et al. Carcinoids associated with multiple endocrine neoplasia syndromes. Am J Surg 1987:154:142-8.

48. Griffiths DF, Williams GT, Williams ED. Duodenal carcinoid tumours, phaeochromocytoma and neurofibromatosis: islet cell tumour, phaeochromocytoma and the von Hippel-Lindau complex: two distinctive neuroendocrine syndromes. $Q \mathrm{~J}$ Med 1987;64:769-82.

49. Hough DR, Chan A, Davidson H. Von Recklinghausen's disease associated with gastrointestinal carcinoid tumors. Cancer 1983;51:2206-8.

50. Kytola S, Nord B, Elder EE, et al. Alterations of the SDHD gene locus in midgut carcinoids, Merkel cell carcinomas, pheochromocytomas, and abdominal paragangliomas. Genes Chromosomes Cancer 2002;34:325-32.

51. Jarhult J, Landerholm K, Falkmer S, et al. First report on metastasizing small bowe carcinoids in first-degree relatives in three generations. Neuroendocrinology 2010;91:318-23.

52. Dworakowska D, Grossman AB. Are neuroendocrine tumours a feature of tuberous sclerosis? A systematic review. Endocr Relat Cancer 2009:16:45-58.

53. Ardill JE. Circulating markers for endocrine tumours of the gastroenteropancreatic tract. Ann Clin Biochem 2008:45:539-59.

54. Oberg K. Biochemical diagnosis of neuroendocrine GEP tumor. Yale J Biol Med 1997; 70:501-8. 
55. Hutton JC, Davidson HW, Peshavaria M. Proteolytic processing of chromogranin A in purified insulin granules. Formation of a $20 \mathrm{kDa} \mathrm{N}$-terminal fragment (betagranin) by the concerted action of a $\mathrm{Ca} 2+-$ dependent endopeptidase and carboxypeptidase H (EC 3.4.17.10). Biochem J 1987;244:457-64.

56. Lamberts SW, Hofland LJ, Nobels FR. Neuroendocrine tumor markers. Front Neuroendocrinol 2001:22:309-39.

57. Fahrenkamp AG, Wibbeke C, Winde G, et al. Immunohistochemical distribution of chromogranins $A$ and $B$ and secretogranin II in neuroendocrine tumours of the gastrointestinal tract. Virchows Arch 1995:426:361-7.

58. Stridsberg M, Eriksson B, Fellstrom B, et al. Measurements of chromogranin B can serve as a complement to chromogranin A. Regul Pept 2007;139:80-3.

59. Stronge RL, Turner GB, Johnston BT, et al. A rapid rise in circulating pancreastatin in response to somatostatin analogue therapy is associated with poor survival in patients with neuroendocrine tumours. Ann Clin Biochem 2008;45:560-6.

60. O'Dorisio TM, Krutzik SR, Woltering EA, et al. Development of a highly sensitive and specific carboxy-terminal human pancreastatin assay to monitor neuroendocrine tumor behavior. Pancreas 2010:39:611-16.

61. Eriksson B, Oberg K, Stridsberg M. Tumor markers in neuroendocrine tumors. Digestion 2000;62(Suppl 1):33-8.

62. Carling RS, Degg TJ, Allen KR, et al. Evaluation of whole blood serotonin and plasma and urine 5 -hydroxyindole acetic acid in diagnosis of carcinoid disease. Ann Clin Biochem 2002;39:577-82.

63. Cunningham JL, Janson ET, Agarwal S, et al. Tachykinins in endocrine tumors and the carcinoid syndrome. Eur J Endocrinol 2008;159:275-82.

64. Turner GB, Johnston BT, McCance DR, et al. Circulating markers of prognosis and response to treatment in patients with midgut carcinoid tumours. Gut 2006;55:1586-91.

65. Stridsberg M, Eriksson B, Janson ET. Measurements of secretogranins II, III, V and proconvertases $1 / 3$ and 2 in plasma from patients with neuroendocrine tumours. Regul Pept 2008;148:95-8.

66. Borch K, Renvall H, Liedberg G, et al. Relations between circulating gastrin and endocrine cell proliferation in the atrophic gastric fundic mucosa. Scand J Gastroenterol 1986;21:357-63.

67. Peracchi M, Gebbia C, Basilisco G, et al. Plasma chromogranin A in patients with autoimmune chronic atrophic gastritis, enterochromaffin-like cell lesions and gastric carcinoids. Eur J Endocrinol 2005;152:443-8.

68. O'Toole D, Grossman A, Gross D, et al. ENETS Consensus Guidelines for the Standards of Care in Neuroendocrine Tumors: biochemical markers. Neuroendocrinology 2009:90:194-202.

69. Larkin CJ, Ardill JE, Johnston CF, et al. Gastrinomas and the change in their presentation and management in Northern Ireland, UK, from 1970 to 1996. Eur J Gastroenterol Hepatol 1998:10:947-52.

70. Cryer PE, Axelrod L, Grossman AB, et al. Evaluation and management of adult hypoglycemic disorders: an Endocrine Society Clinical Practice Guideline. J Clin Endocrinol Metab 2009:94:709-28.

71. Schwartz TW, Rehfeld JF, Stadil F, et al. Pancreatic-polypeptide response to food in duodenal-ulcer patients before and after vagotomy. Lancet 1976:1:1102-5.

72. Doherty CC, Buchanan KD, Ardill J, et al. Elevations of gastrointestinal hormones in chronic renal failure. Proc Eur Dial Transplant Assoc 1978;15:456-65.

73. Hallgren R, Karlsson FA, Lundqvist G. Serum level of immunoreactive gastrin: influence of kidney function. Gut 1978;19:207-13.

74. Oberg K, Stridsberg M. Chromogranins as diagnostic and prognostic markers in neuroendocrine tumours. Adv Exp Med Biol 2000;482:329-37.

75. Ardill JE, Banerjee $S$, Beattie A, et al. Molecular forms of gastrin in the circulation of patients with achlorhydria. Eur J Gastroenterol Hepatol 1999;11:661-7.

76. Halfdanarson TR, Rubin J, Farnell MB, et al. Pancreatic endocrine neoplasms: epidemiology and prognosis of pancreatic endocrine tumors. Endocr Relat Cancer 2008:15:409-27.

77. Ilias I, Torpy DJ, Pacak K, et al. Cushing's syndrome due to ectopic corticotropin secretion: twenty years' experience at the National Institutes of Health. J Clin Endocrinol Metab 2005:90:4955-62.

78. Brandi ML, Gagel RF, Angeli A, et al. Guidelines for diagnosis and therapy of MEN type 1 and type 2. J Clin Endocrinol Metab 2001;86:5658-71.

79. Yoshida M, Tsukamoto $Y$, Niwa $Y$, et al. Endoscopic assessment of invasion of colorectal tumors with a new high-frequency ultrasound probe. Gastrointest Endosc 1995:41:587-92

80. Rosch T, Lightdale CJ, Botet JF, et al. Localization of pancreatic endocrine tumors by endoscopic ultrasonography. N Engl J Med 1992;326:1721-6.

81. Zimmer T, Ziegler K, Liehr RM, et al. Endosonography of neuroendocrine tumors of the stomach, duodenum, and pancreas. Ann N Y Acad Sci 1994;733:425-36.

82. Jeung MY, Gasser B, Gangi A, et al. Imaging of cystic masses of the mediastinum. Radiographics 2002:22:S79-93.

83. Binstock AJ, Johnson CD, Stephens DH, et al. Carcinoid tumors of the stomach: a clinical and radiographic study. AJR Am J Roentgenol 2001;176:947-51.

84. Pilleul F, Penigaud M, Milot L, et al. Possible small-bowel neoplasms: contrastenhanced and water-enhanced multidetector CT enteroclysis. Radiology 2006;241:796-801.

85. Masselli G, Polettini E, Casciani E, et al. Small-bowel neoplasms: prospective evaluation of MR enteroclysis. Radiology 2009;251:743-50.

86. Gouya H, Vignaux 0, Augui J, et al. CT, endoscopic sonography, and a combined protocol for preoperative evaluation of pancreatic insulinomas. AJR Am J Roentgenol 2003;181:987-92.
87. Ichikawa T, Peterson MS, Federle MP, et al. Islet cell tumor of the pancreas: biphasic CT versus MR imaging in tumor detection. Radiology 2000; 216:163-71.

88. Thoeni RF, Mueller-Lisse UG, Chan R, et al. Detection of small, functional islet cell tumors in the pancreas: selection of MR imaging sequences for optimal sensitivity. Radiology 2000;214:483-90.

89. de Herder WW, Kwekkeboom DJ, Valkema R, et al. Neuroendocrine tumors and somatostatin: imaging techniques. J Endocrinol Invest 2005;28:132-6.

90. Gabriel M, Decristoforo C, Kendler D, et al. 68Ga-D0TA-Tyr3-octreotide PET in neuroendocrine tumors: comparison with somatostatin receptor scintigraphy and CT. J Nucl Med 2007;48:508-18.

91. Versari A, Camellini L, Carlinfante G, et al. Ga-68 DOTATOC PET, endoscopic ultrasonography, and multidetector CT in the diagnosis of duodenopancreatic neuroendocrine tumors: a single-centre retrospective study. Clin Nucl Med 2010;35:321-8

92. Rockall AG, Planche K, Power N, et al. Detection of neuroendocrine liver metastases with MnDPDP-enhanced MRI. Neuroendocrinology 2009:89:288-95.

93. Woodard PK, Feldman JM, Paine SS, et al. Midgut carcinoid tumors: CT findings and biochemical profiles. J Comput Assist Tomogr 1995;19:400-5.

94. Sugimoto $\mathbf{E}$, Lorelius LE, Eriksson B, et al. Midgut carcinoid tumours. CT appearance. Acta Radiol 1995;36:367-71.

95. Minordi LM, Vecchioli A, Guidi L, et al. Multidetector CT enteroclysis versus barium enteroclysis with methylcellulose in patients with suspected small bowel disease. Eur Radiol 2006;16:1527-36.

96. Rondonotti E, Pennazio M, Toth E, et al. Small-bowel neoplasms in patients undergoing video capsule endoscopy: a multicenter European study. Endoscopy 2008;40:488-95.

97. Hara AK, Leighton JA, Sharma VK, et al. Imaging of small bowel disease: comparison of capsule endoscopy, standard endoscopy, barium examination, and CT. Radiographics 2005;25:697-711; discussion 711-18.

98. Owen NJ, Sohaib SA, Peppercorn PD, et al. MRI of pancreatic neuroendocrine tumours. Br J Radiol 2001;74:968-73.

99. Semelka RC, Custodio CM, Cem Balci N, et al. Neuroendocrine tumors of the pancreas: spectrum of appearances on MRI. J Magn Reson Imaging 2000;11:141-8

100. Ueno $\mathbf{N}$, Tomiyama $T$, Tano $\mathrm{S}$, et al. Utility of endoscopic ultrasonography with color Doppler function for the diagnosis of islet cell tumor. Am J Gastroenterol 1996;91:772-6.

101. Rosch T, Braig C, Gain T, et al. Staging of pancreatic and ampullary carcinoma by endoscopic ultrasonography. Comparison with conventional sonography, computed tomography, and angiography. Gastroenterology 1992;102:188-99.

102. Fein J, Gerdes H. Localization of islet cell tumors by endoscopic ultrasonography. Gastroenterology 1992;103:711-12.

103. Jani N, Dewitt J, Eloubeidi M, et al. Endoscopic ultrasound-guided fine-needle aspiration for diagnosis of solid pseudopapillary tumors of the pancreas: a multicenter experience. Endoscopy 2008;40:200-3.

104. Baker MS, Knuth JL, DeWitt J, et al. Pancreatic cystic neuroendocrine tumors: preoperative diagnosis with endoscopic ultrasound and fine-needle immunocytology. J Gastrointest Surg 2008;12:450-6.

105. Jani N, Moser AJ, Khalid A. Pancreatic endocrine tumors. Gastroenterol Clin North Am 2007;36:431-9, x-xi.

106. Chang F, Chandra A, Culora G, et al. Cytologic diagnosis of pancreatic endocrine tumors by endoscopic ultrasound-guided fine-needle aspiration: a review. Diagn Cytopathol 2006;34:649-58.

107. Grant CS. Surgical aspects of hyperinsulinemic hypoglycemia. Endocrinol Metab Clin North Am 1999:28:533-54

108. Nikfarjam M, Warshaw AL, Axelrod L, et al. Improved contemporary surgical management of insulinomas: a 25-year experience at the Massachusetts General Hospital. Ann Surg 2008;247:165-72

109. Turner JJ, Wren AM, Jackson JE, et al. Localization of gastrinomas by selective intra-arterial calcium injection. Clin Endocrinol (Oxf) 2002:57:821-5.

110. Lo CY, Chan FL, Tam SC, et al. Value of intra-arterial calcium stimulated venous sampling for regionalization of pancreatic insulinomas. Surgery 2000;128: 903-9.

111. Aoki T, Sakon M, Ohzato $\mathrm{H}$, et al. Evaluation of preoperative and intraoperative arterial stimulation and venous sampling for diagnosis and surgical resection of insulinoma. Surgery 1999;126:968-73.

112. Ricke J, Klose KJ, Mignon M, et al. Standardisation of imaging in neuroendocrine tumours: results of a European delphi process. Eur J Radiol 2001;37:8-17.

113. Krenning EP, Kwekkeboom DJ, Bakker WH, et al. Somatostatin receptor scintigraphy with [111ln-DTPA-D-Phe1]- and [123I-Tyr3]-octreotide: the Rotterdam experience with more than 1000 patients. Eur J Nucl Med 1993;20:716-31.

114. Termanini B, Gibril F, Reynolds JC, et al. Value of somatostatin receptor scintigraphy: a prospective study in gastrinoma of its effect on clinical management. Gastroenterology 1997;112:335-47.

115. Lebtahi R, Cadiot G, Sarda L, et al. Clinical impact of somatostatin receptor scintigraphy in the management of patients with neuroendocrine gastroenteropancreatic tumors. J Nucl Med 1997;38:853-8.

116. Meko JB, Doherty GM, Siegel BA, et al. Evaluation of somatostatin-receptor scintigraphy for detecting neuroendocrine tumors. Surgery 1996;120:975-83; discussion 83-4. 
117. Chiti A, Fanti S, Savelli G, et al. Comparison of somatostatin receptor imaging computed tomography and ultrasound in the clinical management of neuroendocrine gastro-entero-pancreatic tumours. Eur J Nucl Med 1998;25:1396-403.

118. Chiti A, van Graafeiland BJ, Savelli G, et al. Imaging of neuroendocrine gastroentero-pancreatic tumours using radiolabelled somatostatin analogues. Ital $\mathrm{J}$ Gastroenterol Hepatol 1999:31(Suppl 2):S190-4.

119. Chiti A, Briganti V, Fanti S, et al. Results and potential of somatostatin receptor imaging in gastroenteropancreatic tract tumours. $0 \mathrm{~J} \mathrm{Nucl} \mathrm{Med} \mathrm{2000;44:42-9.}$

120. Kaltsas G, Korbonits M, Heintz E, et al. Comparison of somatostatin analog and meta-iodobenzylguanidine radionuclides in the diagnosis and localization of advanced neuroendocrine tumors. J Clin Endocrinol Metab 2001:86:895-902.

121. Schillaci 0, Spanu A, Scopinaro F, et al. Somatostatin receptor scintigraphy in liver metastasis detection from gastroenteropancreatic neuroendocrine tumors. J Nucl Med 2003;44:359-68.

122. Frilling $\mathbf{A}$, Malago $\mathrm{M}$, Martin $\mathrm{H}$, et al. Use of somatostatin receptor scintigraphy to image extrahepatic metastases of neuroendocrine tumors. Surgery 1998;124:1000-4.

123. Modlin IM, Latich I, Kidd M, et al. Therapeutic options for gastrointestinal carcinoids. Clin Gastroenterol Hepatol 2006;4:526-47.

124. Hoefnagel CA. Metaiodobenzylguanidine and somatostatin in oncology: role in the management of neural crest tumours. Eur J Nucl Med 1994:21:561-81.

125. Kaltsas G, Mukherjee JJ, Plowman PN, et al. The role of chemotherapy in the nonsurgical management of malignant neuroendocrine tumours. Clin Endocrinol (Oxf) 2001;55:575-87.

126. Kaltsas GA, Mukherjee JJ, Grossman AB. The value of radiolabelled MIBG and octreotide in the diagnosis and management of neuroendocrine tumours. Ann Oncol 2001;12(Suppl 2):S47-50.

127. Ambrosini V, Tomassetti P, Castellucci P, et al. Comparison between 68Ga-DOTANOC and 18F-DOPA PET for the detection of gastro-entero-pancreatic and lung neuro-endocrine tumours. Eur J Nucl Med Mol Imaging 2008;35:1431-8.

128. Ambrosini V, Campana D, Bodei L, et al. 68Ga-DOTANOC PET/CT clinical impact in patients with neuroendocrine tumors. J Nucl Med 2010;51:669-73.

129. Kayani I, Bomanji JB, Groves A, et al. Functional imaging of neuroendocrine tumors with combined PET/CT using 68Ga-DOTATATE (DOTA-DPhe1, Tyr3-octreotate) and 18F-FDG. Cancer 2008;112:2447-55.

130. Koopmans KP, de Vries EG, Kema IP, et al. Staging of carcinoid tumours with 18F-DOPA PET: a prospective, diagnostic accuracy study. Lancet Oncol 2006; 7:728-34.

131. Koopmans KP, Neels OC, Kema IP, et al. Improved staging of patients with carcinoid and islet cell tumors with 18F-dihydroxy-phenyl-alanine and 11C-5hydroxy-tryptophan positron emission tomography. J Clin Oncol 2008;26:1489-95.

132. Orlefors H, Sundin A, Lu L, et al. Carbidopa pretreatment improves image interpretation and visualisation of carcinoid tumours with 11C-5-hydroxytryptophan positron emission tomography. Eur J Nucl Med Mol Imaging 2006;33:60-5.

133. Falconi M, Plockinger U, Kwekkeboom DJ, et al. Well-differentiated pancreatic nonfunctioning tumors/carcinoma. Neuroendocrinology 2006;84:196-211.

134. Modlin IM, Tang LH. Approaches to the diagnosis of gut neuroendocrine tumors: the last word (today). Gastroenterology 1997:112:583-90.

135. McCarthy SM, Stark DD, Moss AA, et al. Computed tomography of malignant carcinoid disease. J Comput Assist Tomogr 1984;8:846-50.

136. Larsson G, Sjoden PO, Oberg K et al. Importance-satisfaction discrepancies are associated with health-related quality of life in five-year survivors of endocrine gastrointestinal tumours. Ann Oncol 1999;10:1321-7

137. Barbour AP, Lagergren $P$, Hughes $R$, et al. Health-related quality of life among patients with adenocarcinoma of the gastro-oesophageal junction treated by gastrectomy or oesophagectomy. Br J Surg 2008;95:80-4.

138. Fallowfield L. Quality of quality-of-life data. Lancet 1996:348:421-2.

139. Lagergren $\mathbf{P}$, Fayers $\mathrm{P}$, Conroy $\mathrm{T}$, et al. Clinical and psychometric validation of a questionnaire module, the EORTC OLO-OG25, to assess health-related quality of life in patients with cancer of the oesophagus, the oesophago-gastric junction and the stomach. Eur J Cancer 2007; 43:2066-73.

140. Davies AH, Larsson G, Ardill J, et al. Development of a disease-specific quality of life questionnaire module for patients with gastrointestinal neuroendocrine tumours. Eur J Cancer 2006;42:477-84.

141. Aaronson NK, Ahmedzai S, Bergman B, et al. The European Organization for Research and Treatment of Cancer OLO-C30: a quality-of-life instrument for use in international clinical trials in oncology. J Natl Cancer Inst 1993;85:365-76.

142. Bosman FT, Carneiro F, Hruban RH, et al. WHO Classification of Tumours of the Digestive System. Lyon: IARC, 2010

143. Hamilton SR, Aaltonen LA. World Health Organization Classification of Tumours Pathology and Genetics of Tumours of the Digestive System. 3rd edn. Lyon: IARC, 2000.

144. Sobin LH, Gospodarowicz MK, Wittekind C, eds. TNM Classification of Malignant Tumours. Oxford: Wiley-Blackwell, 2009.

145. Rindi G, Klöppel G, Alhman H, et al. TNM staging of foregut (neuro)endocrine tumors: a consensus proposal including a grading system. Virchows Arch 2006; 449:395-401.

146. Rindi G, Klöppel G, Couvelard A, et al. TNM staging of midgut and hindgut (neuro) endocrine tumors: a consensus proposal including a grading system. Virchows Arch 2007; 451:757-62.

147. Kloppel G, Rindi G, Perren A, et al. The ENETS and AJCC/UICC TNM classifications of the neuroendocrine tumors of the gastrointestinal tract and the pancreas: a statement. Virchows Arch 2010;456:595-7.
148. Ferrone CR, Tang LH, Tomlinson J, et al. Determining prognosis in patients with pancreatic endocrine neoplasms: can the WHO classification system be simplified? J Clin Oncol 2007;25:5609-15.

149. Fischer L, Kleeff J, Esposito I, et al. Clinical outcome and long-term survival in 118 consecutive patients with neuroendocrine tumours of the pancreas. $\mathrm{Br} J$ Surg 2008:95:627-35.

150. Ekeblad S, Skogseid B, Dunder K, et al. Prognostic factors and survival in 324 patients with pancreatic endocrine tumor treated at a single institution. Clin Cancer Res 2008;14:7798-803.

151. Scarpa A, Mantovani W, Capelli P, et al. Pancreatic endocrine tumors: improved TNM staging and histopathological grading permit a clinically efficient prognostic stratification of patients. Mod Pathol 2010;23:824-33.

152. Jann H, Roll S, Couvelard A, et al. Neuroendocrine tumors of midgut and hindgut origin: Tumor-node-metastasis classification determines clinical outcome. Cancer 2011;117:3332-41.

153. The Royal College of Pathologists. Standards and Datasets for Reporting Cancers. Dataset for Endocrine Tumours of the Gastrointestinal Tract Including Pancreas. London: The Royal College of Pathologists, 2009.

154. Kloppel G, Couvelard A, Perren A, et al. ENETS Consensus Guidelines for the Standards of Care in Neuroendocrine Tumors: towards a standardized approach to the diagnosis of gastroenteropancreatic neuroendocrine tumors and their prognostic stratification. Neuroendocrinology 2009:90:162-6

155. Sutton R, Doran HE, Williams EM, et al. Surgery for midgut carcinoid. Endocr Relat Cancer 2003;10:469-81.

156. Shebani KO, Souba WW, Finkelstein DM, et al. Prognosis and survival in patients with gastrointestinal tract carcinoid tumors. Ann Surg 1999;229:815-21; discussion 22-3.

157. Grama D, Eriksson B, Martensson $\mathrm{H}$, et al. Clinical characteristics, treatment and survival in patients with pancreatic tumors causing hormonal syndromes. World $\mathrm{J}$ Surg 1992;16:632-9.

158. Roy RC, Carter RF, Wright PD. Somatostatin, anaesthesia, and the carcinoid syndrome. Peri-operative administration of a somatostatin analogue to suppress carcinoid tumour activity. Anaesthesia 1987:42:627-32.

159. Bassi C, Falconi M, Pederzoli P. Role of somatostatin and somatostatin analogues in the treatment of gastrointestinal diseases: prevention of complications after pancreatic surgery. Gut 1994;35(3 Suppl):S20-2

160. Sarmiento JM, Que FG. Hepatic surgery for metastases from neuroendocrine tumors. Surg Oncol Clin N Am 2003;12:231-42.

161. Chamberlain RS, Canes D, Brown KT, et al. Hepatic neuroendocrine metastases: does intervention alter outcomes? J Am Coll Surg 2000;190:432-45.

162. Nave H, Mossinger E, Feist $H$, et al. Surgery as primary treatment in patients with liver metastases from carcinoid tumors: a retrospective, unicentric study over 13 years. Surgery 2001;129:170-5.

163. Pederzoli P, Falconi M, Bonora A, et al. Cytoreductive surgery in advanced endocrine tumours of the pancreas. Ital J Gastroenterol Hepatol 1999;31(Suppl 2): S207-12.

164. Dougherty TB, Cronau LH Jr. Anesthetic implications for surgical patients with endocrine tumors. Int Anesthesiol Clin 1998;36:31-44.

165. Holdcroft A. Hormones and the gut. Br J Anaesth 2000;85:58-68

166. Lim E, Goldstraw P, Nicholson AG, et al. Proceedings of the IASLC International Workshop on Advances in Pulmonary Neuroendocrine Tumors 2007. J Thorac Oncol 2008;3:1194-201.

167. Sarraf KM, Belcher E, Price S, et al. Clinical application of direct bronchial ultrasound to visualize and determine endobronchial tumor margins for surgical resection. Ann Thorac Surg 2008;86:1339-41.

168. Vadasz P, Kotsis L, Egervary $\mathrm{M}$, et al. Radicality and prognosis of surgical treatment of thoracal carcinoid tumors: a review of 152 operated cases. Thorac Cardiovasc Surg 1999:47:235-9.

169. Ferguson MK, Landreneau RJ, Hazelrigg SR, et al. Long-term outcome after resection for bronchial carcinoid tumors. Eur J Cardiothorac Surg 2000:18:156-61.

170. Carretta A, Ceresoli GL, Arrigoni G, et al. Diagnostic and therapeutic management of neuroendocrine lung tumors: a clinical study of 44 cases. Lung Cancer 2000;29:217-25.

171. Cooper WA, Thourani VH, Gal AA, et al. The surgical spectrum of pulmonary neuroendocrine neoplasms. Chest 2001:119:14-18.

172. Ferolla P, Daddi N, Urbani M, et al. Tumorlets, multicentric carcinoids, lymph-nodal metastases, and long-term behavior in bronchial carcinoids. J Thorac Oncol 2009:4:383-7.

173. Rea F, Rizzardi G, Zuin A, et al. Outcome and surgical strategy in bronchial carcinoid tumors: single institution experience with 252 patients. Eur J Cardiothorac Surg 2007:31:186-91.

174. Garcia-Yuste M, Molins L, Matilla JM, et al. Trends in prognostic factors for neuroendocrine lung tumors. Arch Bronconeumol 2007:43:549-56.

175. Bini A, Brandolini J, Cassanelli N, et al. Typical and atypical pulmonary carcinoids our institutional experience. Interact Cardiovasc Thorac Surg 2008;7:415-18.

176. Aubry MC, Thomas CF Jr, Jett JR, et al. Significance of multiple carcinoid tumors and tumorlets in surgical lung specimens: analysis of 28 patients. Chest 2007:131:1635-43.

177. Lucchi M, Melfi F, Baldini $\mathrm{E}$, et al. Sentinel lymph node mapping: detection of micrometastases by polymerase chain reaction in non-small cell lung cancer J Thorac Oncol 2007;2(5 Suppl):S37. 
178. Thomas R, Christopher DJ, Balamugesh T, et al. Clinico-pathologic study of pulmonary carcinoid tumours - a retrospective analysis and review of literature. Respir Med 2008;102:1611-14.

179. Bak M, Jorgensen LJ. Adenocarcinoid of the appendix presenting with metastases to the liver. Dis Colon Rectum 1987;30:112-15.

180. Moertel CG, Weiland LH, Nagorney DM, et al. Carcinoid tumor of the appendix: treatment and prognosis. N Engl J Med 1987;317:1699-701.

181. Moertel CG, Dockerty MB, Judd ES. Carcinoid tumors of the vermiform appendix. Cancer 1968:21:270-8.

182. Tang LH, Shia J, Soslow RA, et al. Pathologic classification and clinical behavior of the spectrum of goblet cell carcinoid tumors of the appendix. Am J Surg Pathol 2008:32:1429-43.

183. Soga J. Statistical evaluation of 2001 carcinoid cases with metastases, collected from literature: a comparative study between ordinary carcinoids and atypical varieties. J Exp Clin Cancer Res 1998;17:3-12.

184. Toumpanakis C, Standish RA, Baishnab E, et al. Goblet cell carcinoid tumors (adenocarcinoid) of the appendix. Dis Colon Rectum 2007:50:315-22.

185. Plockinger U, Couvelard A, Falconi $M$, et al. Consensus guidelines for the management of patients with digestive neuroendocrine tumours: well-differentiated tumour/carcinoma of the appendix and goblet cell carcinoma. Neuroendocrinology 2008;87:20-30.

186. McGory ML, Maggard MA, Kang $\mathrm{H}$, et al. Malignancies of the appendix: beyond case series reports. Dis Colon Rectum 2005:48:2264-71.

187. Pahlavan PS, Kanthan R. Goblet cell carcinoid of the appendix. World J Surg Oncol 2005;3:36

188. Mahteme H, Sugarbaker PH. Treatment of peritoneal carcinomatosis from adenocarcinoid of appendiceal origin. Br J Surg 2004;91:1168-73.

189. Makridis C, Oberg K, Juhlin C, et al. Surgical treatment of mid-gut carcinoid tumors. World J Surg 1990;14:377-83; discussion 84-5.

190. Soreide 0, Berstad T, Bakka A, et al. Surgical treatment as a principle in patients with advanced abdominal carcinoid tumors. Surgery 1992:111:48-54.

191. Granberg D, Wilander E, Stridsberg M, et al. Clinical symptoms, hormone profiles, treatment, and prognosis in patients with gastric carcinoids. Gut 1998; 43:223-8.

192. Solcia E, Capella C, Sessa F, et al. Gastric carcinoids and related endocrine growths. Digestion 1986;35(Suppl 1):3-22.

193. Dakin GF, Warner RR, Pomp A, et al. Presentation, treatment, and outcome of type 1 gastric carcinoid tumors. J Surg Oncol 2006;93:368-72.

194. Manfredi S, Pagenault M, de Lajarte-Thirouard AS, et al. Type 1 and 2 gastric carcinoid tumors: long-term follow-up of the efficacy of treatment with a slowrelease somatostatin analogue. Eur J Gastroenterol Hepatol 2007;19:1021-5.

195. Hosokawa 0, Kaizaki Y, Hattori M, et al. Long-term follow up of patients with multiple gastric carcinoids associated with type A gastritis. Gastric Cancer 2005;8:42-6.

196. Hirschowitz BI, Griffith J, Pellegrin D, et al. Rapid regression of enterochromaffinlike cell gastric carcinoids in pernicious anemia after antrectomy Gastroenterology 1992;102:1409-18.

197. McAleese P, Moorehead J. Multiple gastric carcinoid tumours in a patient with pernicious anaemia: endoscopic removal or gastric resection? Eur J Surg 1994:160:243-6.

198. Thirlby RC. Management of patients with gastric carcinoid tumors Gastroenterology 1995;108:296-7.

199. Solcia E, Capella C, Fiocca R, et al. Gastric argyrophil carcinoidosis in patients with Zollinger-Ellison syndrome due to type 1 multiple endocrine neoplasia. A newly recognized association. Am J Surg Pathol 1990;14:503-13.

200. Rindi G, Luinetti 0, Cornaggia M, et al. Three subtypes of gastric argyrophil carcinoid and the gastric neuroendocrine carcinoma: a clinicopathologic study. Gastroenterology 1993;104:994-1006.

201. Richards ML, Gauger P, Thompson NW, et al. Regression of type II gastric carcinoids in multiple endocrine neoplasia type 1 patients with Zollinger-Ellison syndrome after surgical excision of all gastrinomas. World J Surg 2004:28:652-8.

202. Jordan PH Jr, Barroso A, Sweeney J. Gastric carcinoids in patients with hypergastrinemia. J Am Coll Surg 2004;199:552-5

203. Borch K, Ahren B, Ahlman H, et al. Gastric carcinoids: biologic behavior and prognosis after differentiated treatment in relation to type. Ann Surg 2005;242:64-73.

204. Ahmed A, Turner G, King B, et al. Midgut neuroendocrine tumours with liver metastases: results of the UKINETS study. Endocr Relat Cancer 2009;16:885-94.

205. Hellman $\mathbf{P}$, Lundstrom T, Ohrvall $U$, et al. Effect of surgery on the outcome of midgut carcinoid disease with lymph node and liver metastases. World J Surg 2002;26:991-7.

206. Bernick PE, Klimstra DS, Shia J, et al. Neuroendocrine carcinomas of the colon and rectum. Dis Colon Rectum 2004;47:163-9.

207. Bloomston M, Muscarella P, Shah $\mathbf{M H}$, et al. Cytoreduction results in high perioperative mortality and decreased survival in patients undergoing pancreatectomy for neuroendocrine tumors of the pancreas. J Gastrointest Surg 2006;10:1361-70.

208. Schurr PG, Strate T, Rese K, et al. Aggressive surgery improves long-term survival in neuroendocrine pancreatic tumors: an institutional experience. Ann Surg 2007:245:273-81.

209. Hung JS, Yang CY, Hu RH, et al. Surgical treatment of pancreatic serous cystadenoma: aggressive for operations but limited resections. Pancreas 2007;35:358-60.
210. Bahra M, Jacob D, Pascher A, et al. Surgical strategies and predictors of outcome for malignant neuroendocrine tumors of the pancreas. J Gastroenterol Hepatol 2007;22:930-5

211. Muller MW, Friess $\mathrm{H}$, Kleeff $\mathrm{J}$, et al. Is there still a role for total pancreatectomy? Ann Surg 2007;246:966-74; discussion 74-5

212. Teh SH, Deveney C. Sheppard BC. Aggressive pancreatic resection for primary pancreatic neuroendocrine tumor: is it justifiable? Am J Surg 2007;193:610-13; discussion 613 .

213. Mabrut JY, Boulez J, Peix JL, et al. Laparoscopic pancreatic resection: a preliminary experience of 15 patients. Hepatogastroenterology 2005;52:230-2.

214. Mabrut JY, Fernandez-Cruz L, Azagra JS, et al. Laparoscopic pancreatic resection results of a multicenter European study of 127 patients. Surgery 2005; 137:597-605

215. Tang CN, Tsui KK, Ha JP, et al. Laparoscopic distal pancreatectomy: a comparative study. Hepatogastroenterology 2007;54:265-71.

216. Fernandez-Cruz L, Blanco L, Cosa R, et al. Is laparoscopic resection adequate in patients with neuroendocrine pancreatic tumors? World J Surg 2008:32:904-17.

217. Kaczirek K, Ba-Ssalamah A, Schima W, et al. The importance of preoperative localisation procedures in organic hyperinsulinism-experience in 67 patients. Wien Klin Wochenschr 2004:116:373-8.

218. Clark G, Sadur C, Puligandla B. Multiple proinsulin-secreting tumors of the pancreas treated by laparoscopic distal pancreatectomy and splenectomy. World J Surg 2009;33:397-9

219. Falconi M, Bettini R, Scarpa A, et al. Surgical strategy in the treatment of gastrointestinal neuroendocrine tumours. Ann Oncol 2001;12(Suppl 2):S101-3.

220. Norton JA, Fang TD, Jensen RT. Surgery for gastrinoma and insulinoma in multiple endocrine neoplasia type 1. J Natl Compr Canc Netw 2006;4:148-53.

221. Hill JS, McPhee JT, McDade TP, et al. Pancreatic neuroendocrine tumors: the impact of surgical resection on survival. Cancer 2009;115:741-51.

222. Kianmanesh R, O'Toole D, Sauvanet A, et al. Surgical treatment of gastric, enteric and pancreatic endocrine tumors Part 1. Treatment of primary endocrine tumors. J Chir (Paris) 2005;142:132-49.

223. Roeyen G, Chapelle T, Borbath I, et al. The role of surgery and transplantation in neuroendocrine tumours. Acta Gastroenterol Belg 2009:72:39-43.

224. Mayo SC, de Jong MC, Pulitano C, et al. Surgical management of hepatic neuroendocrine tumor metastasis: results from an international multi-institutional analysis. Ann Surg Oncol 2010;17:3129-36.

225. Capurso G, Bettini R, Rinzivillo $M$, et al. Role of resection of the primary pancreatic neuroendocrine tumour only in patients with unresectable metastatic liver disease: a systematic review. Neuroendocrinology 2011;93:223-9.

226. Safioleas MC, Moulakakis KG, Kontzoglou K, et al. Carcinoid tumors of the appendix. Prognostic factors and evaluation of indications for right hemicolectomy. Hepatogastroenterology 2005;52:123-7.

227. Fornaro R, Frascio M, Sticchi C, et al. Appendectomy or right hemicolectomy in the treatment of appendiceal carcinoid tumors? Tumori 2007:93:587-90.

228. O'Donnell ME, Carson J, Garstin WI. Surgical treatment of malignant carcinoid tumours of the appendix. Int J Clin Pract 2007;61:431-7.

229. Varisco B, McAlvin B, Dias J, et al. Adenocarcinoid of the appendix: is right hemicolectomy necessary? A meta-analysis of retrospective chart reviews. Am Surg 2004:70:593-9.

230. Bucher P, Gervaz P, Ris F, et al. Surgical treatment of appendiceal adenocarcinoid (goblet cell carcinoid). World J Surg 2005;29:1436-9

231. Chen H, Hardacre JM, Uzar A, et al. Isolated liver metastases from neuroendocrine tumors: does resection prolong survival? J Am Coll Surg 1998;187:88-92; discussion 92-3.

232. Que FG, Nagorney DM, Batts KP, et al. Hepatic resection for metastatic neuroendocrine carcinomas. Am J Surg 1995;169:36-42; discussion 42-3.

233. Touzios JG, Kiely JM, Pitt SC, et al. Neuroendocrine hepatic metastases: does aggressive management improve survival? Ann Surg 2005;241:776-83; discussion 783-5.

234. Gomez D, Malik HZ, Al-Mukthar A et al. Hepatic resection for metastatic gastrointestinal and pancreatic neuroendocrine tumours: outcome and prognostic predictors. HPB (Oxford) 2007:9:345-51.

235. Chambers AJ, Pasieka JL, Dixon E, et al. The palliative benefit of aggressive surgical intervention for both hepatic and mesenteric metastases from neuroendocrine tumors. Surgery 2008:144:645-51; discussion 651-3.

236. Eriksson J, Stalberg P, Nilsson A, et al. Surgery and radiofrequency ablation for treatment of liver metastases from midgut and foregut carcinoids and endocrine pancreatic tumors. World J Surg 2008;32:930-8.

237. Grazi GL, Cescon M, Pierangeli F, et al. Highly aggressive policy of hepatic resections for neuroendocrine liver metastases. Hepatogastroenterology 2000;47:481-6

238. Elias D, Lasser $\mathrm{P}$, Ducreux $\mathrm{M}$, et al. Liver resection (and associated extrahepatic resections) for metastatic well-differentiated endocrine tumors: a 15-year single center prospective study. Surgery 2003;133:375-82.

239. Ruckert RI, Ruckert JC, Dorffel Y, et al. Primary hepatic neuroendocrine tumor: successful hepatectomy in two cases and review of the literature. Digestion 1999;60:110-16.

240. Iwao M, Nakamuta M, Enjoji M, et al. Primary hepatic carcinoid tumor: case repor and review of 53 cases. Med Sci Monit 2001:7:746-50.

241. Schweizer RT, Alsina AE, Rosson R, et al. Liver transplantation for metastatic neuroendocrine tumors. Transplant Proc 1993;25:1973. 
242. Frilling $\mathbf{A}$, Rogiers $\mathbf{X}$, Knofel WT, et al. Liver transplantation for metastatic carcinoid tumors. Digestion 1994;55(Suppl 3):104-6.

243. Routley D, Ramage JK, McPeake J, et al. Orthotopic liver transplantation in the treatment of metastatic neuroendocrine tumors of the liver. Liver Transp/ Surg 1995; 1:118-21.

244. Lang $\mathbf{H}$, Oldhafer KJ, Weimann A, et al. Liver transplantation for metastatic neuroendocrine tumors. Ann Surg 1997;225:347-54.

245. Frilling A, Malago $\mathbf{M}$, Weber $\mathrm{F}$, et al. Liver transplantation for patients with metastatic endocrine tumors: single-center experience with 15 patients. Liver Transp/ 2006;12:1089-96.

246. Nakajima Y, Takagi H, Sohara N, et al. Living-related liver transplantation for multiple liver metastases from rectal carcinoid tumor: a case report. World J Gastroenterol 2006;12:1805-9.

247. van Vilsteren FG, Baskin-Bey ES, Nagorney DM, et al. Liver transplantation for gastroenteropancreatic neuroendocrine cancers: Defining selection criteria to improve survival. Liver Transp/ 2006;12:448-56.

248. Dousset B, Houssin D, Soubrane 0, et al. Metastatic endocrine tumors: is there a place for liver transplantation? Liver Transp/ Surg 1995;1:111-17.

249. Jamil A, Taylor-Robinson S, Millson C, et al. Orthotopic liver transplantation for the treatment of metastatic neuroendocrine tumours - analysis of all UK patients. Gut 2002; $50: e 1-27$.

250. Le Treut YP, Delpero JR, Dousset B, et al. Results of liver transplantation in the treatment of metastatic neuroendocrine tumors. A 31-case French multicentric report. Ann Surg 1997;225:355-64.

251. Le Treut YP, Gregoire E, Belghiti J, et al. Predictors of long-term survival after liver transplantation for metastatic endocrine tumors: an 85-case French multicentric report. Am J Transplant 2008;8:1205-13.

252. Gregoire E, Le Treut YP. Liver transplantation for primary or secondary endocrine tumors. Transpl Int 2010;23:704-11.

253. Kulaksiz H, Eissele R, Rossler D, et al. Identification of somatostatin receptor subtypes $1,2 \mathrm{~A}, 3$, and 5 in neuroendocrine tumours with subtype specific antibodies. Gut 2002;50:52-60.

254. Shah T, Caplin M. Endocrine tumours of the gastrointestinal tract. Biotherapy for metastatic endocrine tumours. Best Pract Res Clin Gastroenterol 2005; 19:617-36.

255. Ruszniewski $\mathbf{P}$, Ducreux M, Chayvialle JA, et al. Treatment of the carcinoid syndrome with the longacting somatostatin analogue lanreotide: a prospective study in 39 patients. Gut 1996;39:279-83.

256. Garland J, Buscombe JR, Bouvier C, et al. Sandostatin LAR llong-acting octreotide acetate) for malignant carcinoid syndrome: a 3-year experience. Aliment Pharmacol Ther 2003;17:437-44

257. Toumpanakis C, Garland J, Marelli L, et al. Long-term results of patients with malignant carcinoid syndrome receiving octreotide LAR. Aliment Pharmacol Ther 2009:30:733-40.

258. Tomassetti P, Migliori M, Corinaldesi R, et al. Treatment of gastroenteropancreatic neuroendocrine tumours with octreotide LAR. Aliment Pharmacol Ther 2000; 14:557-60

259. Oberg K, Kvols L, Caplin M, et al. Consensus report on the use of somatostatin analogs for the management of neuroendocrine tumors of the gastroenteropancreatic system. Ann Oncol 2004:15:966-73.

260. Kwekkeboom DJ, Krenning EP, Lebtahi R, et al. ENETS Consensus Guidelines for the Standards of Care in Neuroendocrine Tumors: peptide receptor radionuclide therapy with radiolabeled somatostatin analogs. Neuroendocrinology 2009;90:220-6.

261. Tomassetti P, Migliori M, Gullo L. Slow-release lanreotide treatment in endocrine gastrointestinal tumors. Am J Gastroenterol 1998;93:1468-71.

262. O'Toole D, Ducreux M, Bommelaer G, et al. Treatment of carcinoid syndrome: a prospective crossover evaluation of lanreotide versus octreotide in terms of efficacy, patient acceptability, and tolerance. Cancer 2000;88:770-6.

263. Norlen 0, Hessman 0, Stalberg P, et al. Prophylactic cholecystectomy in midgut carcinoid patients. World J Surg 2010;34:1361-7.

264. Stinton LM, Myers RP, Shaffer EA. Epidemiology of gallstones. Gastroenterol Clin North Am 2010;39:157-69, vii.

265. Trendle MC, Moertel CG, Kvols LK. Incidence and morbidity of cholelithiasis in patients receiving chronic octreotide for metastatic carcinoid and malignant islet cell tumors. Cancer 1997;79:830-4.

266. Plockinger U, Wiedenmann B. Neuroendocrine tumors. Biotherapy. Best Pract Res Clin Endocrinol Metab 2007;21:145-62.

267. Rubin J, Ajani J, Schirmer W, et al. Octreotide acetate long-acting formulation versus open-label subcutaneous octreotide acetate in malignant carcinoid syndrome. J Clin Oncol 1999;17:600-6.

268. Soga J, Yakuwa Y. Vipoma/diarrheogenic syndrome: a statistical evaluation of 241 reported cases. J Exp Clin Cancer Res 1998;17:389-400.

269. Nikou GC, Toubanakis C, Nikolaou P, et al. VIPomas: an update in diagnosis and management in a series of 11 patients. Hepatogastroenterology 2005;52:1259-65.

270. Frankton S, Bloom SR. Gastrointestinal endocrine tumours. Glucagonomas. Baillieres Clin Gastroenterol 1996:10:697-705.

271. Stehouwer CD, Lems WF, Fischer HR, et al. Aggravation of hypoglycemia in insulinoma patients by the long-acting somatostatin analogue octreotide (Sandostatin). Acta Endocrinol (Copenh) 1989:121:34-40.

272. Lamberts SW, van der Lely AJ, de Herder WW, et al. Octreotide. N Engl J Med 1996; 334:246-54.
273. Gill GV, Rauf O, MacFarlane IA. Diazoxide treatment for insulinoma: a national UK survey. Postgrad Med J 1997; 73:640-1.

274. Srirajaskanthan R, McStay M, Toumpanakis C, et al. Parathyroid hormone-related peptide-secreting pancreatic neuroendocrine tumours: case series and literature review. Neuroendocrinology 2009;89:48-55.

275. Lamberts SW, de Herder WW, Krenning EP, et al. A role of (labeled) somatostatin analogs in the differential diagnosis and treatment of Cushing's syndrome. J Clin Endocrinol Metab 1994;78:17-19.

276. von Werder K, Losa M, Muller OA, et al. Treatment of metastasising GRFproducing tumour with a long-acting somatostatin analogue. Lancet 1984;2:282-3.

277. Faiss S, Rath U, Mansmann U, et al. Ultra-high-dose lanreotide treatment in patients with metastatic neuroendocrine gastroenteropancreatic tumors. Digestion 1999;60:469-76.

278. Imam H, Eriksson B, Lukinius A, et al. Induction of apoptosis in neuroendocrine tumors of the digestive system during treatment with somatostatin analogs. Acta Oncol 1997;36:607-14.

279. Jacobsen MB, Hanssen LE. Clinical effects of octreotide compared to placebo in patients with gastrointestinal neuroendocrine tumours. Report on a double-blind, randomized trial. J Intern Med 1995;237:269-75.

280. Arnold R, Trautmann ME, Creutzfeldt W, et al. Somatostatin analogue octreotide and inhibition of tumour growth in metastatic endocrine gastroenteropancreatic tumours. Gut 1996;38:430-8.

281. Aparicio T, Ducreux M, Baudin E, et al. Antitumour activity of somatostatin analogues in progressive metastatic neuroendocrine tumours. Eur $\mathrm{J}$ Cancer 2001; 37:1014-19.

282. Welin SV, Janson ET, Sundin A, et al. High-dose treatment with a long-acting somatostatin analogue in patients with advanced midgut carcinoid tumours. Eur $J$ Endocrinol 2004:151:107-12.

283. Panzuto F, Di Fonzo M, lannicelli E, et al. Long-term clinical outcome of somatostatin analogues for treatment of progressive, metastatic, well-differentiated entero-pancreatic endocrine carcinoma. Ann Oncol 2006:17:461-6.

284. Shojamanesh H, Gibril F, Louie A, et al. Prospective study of the antitumor efficacy of long-term octreotide treatment in patients with progressive metastatic gastrinoma. Cancer 2002:94:331-43.

285. Rinke A, Muller HH, Schade-Brittinger C, et al. Placebo-controlled, double-blind, prospective, randomized study on the effect of octreotide LAR in the control of tumor growth in patients with metastatic neuroendocrine midgut tumors: a report from the PROMID Study Group. J Clin Oncol 2009;27:4656-63.

286. Kulke MH, Bergsland EK, Yao JC. Glycemic control in patients with insulinoma treated with everolimus. N Engl J Med 2009;360:195-7.

287. Bourcier ME, Sherrod A, DiGuardo M, et al. Successful control of intractable hypoglycemia using rapamycin in an 86-year-old man with a pancreatic insulinsecreting islet cell tumor and metastases. J Clin Endocrinol Metab 2009;94:3157-62.

288. Grozinsky-Glasberg S, Shimon I, Korbonits $\mathrm{M}$, et al. Somatostatin analogues in the control of neuroendocrine tumours: efficacy and mechanisms. Endocr Relat Cancer 2008;15:701-20.

289. Woodward EJ, Coleman RE. Prevention and treatment of bone metastases. Curr Pharm Des 2010;16:2998-3006.

290. von Marschall Z, Scholz A, Cramer T, et al. Effects of interferon alpha on vascular endothelial growth factor gene transcription and tumor angiogenesis. J Natl Cancer Inst 2003;95:437-48.

291. Frank M, Klose KJ, Wied M, et al. Combination therapy with octreotide and alphainterferon: effect on tumor growth in metastatic endocrine gastroenteropancreatic tumors. Am J Gastroenterol 1999;94:1381-7.

292. Oberg K, Funa K, Alm G. Effects of leukocyte interferon on clinical symptoms and hormone levels in patients with mid-gut carcinoid tumors and carcinoid syndrome. N Engl J Med 1983;309:129-33.

293. Oberg K, Norheim I, Alm G. Treatment of malignant carcinoid tumors: a randomized controlled study of streptozocin plus 5-FU and human leukocyte interferon. Eur $\mathrm{J}$ Cancer Clin Oncol 1989:25:1475-9.

294. Tiensuu Janson EM, Ahlström H, Andersson T, et al. Octreotide and interferon alfa: a new combination for the treatment of malignant carcinoid tumours. Eur $\mathrm{J}$ Cancer 1992;28A:1647-50.

295. Kolby L, Persson G, Franzen S, et al. Randomized clinical trial of the effect of interferon alpha on survival in patients with disseminated midgut carcinoid tumours. Br J Surg 2003;90:687-93.

296. Faiss S, Pape UF, Bohmig M, et al. Prospective, randomized, multicenter trial on the antiproliferative effect of lanreotide, interferon alfa, and their combination for therapy of metastatic neuroendocrine gastroenteropancreatic tumors-the International Lanreotide and Interferon Alfa Study Group. J Clin Oncol 2003:21:2689-96

297. Arnold R, Rinke A, Klose KJ, et al. Octreotide versus octreotide plus interferonalpha in endocrine gastroenteropancreatic tumors: a randomized trial. Clin Gastroenterol Hepatol 2005:3:761-71.

298. Pavel ME, Baum U, Hahn EG, et al. Efficacy and tolerability of pegylated IFN-alpha in patients with neuroendocrine gastroenteropancreatic carcinomas. J Interferon Cytokine Res 2006;26:8-13.

299. Yao JC, Phan A, Hoff PM, et al. Targeting vascular endothelial growth factor in advanced carcinoid tumor: a random assignment phase II study of depot octreotide with bevacizumab and pegylated interferon alpha-2b. J Clin Oncol 2008;26:1316-23. 
300. Sun W, Lipsitz S, Catalano P, et al. Phase II/III study of doxorubicin with fluorouracil compared with streptozocin with fluorouracil or dacarbazine in the treatment of advanced carcinoid tumors: Eastern Cooperative Oncology Group Study E1281. J Clin Oncol 2005:23:4897-904

301. Engstrom PF, Lavin PT, Moertel CG, et al. Streptozocin plus fluorouracil versus doxorubicin therapy for metastatic carcinoid tumor. J Clin Oncol 1984:2:1255-9.

302. Toumpanakis C, Meyer T, Caplin ME. Cytotoxic treatment including embolization/ chemoembolization for neuroendocrine tumours. Best Pract Res Clin Endocrinol Metab 2007;21:131-44.

303. Basu B, Sirohi B, Corrie P. Systemic therapy for neuroendocrine tumours of gastroenteropancreatic origin. Endocr Relat Cancer 2010;17:R75-90. Print 2010 Mar

304. Moertel CG, Hanley JA, Johnson LA. Streptozocin alone compared with streptozocin plus fluorouracil in the treatment of advanced islet-cell carcinoma. N Engl J Med 1980;303:1189-94.

305. Moertel CG, Lefkopoulo M, Lipsitz S, et al. Streptozocin-doxorubicin, streptozocinfluorouracil or chlorozotocin in the treatment of advanced islet-cell carcinoma. N Engl J Med 1992;326:519-23.

306. Delaunoit T, Ducreux M, Boige V, et al. The doxorubicin-streptozotocin combination for the treatment of advanced well-differentiated pancreatic endocrine carcinoma; a judicious option? Eur J Cancer 2004;40:515-20

307. Kouvaraki MA, Ajani JA, Hoff P, et al. Fluorouracil, doxorubicin, and streptozocin in the treatment of patients with locally advanced and metastatic pancreatic endocrine carcinomas. J Clin Oncol 2004;22:4762-71.

308. Turner NC, Strauss SJ, Sarker D, et al. Chemotherapy with 5-fluorouracil, cisplatin and streptozocin for neuroendocrine tumours. Br J Cancer 2010;102:1106-12

309. Strosberg JR, Fine RL, Choi J, et al. First-line chemotherapy with capecitabine and temozolomide in patients with metastatic pancreatic endocrine carcinomas. Cancer 2011;117:268-75.

310. Kulke MH, Stuart K, Enzinger PC, et al. Phase II study of temozolomide and thalidomide in patients with metastatic neuroendocrine tumors. J Clin Oncol 2006;24:401-6.

311. Ekeblad S, Sundin A, Janson ET, et al. Temozolomide as monotherapy is effective in treatment of advanced malignant neuroendocrine tumors. Clin Cancer Res 2007:13:2986-91.

312. Kulke MH, Hornick JL, Frauenhoffer C, et al. 06-methylguanine DNA methyltransferase deficiency and response to temozolomide-based therapy in patients with neuroendocrine tumors. Clin Cancer Res 2009:15:338-45.

313. Ansell SM, Pitot HC, Burch PA, et al. A phase II study of high-dose paclitaxel in patients with advanced neuroendocrine tumors. Cancer 2001;91:1543-8.

314. Kulke MH, Kim H, Clark JW, et al. A phase II trial of gemcitabine for metastatic neuroendocrine tumors. Cancer 2004;101:934-9.

315. Chan JA, Zhu AX, Stuart K, et al. Phase II study of pemetrexed in patients with advanced neuroendocrine tumors. Cancer Chemother Pharmacol 2010:66:961-8.

316. Ansell SM, Mahoney MR, Green EM, et al. Topotecan in patients with advanced neuroendocrine tumors: a phase II study with significant hematologic toxicity. Am J Clin Oncol 2004:27:232-5.

317. Moertel CG, Kvols LK, O'Connell MJ, et al. Treatment of neuroendocrine carcinomas with combined etoposide and cisplatin. Evidence of major therapeutic activity in the anaplastic variants of these neoplasms. Cancer 1991;68:227-32.

318. Fjallskog ML, Granberg DP, Welin SL, et al. Treatment with cisplatin and etoposide in patients with neuroendocrine tumors. Cancer 2001:92:1101-7.

319. Mitry E, Baudin E, Ducreux M, et al. Treatment of poorly differentiated neuroendocrine tumours with etoposide and cisplatin. $\mathrm{Br} J$ Cancer 1999:81:1351-5

320. Hainsworth JD, Spigel DR, Litchy S, et al. Phase II trial of paclitaxel, carboplatin, and etoposide in advanced poorly differentiated neuroendocrine carcinoma: a Minnie Pearl Cancer Research Network Study. J Clin Oncol 2006;24:3548-54.

321. Gurusamy KS, Ramamoorthy R, Sharma D, et al. Liver resection versus other treatments for neuroendocrine tumours in patients with resectable liver metastases. Cochrane Database Syst Rev 2009;(2):CD007060.

322. Wessels FJ, Schell SR. Radiofrequency ablation treatment of refractory carcinoid hepatic metastases. J Surg Res 2001;95:8-12.

323. Siperstein AE, Rogers SJ, Hansen PD, et al. Laparoscopic thermal ablation of hepatic neuroendocrine tumor metastases. Surgery 1997;122:1147-54; discussion 1154-5.

324. Berber $\mathbf{E}$, Siperstein A. Local recurrence after laparoscopic radiofrequency ablation of liver tumors: an analysis of 1032 tumors. Ann Surg Oncol 2008:15:2757-64.

325. Frilling A, Li J, Malamutmann E, et al. Treatment of liver metastases from neuroendocrine tumours in relation to the extent of hepatic disease. $\mathrm{Br} J$ Surg 2009:96:175-84.

326. Gillams AR. Radiofrequency ablation in the management of liver tumours. Eur $J$ Surg Oncol 2003;29:9-16.

327. Siperstein A, Garland A, Engle K, et al. Local recurrence after laparoscopic radiofrequency thermal ablation of hepatic tumors. Ann Surg Oncol 2000; 7:106-13.

328. Siperstein A, Garland A, Engle K, et al. Laparoscopic radiofrequency ablation of primary and metastatic liver tumors. Technical considerations. Surg Endosc 2000; 14:400-5

329. Siperstein $\mathbf{A E}$, Berber E. Cryoablation, percutaneous alcohol injection, and radiofrequency ablation for treatment of neuroendocrine liver metastases. World $\mathrm{J}$ Surg 2001;25:693-6.
330. Hellman P, Ladjevardi S, Skogseid B, et al. Radiofrequency tissue ablation using cooled tip for liver metastases of endocrine tumors. World J Surg 2002:26:1052-6.

331. Tait IS, Yong SM, Cuschieri SA. Laparoscopic in situ ablation of liver cancer with cryotherapy and radiofrequency ablation. Br J Surg 2002;89:1613-19.

332. Mazzaglia PJ, Berber E, Milas $\mathrm{M}$, et al. Laparoscopic radiofrequency ablation of neuroendocrine liver metastases: a 10-year experience evaluating predictors of survival. Surgery 2007;142:10-19.

333. Hanson MW, Feldman JM, Blinder RA, et al. Carcinoid tumors: iodine-131 MIBG scintigraphy. Radiology 1989;172:699-703.

334. Mukherjee JJ, Kaltsas GA, Islam N, et al. Treatment of metastatic carcinoid tumours, phaeochromocytoma, paraganglioma and medullary carcinoma of the thyroid with (131)I-meta-iodobenzylguanidine [(131)I-mIBG]. Clin Endocrinol (Oxf) 2001;55:47-60.

335. Safford SD, Coleman RE, Gockerman JP, et al. Iodine-131 metaiodobenzylguanidine treatment for metastatic carcinoid. Results in 98 patients. Cancer 2004;101:1987-93.

336. Pathirana AA, Vinjamuri S, Byrne C, et al. (131)I-MIBG radionuclide therapy is safe and cost-effective in the control of symptoms of the carcinoid syndrome. Eur J Surg Oncol 2001;27:404-8.

337. Bushnell DL Jr, O'Dorisio TM, O'Dorisio MS, et al. 90Y-edotreotide for metastatic carcinoid refractory to octreotide. J Clin Oncol 2010;28:1652-9.

338. Perez EA, Koniaris LG, Snell SE, et al. 7201 carcinoids: increasing incidence overall and disproportionate mortality in the elderly. World I Surg 2007:31:1022-30.

339. Van Essen M, Krenning EP, De Jong M, et al. Peptide Receptor Radionuclide Therapy with radiolabelled somatostatin analogues in patients with somatostatin receptor positive tumours. Acta Oncol 2007:46:723-34.

340. Valkema R, Pauwels SA, Kvols LK, et al. Long-term follow-up of renal function after peptide receptor radiation therapy with (90)Y-DOTA(0), Tyr(3)-octreotide and (177) Lu-DOTA(0). Tyr(3)-octreotate. J Nucl Med 2005:46(Suppl 1):83S-91S.

341. Cwikla JB, Sankowski A, Seklecka N, et al. Efficacy of radionuclide treatment DOTATATE Y-90 in patients with progressive metastatic gastroenteropancreatic neuroendocrine carcinomas (GEP-NETs): a phase II study. Ann Oncol 2010;21:787-94.

342. Kwekkeboom DJ, Teunissen JJ, Bakker WH, et al. Radiolabeled somatostatin analog [177Lu-DOTA0, Tyr3]octreotate in patients with endocrine gastroenteropancreatic tumors. J Clin Oncol 2005;23:2754-62.

343. Nayak TK, Atcher RW, Prossnitz ER, et al. Enhancement of somatostatin-receptortargeted (177)Lu-[DOTA(0)-Tyr(3)]-octreotide therapy by gemcitabine pretreatmentmediated receptor uptake, up-regulation and cell cycle modulation. Nucl Med Biol 2008:35:673-8.

344. Miederer M, Henriksen G, Alke A, et al. Preclinical evaluation of the alpha-particle generator nuclide 225Ac for somatostatin receptor radiotherapy of neuroendocrine tumors. Clin Cancer Res 2008:14:3555-61.

345. Carrasco $\mathbf{C H}$, Chuang VP, Wallace S. Apudomas metastatic to the liver: treatment by hepatic artery embolization. Radiology 1983;149:79-83.

346. Drougas JG, Anthony LB, Blair TK, et al. Hepatic artery chemoembolization for management of patients with advanced metastatic carcinoid tumors. Am J Surg 1998:175:408-12.

347. Eriksson BK, Larsson EG, Skogseid BM, et al. Liver embolizations of patients with malignant neuroendocrine gastrointestinal tumors. Cancer 1998;83:2293-301.

348. Ajani JA, Carrasco $\mathrm{CH}$, Charnsangavej $\mathrm{C}$, et al. Islet cell tumors metastatic to the liver: effective palliation by sequential hepatic artery embolization. Ann Intern Med 1988:108:340-4.

349. Kim YH, Ajani JA, Carrasco CH, et al. Selective hepatic arterial chemoembolization for liver metastases in patients with carcinoid tumor or islet cell carcinoma. Cancer Invest 1999:17:474-8.

350. Ruszniewski P, Rougier P, Roche A, et al. Hepatic arterial chemoembolization in patients with liver metastases of endocrine tumors. A prospective phase II study in 24 patients. Cancer 1993: 11:2624-30

351. Hajarizadeh $\mathbf{H}$, Ivancev $\mathrm{K}$, Mueller $\mathrm{CR}$, et al. Effective palliative treatment of metastatic carcinoid tumors with intra-arterial chemotherapy/chemoembolization combined with octreotide acetate. Am J Surg 1992:163:479-83.

352. Sward C, Johanson V, Nieveen van Dijkum E, et al. Prolonged survival after hepatic artery embolization in patients with midgut carcinoid syndrome. Br J Surg 2009:96:517-21.

353. Christante D, Pommier S, Givi B, et al. Hepatic artery chemoinfusion with chemoembolization for neuroendocrine cancer with progressive hepatic metastases despite octreotide therapy. Surgery 2008;144:885-93; discussion 893-4.

354. Ho AS, Picus J, Darcy MD, et al. Long-term outcome after chemoembolization and embolization of hepatic metastatic lesions from neuroendocrine tumors. AJR Am J Roentgenol 2007;188:1201-7.

355. Ruutiainen AT, Soulen MC, Tuite CM, et al. Chemoembolization and bland embolization of neuroendocrine tumor metastases to the liver. J Vasc Interv Radiol 2007:18:847-55.

356. Osborne DA, Zervos EE, Strosberg J, et al. Improved outcome with cytoreduction versus embolization for symptomatic hepatic metastases of carcinoid and neuroendocrine tumors. Ann Surg Oncol 2006;13:572-81.

357. Strosberg JR, Choi J, Cantor AB, et al. Selective hepatic artery embolization for treatment of patients with metastatic carcinoid and pancreatic endocrine tumors. Cancer Control 2006;13:72-8. 
358. Gupta S, Johnson MM, Murthy $\mathrm{R}$, et al. Hepatic arterial embolization and chemoembolization for the treatment of patients with metastatic neuroendocrine tumors: variables affecting response rates and survival. Cancer 2005:104:1590-602.

359. Simon N, Warner RR, Baron MG, et al. Intra-arterial irradiation of carcinoid tumors of the liver. Am J Roentgenol Radium Ther Nucl Med 1968;102:552-61.

360. King J, Quinn R, Glenn DM, et al. Radioembolization with selective internal radiation microspheres for neuroendocrine liver metastases. Cancer 2008;113:921-9.

361. Kennedy AS, Dezarn WA, McNeillie P, et al. Radioembolization for unresectable neuroendocrine hepatic metastases using resin 90Y-microspheres: early results in 148 patients. Am J Clin Oncol 2008;31:271-9.

362. Murthy R, Kamat $\mathrm{P}$, Nunez $\mathrm{R}$, et al. Yttrium-90 microsphere radioembolotherapy of hepatic metastatic neuroendocrine carcinomas after hepatic arterial embolization. $J$ Vasc Interv Radiol 2008;19:145-51.

363. Chakravarthy A, Abrams RA. Radiation therapy in the management of patients with malignant carcinoid tumors. Cancer 1995;75:1386-90.

364. Raymond E, Dahan L, Raoul JL, et al. Sunitinib malate for the treatment of pancreatic neuroendocrine tumors. N Engl J Med 2011;364:501-13.

365. Yao JC, Shah MH, Ito T, et al. Everolimus for advanced pancreatic neuroendocrine tumors. N Engl J Med 2011:364:514-23.

366. Kulke MH, Lenz HJ, Meropol NJ, et al. Activity of sunitinib in patients with advanced neuroendocrine tumors. J Clin Oncol 2008;26:3403-10.

367. Yao JC, Lombard-Bohas C, Baudin E, et al. Daily oral everolimus activity in patients with metastatic pancreatic neuroendocrine tumors after failure of cytotoxic chemotherapy: a phase II trial. J Clin Oncol 2010;28:69-76.

368. Pellikka PA, Tajik AJ, Khandheria BK, et al. Carcinoid heart disease. Clinical and echocardiographic spectrum in 74 patients. Circulation 1993;87:1188-96.

369. Lundin L, Norheim I, Landelius J, et al. Carcinoid heart disease: relationship of circulating vasoactive substances to ultrasound-detectable cardiac abnormalities. Circulation 1988;77:264-9.

370. Connolly HM, Schaff HV, Mullany CJ, et al. Surgical management of left-sided carcinoid heart disease. Circulation 2001;104:136-40.

371. Greminger $\mathbf{P}$, Hess OM, Muller AE, et al. Bronchial neuroendocrine (carcinoid) tumor causing unilateral left-sided carcinoid heart disease. Klin Wochenschr 1991;69:128-33.

372. Cha SD, Gooch AS, Maranhao V. Intracardiac phonocardiography in tricuspid regurgitation: relation to clinical and angiographic findings. Am J Cardiol 1981; 48:578-83

373. Mukoyama M, Nakao K, Hosoda K, et al. Brain natriuretic peptide as a nove cardiac hormone in humans. Evidence for an exquisite dual natriuretic peptide system, atrial natriuretic peptide and brain natriuretic peptide. J Clin Invest 1991;87:1402-12.

374. Bhattacharyya S, Toumpanakis C, Caplin ME, et al. Usefulness of N-terminal probrain natriuretic peptide as a biomarker of the presence of carcinoid heart disease. Am J Cardiol 2008;102:938-42.

375. Korse CM, Taal BG, de Groot CA, et al. Chromogranin-A and N-terminal pro-brain natriuretic peptide: an excellent pair of biomarkers for diagnostics in patients with neuroendocrine tumor. J Clin Oncol 2009;27:4293-9.

376. Thorson A, Biorck G, Bjorkman G, et al. Malignant carcinoid of the small intestine with metastases to the liver, valvular disease of the right side of the heart (pulmonary stenosis and tricuspid regurgitation without septal defects), peripheral vasomotor symptoms, bronchoconstriction, and an unusual type of cyanosis; a clinical and pathologic syndrome. Am Heart J 1954;47:795-817.

377. Connolly HM, Crary JL, McGoon MD, et al. Valvular heart disease associated with fenfluramine-phentermine. N Engl J Med 1997;337:581-8.

378. Howard RJ, Drobac M, Rider WD, et al. Carcinoid heart disease: diagnosis by twodimensional echocardiography. Circulation 1982;66:1059-65

379. Zanettini R, Antonini A, Gatto G, et al. Regression of Cardiac Valvulopathy Related to Ergot-Derived Dopamine Agonists. Cardiovasc Ther. Published Online First: 11 June 2010. doi:10.1111/j.1755-5922.2010.00169.x.

380. Zanettini R, Antonini A, Gatto G, et al. Valvular heart disease and the use of dopamine agonists for Parkinson's disease. N Engl J Med 2007:356:39-46.

381. Ho SY, Nihoyannopoulos P. Anatomy, echocardiography, and normal right ventricular dimensions. Heart 2006;92(Suppl 1):i2-13.

382. Bhattacharyya S, Burke M, Caplin ME, et al. Utility of 3D transoesophageal echocardiography for the assessment of tricuspid and pulmonary valves in carcinoid heart disease. Eur J Echocardiogr 2011;12:E4

383. Connolly HM, Nishimura RA, Smith HC, et al. Outcome of cardiac surgery for carcinoid heart disease. J Am Coll Cardiol 1995;25:410-16.

384. Denney WD, Kemp WE Jr, Anthony LB, et al. Echocardiographic and biochemical evaluation of the development and progression of carcinoid heart disease. J Am Coll Cardiol 1998;32:1017-22.

385. Moller JE, Connolly HM, Rubin J, et al. Factors associated with progression of carcinoid heart disease. N Engl J Med 2003;348:1005-15.

386. Bastarrika G, Cao MG, Cano D, et al. Magnetic resonance imaging diagnosis of carcinoid heart disease. J Comput Assist Tomogr 2005;29:756-9.

387. Mollet NR, Dymarkowski S, Bogaert J. MRI and CT revealing carcinoid heart disease. Eur Radiol 2003;13(Suppl 6):L14-18.

388. Robiolio PA, Rigolin VH, Harrison JK, et al. Predictors of outcome of tricuspid valve replacement in carcinoid heart disease. Am J Cardiol 1995;75:485-8.

389. Moller JE, Pellikka PA, Bernheim AM, et al. Prognosis of carcinoid heart disease: analysis of 200 cases over two decades. Circulation 2005;112:3320-7.

390. Castillo JG, Filsoufi F, Adams DH, et al. Management of patients undergoing multivalvular surgery for carcinoid heart disease: the role of the anaesthetist. $\mathrm{Br} \mathrm{J}$ Anaesth 2008;101:618-26.

391. Department of Health. The NHS Cancer Plan and the New NHS: Providing a Patient-Centred Service. London: Department of Health, 2004

392. Farrell C. National Service Framework Assessments, no. 1-NHS Cancer Care in England and Wales. Supporting Paper 1. There's No System to the Whole Procedure. Listening to Patients' Views and Experiences of NHS Cancer Services. London: Stationery Office Books, 2001.

393. NHS Centre for Reviews and Dissemination. Informing, communicating and sharing decisions with people who have cancer. Effective Health Care 2000;6:1-8.

394. Borras JM, Sanchez-Hernandez A, Navarro M, et al. Compliance, satisfaction, and quality of life of patients with colorectal cancer receiving home chemotherapy or outpatient treatment: a randomised controlled trial. BMJ 2001;322:826

395. Slevin ML, Nichols SE, Downer SM, et al. Emotional support for cancer patients: what do patients really want? Br J Cancer 1996:74:1275-9. 